Portland State University

PDXScholar

Spring 6-14-2019

\title{
Forest Structure, Composition, and Regeneration after High-Severity and Rapidly Repeated Wildfires in the Central Cascade Range
}

Sebastian Upton Busby

Portland State University

Follow this and additional works at: https://pdxscholar.library.pdx.edu/open_access_etds

Part of the Geography Commons

Let us know how access to this document benefits you.

Recommended Citation

Busby, Sebastian Upton, "Forest Structure, Composition, and Regeneration after High-Severity and Rapidly Repeated Wildfires in the Central Cascade Range" (2019). Dissertations and Theses. Paper 5127. https://doi.org/10.15760/etd.7006

This Thesis is brought to you for free and open access. It has been accepted for inclusion in Dissertations and Theses by an authorized administrator of PDXScholar. Please contact us if we can make this document more accessible: pdxscholar@pdx.edu. 
Forest Structure, Composition, and Regeneration after High-Severity and Rapidly Repeated Wildfires in the Central Cascade Range

\author{
by \\ Sebastian Upton Busby
}

A thesis submitted in partial fulfillment of the requirements for the degree of

\author{
Master of Science \\ in \\ Geography \\ Thesis Committee: \\ Andrés Holz, Chair \\ Jeff Gerwing \\ Melissa Lucash \\ Kevan Moffett
}

Portland State University

2019 


\section{Abstract}

Within mid-to-high elevation conifer forests in the Cascade Range, wildfire extent, severity, and frequency are expected to rise due to increasingly drier forest fuels under climate change. Considering dominant species composition, existing forests may be poorly adapted to absorb stress and recover following altered wildfire patterns. We tested the hypothesis that increased fire activity may disrupt the recovery of uppermontane and subalpine forest types by quantifying post-fire forest structure and conifer regeneration after spatially large, severe, and rapidly repeated wildfires in the Central Cascade Range. A stratified random sampling design was used to select field plots $(n=122)$ and drivers of conifer regeneration were modeled using logistic and negative binomial regression models.

Median conifer regeneration was very poor among sample plots that experienced either a single high-severity fire (49 seedlings/ha) or rapid reburn (14-28 seedlings/ha). Distance to seed source primarily drove seedling abundance, with shadetolerant species abundance being most sensitive to increasing seed source distances and dry, exposed, post-fire environmental conditions. Rapidly repeated fire increased the size of high-severity patches by killing live seed source trees spared during an initial fire, with chronological sequence of burn severity promoting regeneration of all conifer species or primarily fast growing, fire-adapted pines. Low-seedling densities, a general lack of seed source, and future warming trends suggest these forests affected by expansive high-severity and/or repeated wildfire will transition into a patchy, low- 
density forest state. This early-seral state ecosystem will be composed of fire-adapted pines farther from live seed source and incorporate a patchwork of shrubby grassland that in turn, may be more resilient to frequent wildfire than prior forests. If future wildfire patterns manifest as expected in the Cascade Range, recovering mid-tohigh elevation forests may begin resembling their drier, lower-elevation mixed-conifer counterparts in structure and composition. 


\section{Acknowledgements}

Funding for this research was provided by the National Science Foundation (NSF EAR1738104).

Access to conduct fieldwork within our study areas was graciously provided by the Gifford Pinchot National Forest (USFS) and the Confederated Tribes of the Yakima and Warm Springs Nations.

This work wouldn't have been possible without help from our dedicated field assistants. Thank you Emily Sykes, Brian Michie, Anthony Lefort, and Christine (Crissy) Johnson for the many hours and days spent hiking up and down rugged terrain, through smoke and sweat, to search for tiny (or not so tiny) conifer seedlings.

A great thanks to my advisor, Andrés Holz, for providing the opportunity to conduct this exciting research project and for providing helpful thoughts and feedback. An additional thanks to my thesis committee (Jeff Gerwing, Melissa Lucash, and Kevan Moffett) for taking time out of their busy schedules to provide feedback and assess the quality of this work.

A final thanks to my partner, Caryn, for her excellent editing skills, non-expert feedback, and general support. 


\section{Table of Contents}

Abstract

Assessing SIFs in the Central Cascade Range ...................................................... 7

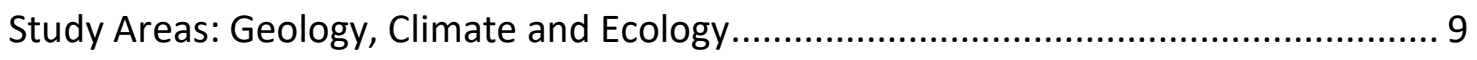

Study Areas: Wildfire Regimes and Recent Wildfire Patterns .................................. 12

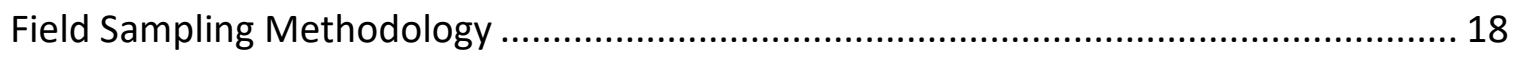

Site Selection: Limiting Human Impacts and Insect Influence ................................. 18

Site Selection: Burn Severity and Fire History..................................................... 19

Site Selection: Topographic Setting \& Final Selection ........................................... 21

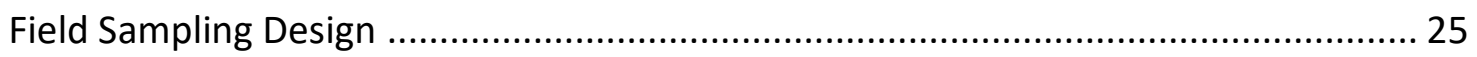

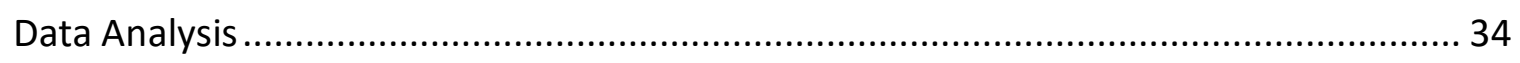

Post-Fire Forest Structure ............................................................................... 34

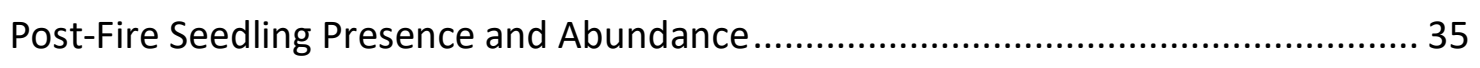

Logistic Regression Models for Seedling Presence/ Absence ................................... 38

Negative Binomial Count Models for Seedling Abundance ..................................... 39

Seedling Probability Curves: Distance to Seed Source and Fire History...................... 41

Seedling Composition and Establishment Across Fire Histories ............................... 41

Distance from High-Severity to Lower Severity Patches......................................... 43

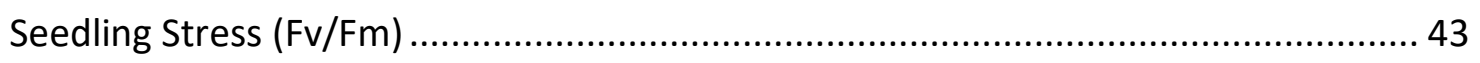

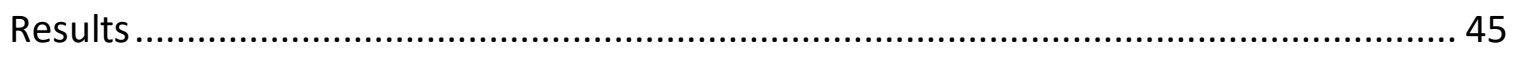

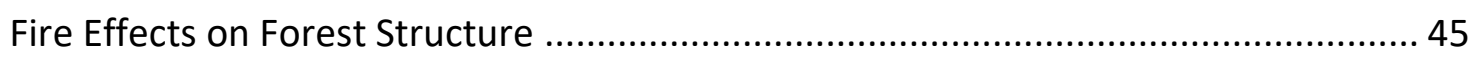

Pre and Post-Fire Species Composition ............................................................ 51 
Seedling Density and Establishment Across Fire Histories ..................................... 53

Drivers of Post-Fire Conifer Regeneration: Binary Models ...................................... 58

Drivers of Post-Fire Conifer Regeneration: Count Models ...................................... 63

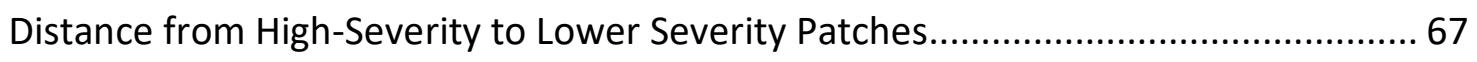

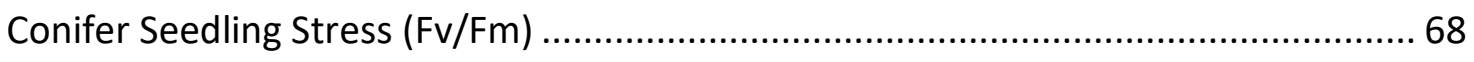

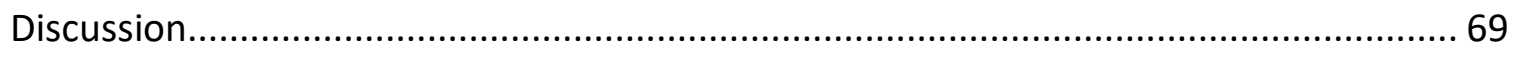

Fire Severity and Frequency Alter Seed Source Availability, Conifer Regeneration .... 70 Secondary Controls on Conifer Regeneration ..................................................... 74

Mechanisms Promoting Persistent Seed Source: Refugia ..................................... 78

Repeated Wildfire Alters Stand Structure, Species Composition .............................. 80

Forest Ecosystem Transitions, Migrations, and Future Resilience ........................... 86

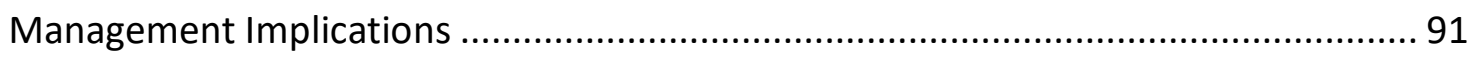

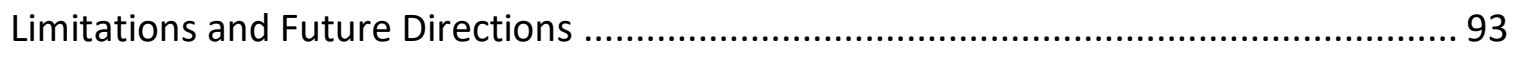

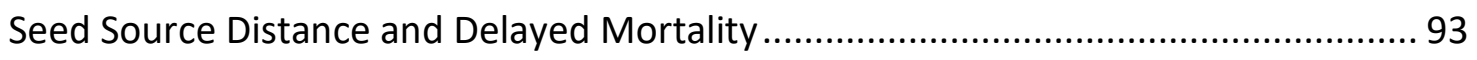

Compound Disturbance Interactions: Insect Outbreak ........................................ 94

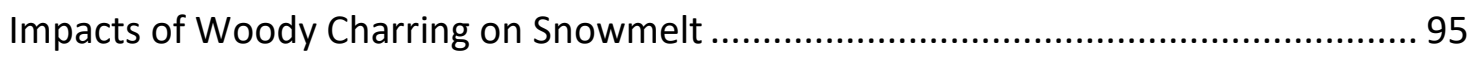

Soil Moisture and Post-Fire Forest Regeneration .............................................. 96

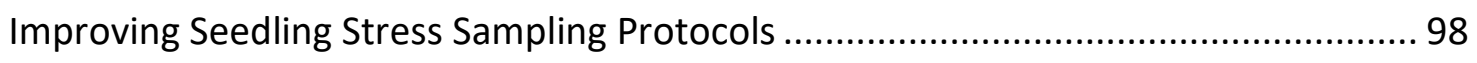

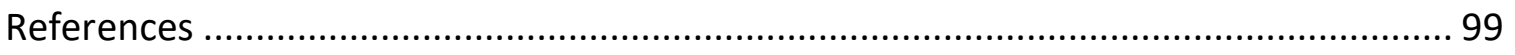




\section{List of Tables}

Table 1: A list of all conifer species encountered within sampled forests.................... 11

Table 2: Burn severity and area burned among studied Cascadian wildfires ................. 17

Table 3: Field sampling stratification per study area (Mt. Adams and Mt. Jefferson)..... 23

Table 4: Summary of plot percentages sampled among forest types and fire histories. 25

Table 5: Field variables used to quantify forest structure, composition, and regeneration

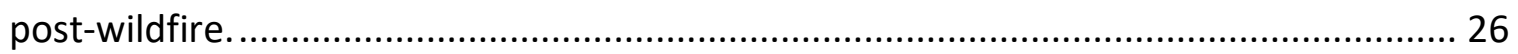

Table 6: Number and percentage of plots moved in the field. .................................. 27

Table 7: Predictor variables included in all postfire seedling regeneration models ........ 36

Table 8: Multivariate analysis (permutation MANOVA) of forest structure* among

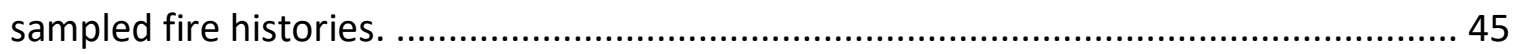

Table 9: Forest structure characteristics across sampled fire histories. ....................... 48

Table 10: Species composition of pre-fire trees and post-fire seedlings. ....................... 52

Table 11: Parameter estimates $(\beta)$ from the reduced seedling presence/ absence

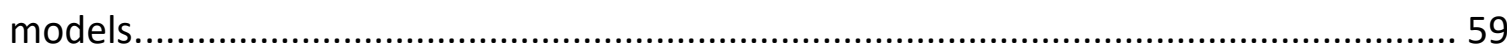

Table 12: Performance metrics among the reduced logistic models............................ 61

Table 13: Parameter estimates $(\beta)$ from the reduced seedling count models. .............. 64

Table 14: Performance metrics among the reduced negative binomial GLM models. ... 65

Table 15: Percentage of study areas burned at a high-severity with varying distances to

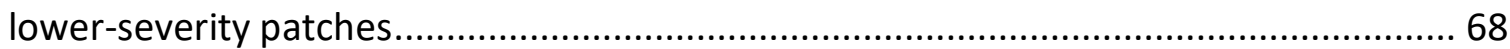




\section{List of Figures}

Figure 1: Conceptual model describing the controls of fire across spatial and temporal scales; from Higuera 2015.

Figure 2: Conceptual representation of forest ecosystems; from Johnstone et al. 2016. 5

Figure 3: Continuum of forest types found of the eastern side of the Cascade Range;

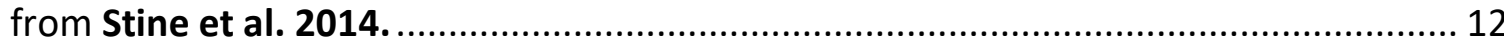

Figure 4: Map of the geographic study area and sampled wildfire perimeters............. 14

Figure 5: Forests burned at a high-severity by recent wildfires affecting study areas .... 16

Figure 6: Final field plot locations for Mt. Adams and Mt. Jefferson ............................. 24

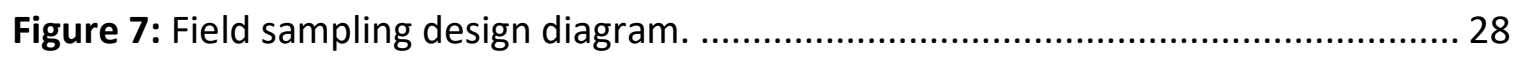

Figure 8: Conceptual diagram illustrating the shading effect coarse woody debris (CWD)

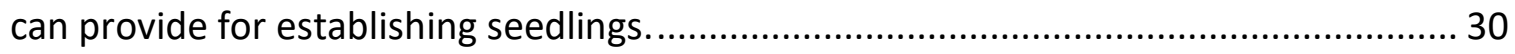

Figure 9: A histogram showing the distribution of seedling densities across burned plots

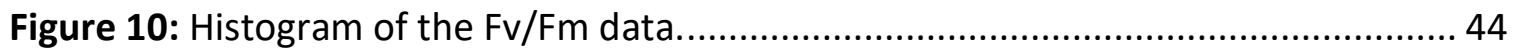

Figure 11: Non-metric multidimensional scaling (NMDS) ordination of multivariate forest

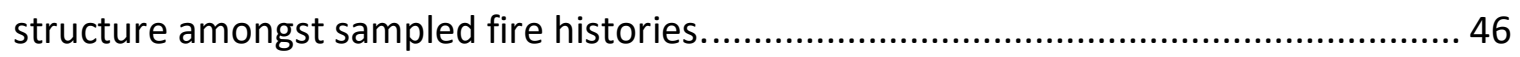

Figure 12: Relationship between the average distance to live seed source and sampled fire histories. 47

Figure 13: Black carbon biochar on down woody debris (left) and snag trees (right).... 49

Figure 14: Field plots from the fire histories sampled on Mt. Adams and Mt. Jefferson 50 Figure 15: Conifer seedling density per hectare among sampled fire histories 54

Figure 16: Non-linear relationship between seedling density and time since a highseverity fire occurred among plots that experienced a high-severity fire 55 Figure 17: NMDS ordination of post-fire seedling presence-absence, by species, amongst sampled fire histories. 56 
Figure 18: NMDS ordination of post-fire seedling abundance, by species, amongst sampled fire histories.

Figure 19: Boxplot showing establishment of conifer seedlings post-fire or post-reburn among the two reburn histories sampled (high-low, low-high).

Figure 20: Probability of seedling presence (individual conifer species) as a function of distance to seed source among fire histories

Figure 21: Probability of seedling presence (any species) as a function of distance to seed source among fire histories.

Figure 22: Seedling abundance probability as a function of distance to seed source $(\mathrm{m})$ among reburn and high-severity fire histories.

Figure 23: Histogram distributions of forest burned at a high-severity and their distance

(m) to lower-severity patches among the two study areas.

Figure 24: Subalpine forests on Mt. Adams (top) and Mt. Jefferson (bottom) affected by SIFs involving a high-severity fire

Figure 25: Related recent studies assessing conifer regeneration after high-severity fire and/ or reburns in the Western United States.

Figure 26: Rocky ridgelines created small bastions of refugia on an otherwise torched landscape for fire-resistant ponderosa pine and some other species.

Figure 27: A lodgepole pine sapling that established after a 2003 high-severity fire, whom survived a 2014 low-severity fire (11 years between events)

Figure 28: Three alternate successional pathways for forest development; from

Donato et al. 2012. 88

Figure 29: Conceptual diagram of anticipated forest composition shifts due to increased fire frequency and climate change impacts within the Central Cascade Range; adapted from Cansler et al. 2018. 


\section{Introduction}

In the U.S. Pacific Northwest (PNW) region, wildfire is the strongest and most pervasive natural disturbance process shaping forest ecosystems. Wildfire promotes biodiversity across landscapes by resetting homogenous ecosystems but can also be a catalyst for rapid ecosystem change (Agee 1993; Veblen 2017). Greater variability in wildfire behavior compared to historical patterns can cause ecosystem state transitions instead of recovery and growth, primarily through regenerative failure of prior forest communities (Enright et al. 2015; Turner et al. 1993). In the PNW, climates drive the long-term spatiotemporal characteristics of wildfire (i.e. fire regime) by shaping forest vegetation composition and density, while weather influences individual fire behavior by controlling vegetation flammability (Figure 1; Higuera 2015). Hot and dry lowelevation forests, especially in the Cascades rain shadow, may experience fires frequently and thus have limited fuel to burn, lowering fire severity. In contrast, coastal and mid-to-high-elevation forests may experience fire infrequently due to cool and wet climate conditions, especially on windward slopes, allowing for high abundance and connectivity of fuels that can promote higher burn severities when fires do occur. These two distinct wildfire regimes are typically considered fuel- and climate-limited systems, respectively (McKenzie and Littell 2017). 


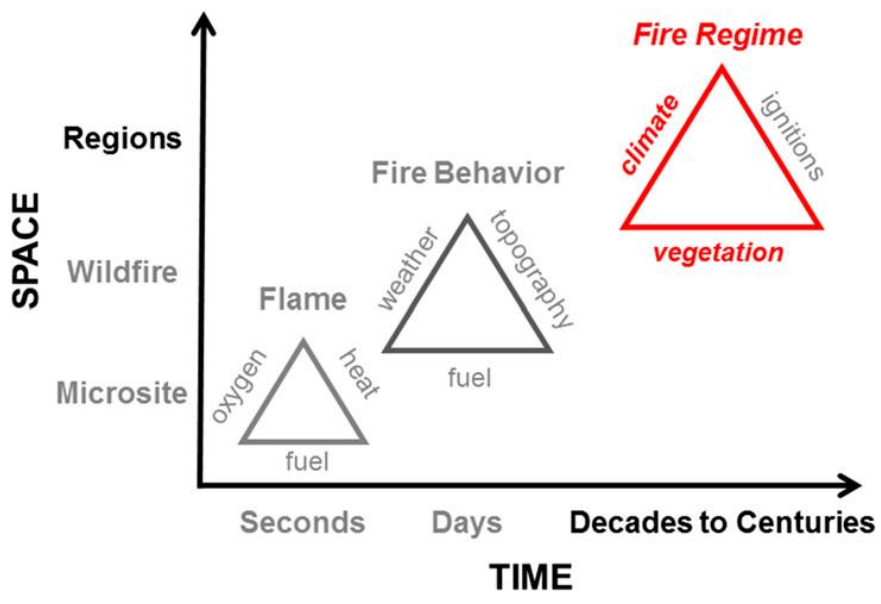

Figure 1: Conceptual model describing the controls of fire across spatial and temporal scales; from Higuera 2015.

Human management of lands, primarily through fire-suppression, has generally increased forest density in historically fuel-limited systems, increasing fire-severity and extent while decreasing frequency (Collins et al. 2011; Dennison et al. 2014; Hessburg and Agee 2005; Naficy et al. 2010). In contrast, fire-suppression is thought to have marginally affected climate-limited systems' fire regime, as wet conditions naturally limit the ignition and spread of fire - except during periods of extreme drought (Agee 1993; Krawchuk and Moritz 2011; Halofsky et al. 2018). Where climate change reduces moisture availability in climate-limited systems, however, increased fire activity may threaten the resilience of previously wet forest types (Stevens-Rumann et al. 2017; Tepley et al. 2018; Halofsky et al. 2018).

Within the PNW region, significant shifts in temperature and precipitation have already been observed. Loss of mountain snowpack and earlier snowmelt, combined with longer, hotter, and drier summers, may be reducing summertime moisture availability to forests, especially at mid-to-high elevations (Abatzoglou and Williams 
2016; Abatzoglou et al. 2017; Mote 2006; Gergel et al. 2017; Fyfe et al. 2017; Holden 2018). Historically, high soil and fuel moisture have kept wildfire frequency low within upper-montane and subalpine forests, despite abundant fuels. If forests dry out earlier in the year (Westerling 2016), however, it may alter how wildfire behaves in these landscapes (Halofsky et al. 2018; Reilly et al. 2018).

Within mid-to-high elevation zones (> 1200m) in the PNW Central Cascade mountain range, an anomalous wildfire pattern has recently emerged. Forests thought too wet and cool to facilitate frequent wildfire, have seen multiple, rapidly succeeding fires since 2003, known as short-interval fires (SIFs; <15 years between wildfire events; Donato et al. 2009b). With historic climate conditions limiting fire occurrence in these environments to an expected 30-100+ year range (Rollins 2009; Stine et al. 2014), the impacts of substantially increasing fire frequency are currently unknown within wet mid-to-high elevation forests of the Central Cascades (Reilly and Spies 2016; Reilly et al. 2017, 2018 a, b).

Other research has addressed the impacts of SIFs on forest dynamics and/ or postfire forest regeneration but primarily in fuel-limited landscapes, the drier climate of which typically facilitates more frequent, low severity wildfire (Prichard et al. 2017). These areas include the Sierra Nevada Range (Coppoletta et al. 2016), Klamath-Siskiyou mountains (Donato et al. 2009a), the Northern Rockies of central Idaho (StevensRumann and Morgan 2016), the Bob Marshall Wilderness of Montana (Larson et al. 2013), and the Jemez mountains of New Mexico (Coop et al. 2016). Generally, these 
ecosystems host more conifer species with fire-adapted traits, such as Douglas fir, ponderosa pine, and lodgepole pine. They additionally facilitate forest structures that limit fuel connectivity and therefore the spread and severity of fire, assuming management practices (e.g., fire suppression) have not drastically altered forest structures, species, and fuels. Conversely, mid-to-high-elevation forests in the Central Cascades are structurally dense and primarily composed of shade-tolerant conifer species, such as grand fir, subalpine fir, mountain hemlock, and Engelmann spruce, which require longer fire-free intervals to regenerate back to typical compositions and densities (Agee 1993). Consequently, the dominant species within these environments may currently be ill-suited to SIFs.

In addition to greater fire frequency, drier forest fuels may also increase fire severity (Abatzoglou and Williams 2016; Abatzoglou et al. 2017), further compounding disturbance effects (Enright et al. 2015; Johnstone et al. 2016). High-severity (“crownreplacing") fires can cause $90-100 \%$ mortality of existing live trees, leaving few local seed sources (legacy trees) in affected patches (Kemp et al. 2016; Haffey et al. 2018; Harvey et al. 2016). If seedlings that established after an initial fire are then killed by a second SIF before they can develop fire resistant traits or reach sexual maturity, or if lone legacy trees are killed by the second fire, then local, live seed sources may be nearly or entirely wiped out from affected forest patches (Stevens-Rumann and Morgan 2016; van Wagtendonk et al. 2012). In this case, a mismatch between species' adaptive 
traits and altered wildfire regimes raises serious concerns about post-fire forest

recovery.

When disturbance regimes change rapidly in frequency, severity, extent, or any combination of dimensions, forest resilience can be threatened (Turner et al. 1993) if existing species are not individually resilient or plastic enough to cope. Regenerative failure by prior communities that then instigates a positive, self-reinforcing feedback (e.g., little conifer legacy $\rightarrow$ few seeds $\rightarrow$ little regrowth of same / more regrowth of alternative $\rightarrow$ circular reinforcement) can lead to persisting alternative ecosystem types and states (Figure 2; Johnstone et al. 2016). Where conifer regeneration is poor, previously dense forests may transition into an open, low-density state primarily dominated by shrubs and grasses (van Wagtendonk et al. 2012). Thus, increasingly large, frequent, and severe wildfires may be powerful catalysts of rapid ecosystem change within affected forests.
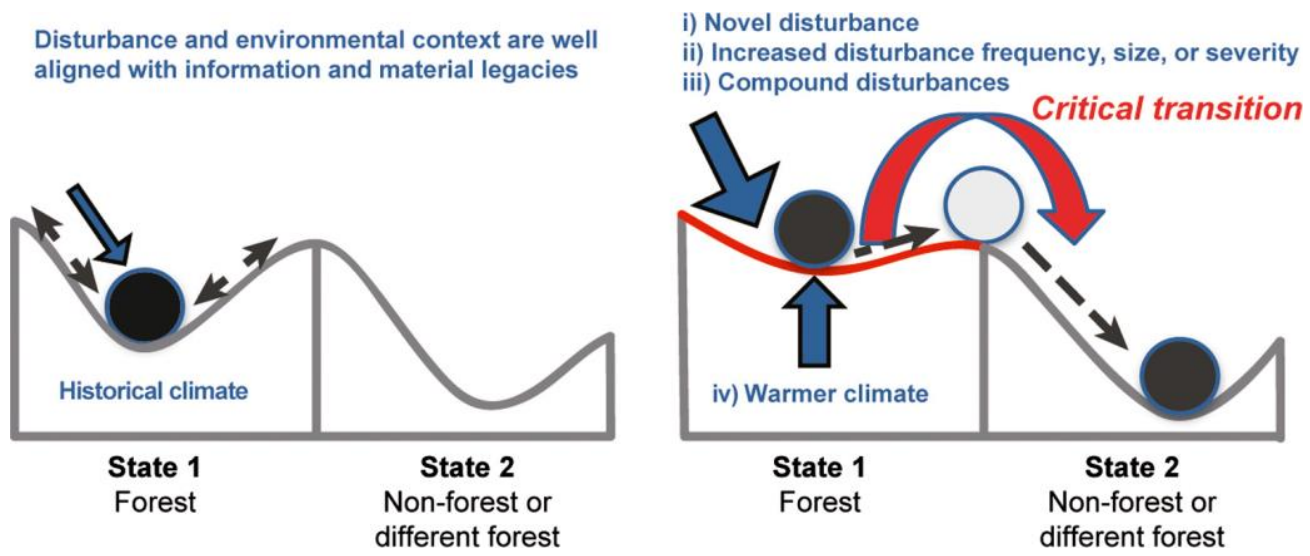

Figure 2: Conceptual representation of forest ecosystems (black ball) within a theoretical landscape of alternative ecosystem states (valleys separated by peaks). (a) Forests are resilient to disturbances lying within the safe operating space, indicated by disturbances that may move the system but not cause it to shift to another state. (b) Forests are likely to shift to a different state in response to four hypothesized mechanisms (i-iv) that move a system outside its safe operating space and trigger a shift to a different forest or non-forest state; from Johnstone et al. 2016. 
Beyond ecological change, altered wildfire regimes within the infrequently burned mid-to-high elevation forests of the Central Cascades also present substantial challenges for the human institutions and stakeholders interacting with them. Area burned in the region per fire season has been steadily increasing over the last several decades and is expected to continue rise, especially in forests with previously climatelimited wildfire regimes, as shifting climatic conditions statistically favor drier forest fuels, more fire ignitions, and extreme weather conditions (Abatzoglou and Williams 2016; Balch et al. 2017; Jolly et al. 2015; McKenzie and Littell 2017; Westerling 2016). For human infrastructure, which has increasingly pushed further into the wildland-urban interface (WUI) creating greater self-imposed risk, future wildfires could mean greater loss of property, human life, and further strained resources from entities engaged with wildland firefighting (Ager et al. 2014; Fischer et al. 2016; Steelman 2016).

Geographically affected timber and recreational industries may also be economically impacted. Traditionally productive for timber harvest, upper-montane forests affected by fires may lose marketable timber or transition into low-density states that are less profitable for harvest (Ager et al. 2019; Halofsky et al. 2018). After wildfire, burned forests within scenic recreation areas may illicit lower perceived values from guests (Hesseln 2004), and post-fire erosion concerns may limit access to sites until vegetation can stabilize soils and infrastructure can be repaired for safety (Bawa 2016). Ultimately, shifting wildfire regimes may greatly affect the ecology and economy of the Pacific Northwest region. 
Toward such eventual broader nature-society coupled understanding, in this study we first specifically sought to understand how SIFs involving a high-severity fire have affected post-fire forest structure, composition, and conifer regeneration within mid-to-high-elevation forests in the Central Cascade Range. We asked: How does forest structure contrast between stands exposed to recent SIFs and those burned only once? How do topographic setting, fire history, post-fire forest structure, and post-fire climate conditions relate to conifer regeneration? Do SIFs, and specifically the sequence of burn severity in SIFs (low-then-high vs. high-then-low severity) appear to influence conifer seedling abundance and composition?

To address these questions, we collected and analyzed field data from two study areas in the Central Cascades. Within study areas, we compared spatially proximate forest patches which recently burned once or rapidly reburned (7-11 year interval), burned at either a low or high severity, and were set in either a wet or dry topographic setting. To understand the impacts of SIFs on wet conifer forests, including identifying significant factors related to conifer regeneration, logistic and negative binomial regression models were used.

\section{Assessing SIFs in the Central Cascade Range}

To select appropriate study areas, we mapped and assessed characteristics of recent SIFs in the Central Cascade Range by analyzing digitized wildfire delineations (perimeters) from the Monitoring Trends in Burn Severity (MTBS) program (Eidenshink et al. 2007). MTBS is an interagency program facilitated by the USGS that has mapped 
fire perimeter and burn severity of large wildfires ( $>200$ hectares) in the western U.S. from 1984 to present. All wildfire perimeters (1984-2016) mapped by MTBS within the Central Cascade Range were uploaded into ArcGIS (ESRI 2018) for spatial analysis. The Intersect tool was used to locate potential field sites that had experienced SIFs. Sites that had experienced more than two recent overlapping wildfires were removed to limit sampling complexity, along with those found in designated wilderness areas or that were logistically inaccessible by foot (greater than two miles hike from an access road). To target forest types with climate-limited wildfire regimes likely to be affected by climate change impacts in the Central Cascades, site elevation was limited between $1200-1650 \mathrm{~m}$ to focus on the transition zone between upper-montane and subalpine forest types. This specific gradient was selected by targeting the Mesic Montane MixedConifer Forest class represented in LANDFIRE's Existing Vegetation Type (EVT) layer (LANDFIRE 2010; Comer et al. 2003). Upper-montane forests in the Central Cascades are highly productive, mid-elevation stands that experience less snowpack and warmer winters than subalpine forests, allowing for longer growing seasons. Subalpine forests occur exclusively at higher elevations and experience substantial snowpack and cooler winters, which facilitates slower tree growth than upper-montane stands. At late seral stages, both forest types are dominated by a dense assemblage of shade-tolerant species (Agee 1993), including grand fir, subalpine fir, mountain hemlock, and Engelmann spruce. 
Two sites stood out as ideal sampling locations based on comparable forest types, climates, geographic positions, and large amounts of reburned area to sample. Both prominent East Cascade volcanic peaks, Mt. Adams, WA and Mt. Jefferson, OR experienced expansive wildfires post-2002 and large subsequent reburns circa 2012, 2014, and 2015 (7-11 years between fires). These associated wildfire events synchronize with increased fire activity and fire-season fuel aridity post-2000 (Abatzoglou and Williams 2016). While we identified many potential field sites in the Western Cascades, reburned areas were generally spatially small ( $<200$ hectares), likely a consequence of wetter climatic conditions that limited fire extent and/or milder weather conditions during fires (Higuera 2015). These substantially smaller fire perimeters would have limited our ability to sample a range of topographic settings and moisture gradients and so were omitted.

\section{Study Areas: Geology, Climate and Ecology}

Mt. Adams and Mt. Jefferson are active stratovolcanoes set in the Central Cascade Range, whose last major eruptions were approximately 3,800 and $>10,000$ years ago, respectively (USGS 2018). Geographically, the Central Cascades are a northsouth mountain range spanning the southern U.S. state of Washington to central Oregon. This range is geologically volcanic, with peaks reaching up to $4,400 \mathrm{~m}$ in elevation (i.e. Mt. Rainier). Soils upon these landscapes are dominantly well draining, ashy sandy loam andisols (USDA 2018). Within the Central Cascades, our study areas are 
biased towards the east side of the crest and include the southern face of Mt. Adams, WA and the eastern face of Mt. Jefferson, OR.

The Central Cascades experience humid Mediterranean conditions with cool and wet winters $\left(-7\right.$ to $\left.5^{\circ} \mathrm{C} ; 1200-2600 \mathrm{~mm}\right)$, while summers can be warm and dry $\left(6-26^{\circ} \mathrm{C}\right.$; $40-400 \mathrm{~mm})^{1}$. A very steep moisture gradient exists west to east along this mountain range, where orographic lifting depletes moisture from saturated air masses moving east off the Pacific Ocean (i.e. westerly winds) as they pass up the windward (eastern) slopes. Mid-to-high elevation areas receive substantial winter precipitation in the form of snowfall, which accumulates as seasonal snowpack typically above $1000 \mathrm{~m}$ in elevation. Within our study areas, total annual average precipitation ranges 1800 to $2300 \mathrm{~mm}$ for Mt. Adams, and 1600 to $2000 \mathrm{~mm}$ for Mt. Jefferson ${ }^{1}$. For Mt. Adams, average temperature ranges -5 to $1^{\circ} \mathrm{C}$ in January and 8 to $21^{\circ} \mathrm{C}$ in July ${ }^{1}$. For Mt. Jefferson, average temperature ranges -4 to $3^{\circ} \mathrm{C}$ in January, and 6 to $25^{\circ} \mathrm{C}$ in July ${ }^{1}$. Climatically, Mt. Jefferson, and specifically its more eastern fire-affected slopes, is somewhat warmer and drier than Mt. Adams, a consequence of geographic position.

As a result of the orographic climate conditions imposed by the Cascades, ecological communities follow a very steep west-to-east gradient, ranging from wet temperate mixed conifer forest west of the crest, to dry temperate conifer forest east of the Cascades, to dry shrub-steppe far east where the range subsides (Agee 1993). In all

\footnotetext{
${ }^{1}$ Climate estimates were extracted from PRISM 30-year normals (1981-2010) at an 800m spatial resolution (PRISM 2018).
} 
these bioclimatic zones, vegetation must survive the seasonal drought of the Mediterranean-like climate, with little precipitation, July through September.

Upon Mt. Adams and Mt. Jefferson, per our observations, mid-elevation uppermontane stands were dominated by grand fir, with smaller components of Douglas fir, ponderosa pine, lodgepole pine, and pacific silver fir. Subalpine fir specifically replaced grand fir as a species component above certain elevations, thus, high-elevation (subalpine) stands were dominated by subalpine fir, with smaller components of ponderosa pine, lodgepole pine, Engelmann spruce, and mountain hemlock. Mountain hemlock generally became more dominant above 1500m and Engelmann spruce in cool, wet, shady drainages. Subalpine forest eventually gives way to sparse alpine meadow above $1850 \mathrm{~m}$ in elevation upon these landscapes- with whitebark pine (Pinus albicaulis) being the highest elevation conifer species to establish. See Table 1 for a list of the conifer tree species we encountered in the study areas.

Table 1: A list of all conifer species encountered within sampled forests. Cascadian elevation range estimates were derived from the USFS Fire Effects System (Abrahamson 2018).

\begin{tabular}{llcc}
\hline Common Name & Scientific Name & Shade Tolerance & Elevation Range (m) \\
\hline Grand fir & Abies grandis & Tolerant & $0-1800$ \\
Douglas fir & Pseudotsuga menziesii & Intolerant & $0-1500$ \\
Lodgepole pine & Pinus contorta & Intolerant & $1000-2000$ \\
Ponderosa pine & Pinus ponderosa & Intolerant & $400-1600$ \\
Engelmann spruce & Picea engelmannii & Tolerant & $1200-1800$ \\
Mountain hemlock & Tsuga mertensiana & Tolerant & $1500-2300$ \\
Western white pine & Pinus monticola & Intolerant & $800-2000$ \\
Western larch & Larix occidentalis & Intolerant & $1000-2000$ \\
Pacific silver fir & Abies amabilis & Tolerant & $240-1800$ \\
Subalpine fir & Abies lasiocarpa & Tolerant & $1200-2000$ \\
\hline
\end{tabular}




\section{Study Areas: Wildfire Regimes and Recent Wildfire Patterns}

Fire history studies within the Cascade Range have noted a great amount of complexity and variability concerning fire severity, extent and frequency across landscapes (Forrestel et al. 2017; Morrison and Swanson 1990; Wright and Agee 2004; see summary table in Reilly et al. 2017). Fire regimes here are primarily related to forest elevation, moisture availability, and climate variability (Agee 1993; Agee 1998), with subalpine and upper-montane forests typically burning more infrequently, but generally at higher severities (Stine et al. 2014; Figure 3). As elevation lowers, especially on the east side of the Cascade crest, higher severity regimes transition toward mixed-severity, where lower fuel connectivity and higher wildfire frequency facilitate more forest burned at low and moderate severities (Hagmann et al. 2014; Merschel et al. 2014; Stine et al. 2014).

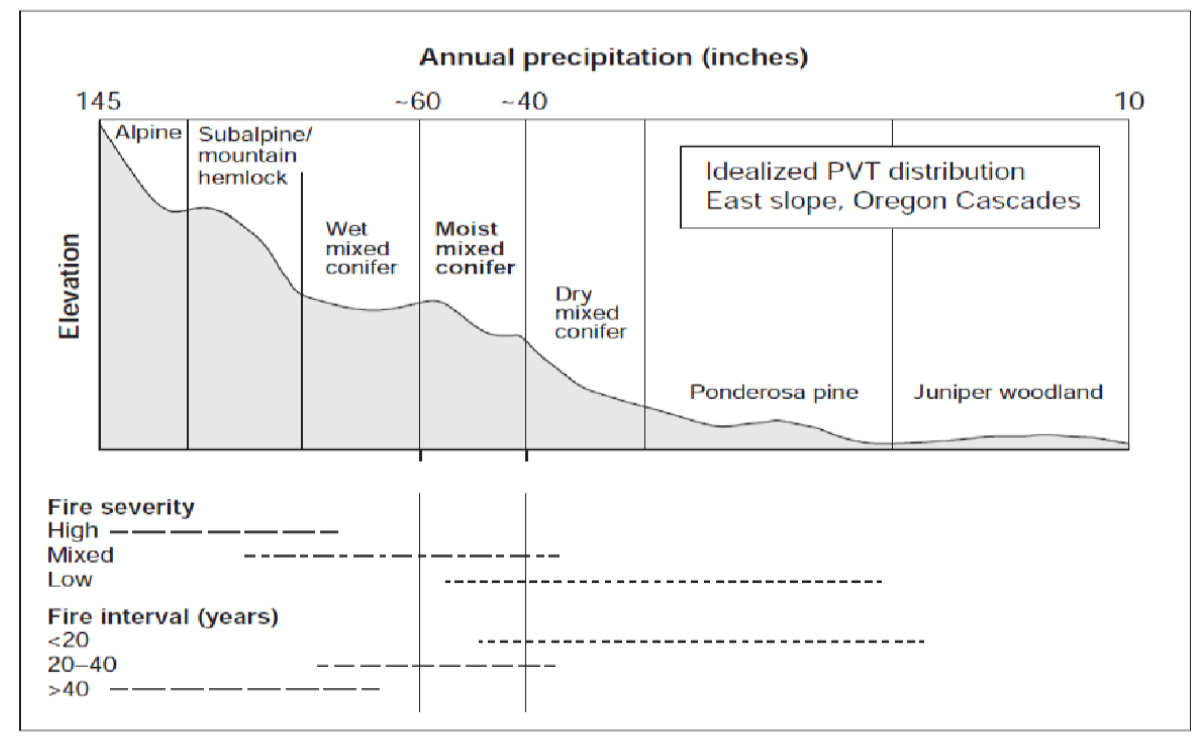

Figure 3: Continuum of forest types found of the eastern side of the Cascade Range and the relationship of forest type to general wildfire regimes. PVT = potential vegetation type. Annual precipitation in our study areas ranges from $65-90$ inches, represented in this diagram as wet mixed conifer and subalpine forest. From Stine et al. 2014. 
Over the past 150 years, Euro-American land-use practices have significantly altered vegetation densities and species compositions within dry and some moist mixedconifer forests of the PNW (Dennison et al. 2014; Hessburg and Agee 2005; Hessburg et al. 2005; Naficy et al. 2010; Stine et al. 2014). Upper-montane and subalpine forests, like those in our study areas, are thought to have been minimally impacted by management practices (i.e. climate-limited wildfire regimes), although mid-to-high elevation sheep and cattle grazing during the $20^{\text {th }}$ century may have altered understory fuel structures (Haugo et al. 2010; Stine et al. 2014). Mt. Adams presently has a small, ongoing cattle grazing allotment upon the southern face of the mountain.

Prior to European colonization, Native American tribes frequently used fire in lower elevation forests for maintaining hunting and foraging grounds, and in subalpine forest to promote huckleberry growth (Boyd 1999). Yakima Nation tribes frequented forested lands on Mt. Adams, and Warm Springs Nation tribes Mt. Jefferson; each respective tribes' current lands span roughly half of these mountain landscapes. Boyd (1999) summarized that while burning for huckleberries within subalpine forests was a common practice in the Cascade ecoregion until recently, the scale of burning (i.e. size of burned patches) was generally small, and often centered along hiking trails for ease of harvest.

On Mt. Adams, our studied wildfires include the 2008 Cold Springs, 2012 Cascade Creek, and 2015 Cougar Creek fires; on Mt. Jefferson, studied wildfires include the 2003 Booth \& Bear Butte (B\&B) Complex, 2007 Warm Springs Area (WSA) Lightning Complex, 


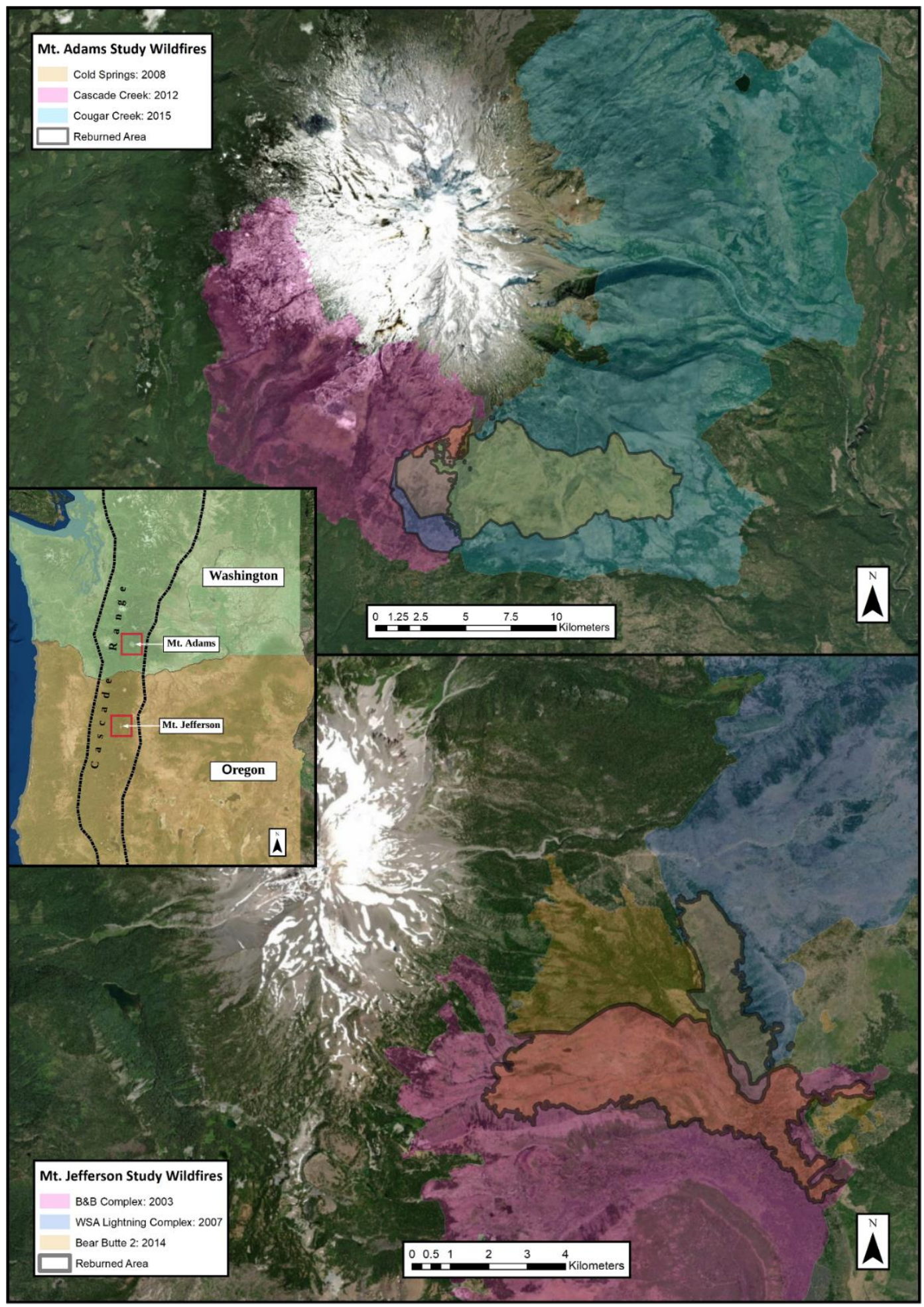

Figure 4: Map of the geographic study area and sampled wildfire perimeters. Bolded outlines and perimeter overlaps indicate where forests have experienced SIFs. 
and 2014 Bear Butte 2 fires (Figure 4). By focusing on areas which burned no more than twice, the time between fire events was either 7 or 11 years in the areas we sampled (2008 and 2015; 2003 and 2014; 2007 and 2014). Additional fires beyond these noted have occurred in recent history on Mt. Adams and south of Mt. Jefferson - but were either spatially small and/ or primarily within wilderness areas. The U.S Forest Service owns and manages the western halves of these two volcanic peaks, while indigenous tribes own and manage the east sides as reservation lands.

Within the recent (2003-present) wildfire perimeters affecting forests on and near Mt. Adams and Mt. Jefferson, total area burned as percentages show mixed to high-severity trends, with a greater percentage burned at high-severity on Mt. Adams (Figure 5; Table 2). High-severity fires can remove conifer tree legacies from affected forest patches by killing live trees and destroying seed banks of non-serotinous species; serotinous species may also be affected in extreme cases (Anderson and Romme 1991; Lotan 1976). So long as high-severity patches are limited in spatial extent, however, live trees at forest edges or protected in refugia islands within fire perimeters can recolonize burned areas (Krawchuk et al. 2016; Meigs and Krawchuck 2018). While the studied wildfires host large percentages of forest burned at low and moderate severities, contiguous high-severity patches were generally of very large spatial extent, especially on Mt. Adams (up to 1000 ha; Figure 5). 


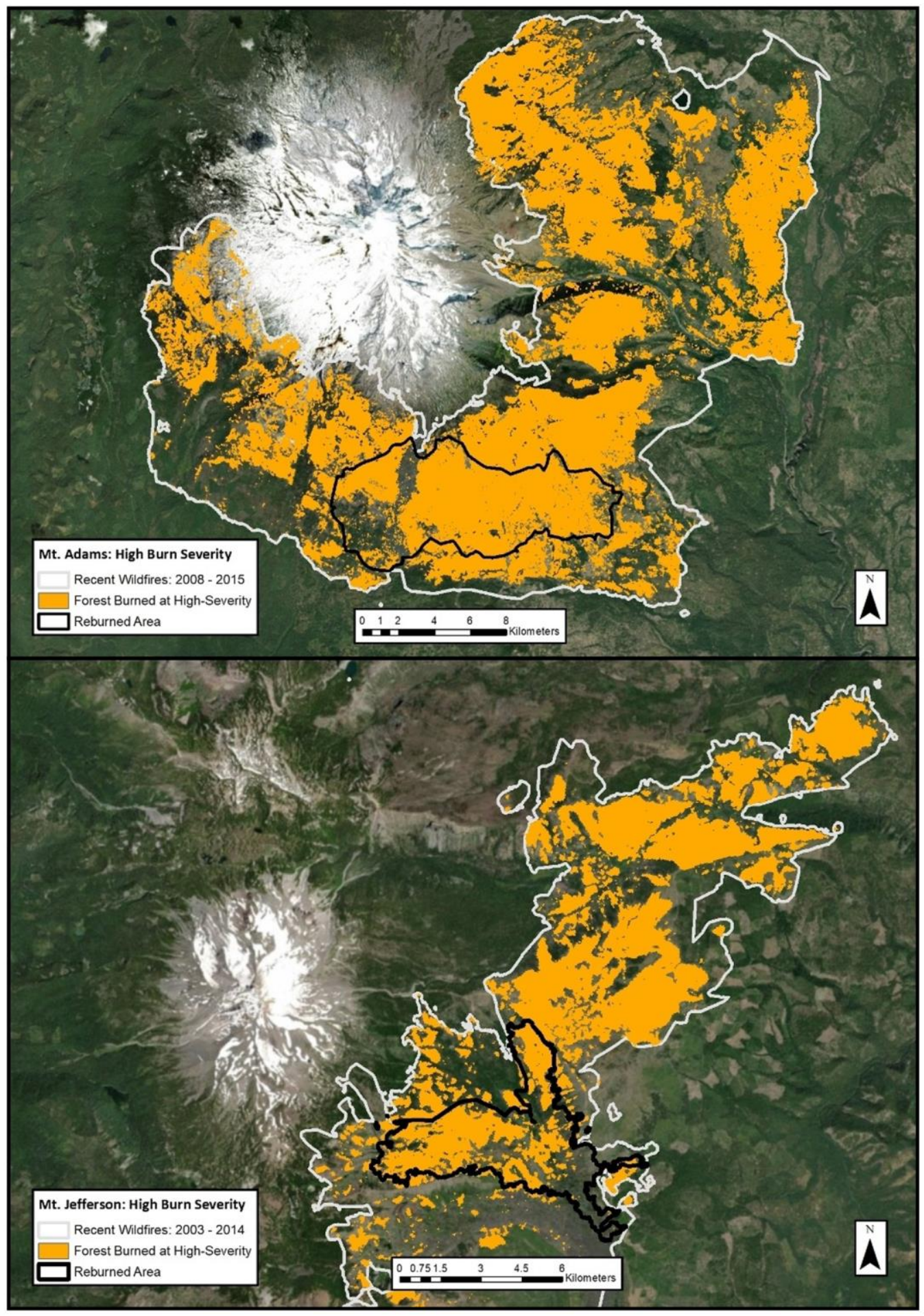

Figure 5: Forests burned at a high-severity by recent wildfires affecting the study areas. Fire severity was classified using remotely-sensed burn severity (RdNBR) from MTBS. Many high-severity patches were spatially large in extent (up to roughly $1000 \mathrm{ha}$ ). Forest burned at high-severity within the Reburned Area refers to any event that burned at high-severity; i.e. either first, second, or third burn. 
Table 2: Burn severity (RdNBR)* and area burned (hectares) among studied Cascadian wildfires.

\begin{tabular}{lccccccc}
\hline & \multicolumn{7}{c}{ Area burned (ha \& \%) by severity class (RdNBR)* } \\
\cline { 2 - 7 } Mt. Adams Wildfires & Low & $\%$ & Moderate & $\%$ & High & $\%$ & $\begin{array}{c}\text { Total Area } \\
\text { Burned }\end{array}$ \\
\hline Cold Springs: 2008 & 338 & $12 \%$ & 442 & $16 \%$ & 1966 & $72 \%$ & 2747 \\
Cascade Creek: 2012 & 2404 & $34 \%$ & 1813 & $26 \%$ & 2871 & $41 \%$ & 7087 \\
Cougar Creek: 2015 & 3684 & $19 \%$ & 4779 & $24 \%$ & 11392 & $57 \%$ & 19855 \\
Cumulative Area Burned: & 6426 & $22 \%$ & 7034 & $24 \%$ & 16229 & $55 \%$ & 29689 \\
Reburned Area: & & & & & & & 6693 \\
Mt. Jefferson Wildfires & & & & & & & 32336 \\
B\&B Complex: 2003 & 11591 & $36 \%$ & 12733 & $39 \%$ & 8013 & $25 \%$ & 3062 \\
WSA Complex: 2007 & 1129 & $22 \%$ & 1290 & $25 \%$ & 2642 & $52 \%$ & $51 \%$ \\
Bear Butte 2: 2014 & 415 & $25 \%$ & 582 & $35 \%$ & 685 & $41 \%$ & 1682 \\
Cumulative Area Burned: & 13135 & $34 \%$ & 14605 & $37 \%$ & 11340 & $29 \%$ & 39080 \\
Reburned Area: & & & & & & & 2416 \\
\hline
\end{tabular}

*Burn severity is represented by classified RdNBR values from MTBS raster imagery and pixel area in ArcGIS; RdNBR stands for Relative differenced Normalized Burn Ratio (see details below). Unburned area within fire perimeters was excluded from these estimates.

Within areas that experienced multiple fires, forest patches which burned at a low or moderate severity during an initial fire often reburned at a high-severity. This may be due to increased understory vegetation regrowth and fuel connectivity following the first lower severity burn. These burn patterns decreased both the connectivity and size of unburned forest patches within reburned areas. Conversely, patches that originally burned at a high-severity primarily reburned at lower severities - a consequence of limited post-fire vegetation, fuel loads, and fuel connectivity (Coppoletta et al. 2016; Donato et al. 2016; Grabinski et al. 2018; Stevens-Rumann et al. 2016). 


\section{Field Sampling Methodology}

A variety of criteria and filters were used to select field-based sampling plots in the two study areas (Mt. Adams and Mt. Jefferson), which broadly involved (1) limiting human impacts and insect influence, (2) stratification by fire history, and (3) stratification by topographic setting.

Site Selection: Limiting Human Impacts and Insect Influence

To reduce the number of influential variables affecting natural forest dynamics outside the scope of this study, several initial criteria were used to filter these factors out. Areas that had experienced documented salvage logging or replanting efforts were removed from the study using maps provided by associated management entities (USFS; Warm Springs Nation). Sampling areas were set back from roads by a distance of at least $100 \mathrm{~m}$, and visual interpretation of 2018 satellite imagery was used to remove areas with visible, but undocumented management activity.

In the PNW, several insect species affecting conifers are known to occur as largescale outbreaks, which can lower tree resilience to future disturbance or cause outright mortality (Hummel \& Agee 2003; Meigs et al. 2015a; Raffa et al. 2008). Two specific native insect species have been documented as significantly affecting conifer forests in the Cascade Range: Western Spruce Budworm (WSB) and Mountain Pine Beetle (MPB). Although insect-affected forest stands are not necessarily more likely to burn than their unaffected counterparts, weakened or killed trees likely alter fire dynamics like burn 
severity, fire temperature, biomass consumed, and subsequent post-fire stand composition to some degree (Hart et al. 2015; Meigs et al. 2015a; Meigs et al. 2016).

Meigs and colleagues mapped tree mortality across the PNW region from MPB and WSB outbreaks by combining Aerial Detection Survey (ADS) data 1970-2012 and Landsat satellite imagery (LT) 1984-2012 (Meigs et al. 2015b). Cumulative tree mortality layers developed from the LT dataset were used to filter out areas of moderate and high insect damage from our study. Cumulative insect-caused tree mortality is represented in the LT dataset using dead tree basal area per hectare (DTBA; $\mathrm{m}^{2} \mathrm{ha}^{-1}$ ) as units. An initial trial was run to remove all insect influence, but the analysis revealed little area left available to sample. As insects are likely present even in areas with no observed tree mortality, we decided to include only a low level of detected insect-caused tree mortality. This threshold was defined as 3.0 (cumulative) DTBA $\mathrm{m}^{2} \mathrm{ha}^{-1}$ per WSB and MPB infestation, or roughly $5 \%$ of the maximum DTBA value observed within the datasets. Area with insect-caused tree mortality values beyond this threshold were removed from the study.

Site Selection: Burn Severity and Fire History

MTBS develops burn severity maps using the Normalized Burn Ratio (NBR) equation for application by landscape managers and scientists (Eidenshink et al. 2007). The NBR index is a common approach to quantify vegetation change post-wildfire using near infrared and short-wave infrared bands from pre-fire and post-fire satellite imagery. Two common indices used by scientists are built from the NBR equation and 
available from MTBS datasets; the delta Normalized Burn Ratio (dNBR) and its relativized form (RdNBR) (Eidenshink et al. 2007). Both indices work to effectively characterize vegetation change post-fire but come with subtle pros and cons depending upon application (Morgan et al. 2014; Parks et al. 2014). Since this study assesses a relatively short period of time between successive wildfires, some sites may not have experienced much vegetation recovery. Miller and Thode (2007) found that among landscapes with low pre-fire vegetation cover, the RdNBR index consistently performed better than its dNBR counterpart at quantifying field-verified burn severity. Thus, to maximize the accuracy of classifications under those conditions, we used the RdNBR index to classify remote burn severity within our field sites.

In its raw form, the RdNBR product is a continuous value scale that is classified by analysts into subcategories that represent brackets of percentile degrees of change. We used classes set by MTBS analysts but focused only on low and high-severity fires, defined roughly as post-fire overstory tree mortality of $<50 \%$ and $>90 \%$, respectively (Whittier and Gray 2016). Forests burned at moderate severity (i.e. 50\%-90\%) likely have their own unique post-fire dynamics and are harder to identify in the field (Stevens-Rumann and Morgan 2016). Thus, we chose low and high-severity classes to distil the sampling strata by and represent the MTBS boundaries as it might best capture full range of current and future potential fire effects.

To isolate and differentiate the effects of SIFs, reburned areas were compared to those recently single-burned (control group) within the same geographic area. This 
comparison allowed us to examine the influence of the initial vs. the secondary wildfire when experienced at varying burn severities (low and high). Our stratification design also considered sequence of burn severity (low-high vs. high-low), which has been shown to alter post-fire conifer regeneration dynamics (Stevens-Rumann and Morgan 2016). A smaller number of unburned sites were also selected to sample and represent local forest structure in the absence of recent wildfire. To remove all potential fire effects from the unburned sample sites, area was selected immediately outside of relevant wildfire perimeters, which also matched the elevation gradient of the other fire histories sampled. Finally, to ensure and increase the accuracy of remote-sensing methods used to delineate fire perimeters, potential sampling areas were buffered $100 \mathrm{~m}$ from all fire-perimeter boundaries to help maintain distinct fire histories in the field (Stevens-Rumann and Morgan 2016).

Site Selection: Topographic Setting \& Final Selection

Within landscapes with complex topography such as the Central Cascade Range, topographic setting strongly affects post-fire stand structure and regeneration by influencing wildfire behavior, moisture availability, and forest productivity via solar radiation (Agee 1993; Franklin and Hemstrom 1981; Morrison and Swan 1990; Tepley et al. 2013). At a given latitude and elevation, and across a gradient of solar-radiation potential, southwest-facing aspects illicit the hottest and driest conditions in the northern hemisphere. In contrast, coolest and wettest conditions are observed in northeast-facing aspects. The Heat Load Index (HLI) developed by McCune and Keon 
(2002) transforms aspect, slope and latitude to represent annual potential solar radiation, and therefore the relative wetness or dryness of a location. To capture topographic trends, a HLI was derived from a 30m Digital Elevation Model (DEM) using the Geomorphometry \& Gradient Metrics toolbox for ArcGIS (Evans et al. 2014).

HLI values range between zero and one, with those closer to zero in a northeastfacing aspect and one in a southwest-facing aspect. HLI values were extracted from each wildfire affected study area using the Intersect Tool in ArcGIS to represent local topography. To isolate topographically wet and dry sites, areas with values in the top and bottom 25th percentiles were retained for stratification purposes. These 25th percentile wet and dry classes were then geographically overlaid upon burn severity classes to produce the final field sampling stratification, represented as strata delineations or polygons within the study areas (Table 3). Although local topography is highly variable on both Mt. Adams and Mt. Jefferson, it's important to keep in mind the positionality or topographic context of the study area on a conic landscape feature at a larger scale. For example, the study area on Mt. Adams exists entirely on the southern face of a large volcano. One could say plots sampled in this area, regardless of local aspect of the micro-topography, are likely to be drier than those on the northeastern face. 
Table 3: Field sampling stratification per study area (Mt. Adams and Mt. Jefferson).

\begin{tabular}{ccccc}
\hline Strata & Wildfire History & Burn Severity & Topographic Setting & Sample Size (n) \\
\hline$\# 1$ & Single Recent Wildfire & Low & Wet & 8 \\
$\# 2$ & Single Recent Wildfire & Low & Dry & 8 \\
$\# 3$ & Single Recent Wildfire & High & Wet & 8 \\
$\# 4$ & Single Recent Wildfire & High & Dry & 8 \\
$\# 5$ & Short-Interval Fire & Low-High & Wet & 8 \\
$\# 6$ & Short-Interval Fire & High-Low & Wet & 8 \\
$\# 7$ & Short-Interval Fire & Low-High & Dry & 8 \\
$\# 8$ & Short-Interval Fire & High-Low & Dry & 8 \\
$\# 9$ & Recently Unburned & N/A & Wet & 4 \\
$\# 10$ & Recently Unburned & N/A & Dry & 4 \\
\hline
\end{tabular}

Stratification was designed to compare effects between (1) SIFs vs. single recent fire, (2) sequence of burn severity in SIFs, and (3) wet and dry topographic settings.

With preliminary buffering and stratification (described above) completed, fieldplot coordinates were randomly generated from strata delineations using the Sampling Design Tool for ArcGIS (Buja and Menza 2013; Figure 6). A stratified random selection was used to generate eight plots per stratum, with four random plot locations for strata $\# 9$ and \#10 (Table 3). During the plot generation process, all potential sampling plots were buffered a minimum distance of $100 \mathrm{~m}$ from each other to minimize spatial autocorrelation. Additionally, to maintain uniformity of field conditions (i.e. burn severity and topographic position), each sampling plot was restricted to a contiguous strata delineation polygon of one hectare or greater in size. This final selection resulted in a total plot sample size of $n=72$ per study area, or $n=144$ plots total. Among the plots we physically sampled $(n=122)$ within our study areas, forest types varied with 


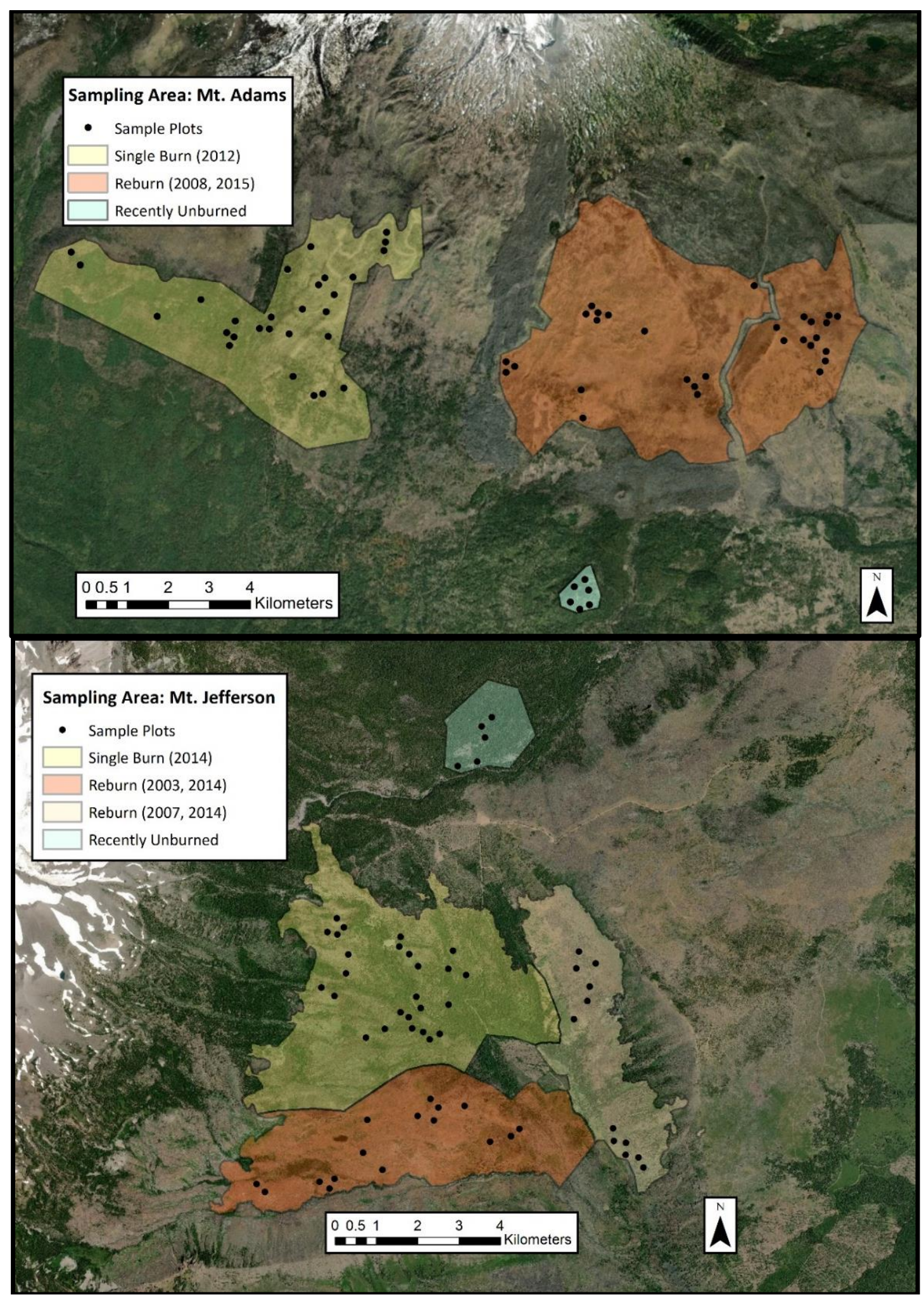

Figure 6: Final field plot locations using a stratified random sampling design for Mt. Adams (top) and Mt. Jefferson (bottom). Various criteria were used to select potential study areas (see above), while fire history and topographic position were used specifically to stratify sampling plots by. 
elevation due to topographic setting and moisture availability. Forest compositions were generally upper-montane at $1215 \mathrm{~m}$, mixed around $1350 \mathrm{~m}$, and characteristically subalpine above 1450m (Franklin and Dyreness 1973; Table 4).

Table 4: Summary of plot percentages sampled among forest types and fire histories.

\begin{tabular}{lccccccc}
\hline & & \multicolumn{5}{c}{ Fire History (\% of plots) } \\
\cline { 5 - 8 } $\begin{array}{l}\text { Forest } \\
\text { Type }\end{array}$ & $\begin{array}{c}\text { Elevation } \\
\text { Range }(\mathrm{m})\end{array}$ & $\begin{array}{c}\text { \% of plots } \\
(\mathrm{n}=122)\end{array}$ & $\begin{array}{c}\text { Unburned } \\
(\mathrm{n}=11)\end{array}$ & $\begin{array}{c}\text { Low } \\
(\mathrm{n}=28)\end{array}$ & $\begin{array}{c}\text { High } \\
(\mathrm{n}=26)\end{array}$ & $\begin{array}{c}\text { High-low } \\
(\mathrm{n}=28)\end{array}$ & $\begin{array}{c}\text { Low-high } \\
(\mathrm{n}=29)\end{array}$ \\
\hline $\begin{array}{l}\text { Upper- } \\
\text { Montane }\end{array}$ & $1215-1425$ & $30 \%$ & $55 \%$ & $32 \%$ & $15 \%$ & $25 \%$ & $38 \%$ \\
Mixed & $1264-1488$ & $23 \%$ & $9 \%$ & $50 \%$ & $12 \%$ & $0 \%$ & $34 \%$ \\
Subalpine & $1342-1662$ & $47 \%$ & $36 \%$ & $18 \%$ & $73 \%$ & $75 \%$ & $28 \%$ \\
\hline
\end{tabular}

Field Sampling Design

Field data was collected from Mt. Adams, WA and Mt. Jefferson, OR during the summer of 2018 (June - August) and include ten variables measured (Table 5). A point database of pre-selected plot locations and rasterized maps of strata by study areas were uploaded to a Trimble Juno and Garmin GPS for field navigation and reference. Plots were accessed by hiking cross-country from the nearest accessible road. Once reached, each site was field verified for desired burn severity and topographic position. Low burn severity was field classified by the presence of surface fire, limited (but present) scorching of tree boles, minor removal of fine woody debris and organic soil, and $<50 \%$ canopy tree mortality within plot; high burn severity was classified by canopy tree mortality $>90 \%$, significant bole charring, and significant removal of organic soils within plot (Key and Benson 2006; Morgan et al. 2014). No known guidelines to us currently exist for classifying field conditions for SIFs. Nonetheless, SIFs visually 
presented fire-effects on forest structure that differed from single high-severity fire plots (i.e. increased bole charring and consumption of standing tree biomass, removal of fine woody debris, increased soil charring).

Table 5: Field variables used to quantify forest structure, composition, and regeneration post-wildfire.

\begin{tabular}{|c|c|c|c|}
\hline Field Variables & Description & Equipment & Field Method Reference \\
\hline Topography & $\begin{array}{l}\text { Field derived elevation, slope and } \\
\text { aspect }\end{array}$ & GPS, compass & $\begin{array}{l}\text { Plot center; Stevens-Rumann } \\
\text { and Morgan (2016) }\end{array}$ \\
\hline $\begin{array}{l}\text { Distance to seed } \\
\text { source }\end{array}$ & $\begin{array}{c}\text { Ten closest live trees of cone } \\
\text { bearing age to plot center; species }\end{array}$ & Rangefinder & $\begin{array}{l}\text { Plot center; Stevens-Rumann } \\
\text { and Morgan (2016) }\end{array}$ \\
\hline $\begin{array}{l}\text { Conifer } \\
\text { regeneration }\end{array}$ & $\begin{array}{l}\text { Post-fire conifer seedlings; species, } \\
\text { age, distance to CWD }\end{array}$ & Observation & $\begin{array}{l}\text { Variable-width belt transect; } \\
\text { Harvey et al. (2016) }\end{array}$ \\
\hline Seedling health & $\begin{array}{c}\text { Fv/Fm measurements on dominant } \\
\text { seedling species in plot }\end{array}$ & Fluorometer & $\begin{array}{l}\text { Variable-width belt transect; } \\
\text { Murchie and Lawson } 2013\end{array}$ \\
\hline $\begin{array}{l}\text { Down woody } \\
\text { debris }\end{array}$ & $\begin{array}{l}\text { Debris classified by time-lag fuel } \\
\text { hour along transects at } 1 \mathrm{~m} \\
\text { intervals }\end{array}$ & Logging tape & $\begin{array}{l}\text { Variable width belt transect; } \\
\text { Stevens-Rumann and Morgan } \\
\text { (2016) }\end{array}$ \\
\hline Litter and duff & $\begin{array}{c}\text { Depth of litter and duff layer along } \\
\text { transects at } 1 \mathrm{~m} \text { intervals }\end{array}$ & Ruler & $\begin{array}{l}\text { Variable width belt transect; } \\
\text { Stevens-Rumann and Morgan } \\
\text { (2016) }\end{array}$ \\
\hline $\begin{array}{l}\text { Overstory } \\
\text { canopy }\end{array}$ & Percentage of overstory cover & Densiometer & $\begin{array}{l}\text { Variable width belt transect; } \\
\text { Stevens-Rumann and Morgan } \\
\text { (2016) }\end{array}$ \\
\hline $\begin{array}{l}\text { Vegetation \& } \\
\text { ground cover }\end{array}$ & $\begin{array}{l}\text { Vegetation and ground coverage } \\
\text { by percentage of class types }\end{array}$ & Observation & $\begin{array}{l}\text { Variable width belt transect; } \\
\text { Stevens-Rumann and Morgan } \\
\text { (2016) }\end{array}$ \\
\hline $\begin{array}{l}\text { Live and dead } \\
\text { mature trees }\end{array}$ & $\begin{array}{c}\text { Standing conifers within circle plot; } \\
\text { species, } \mathrm{DBH} \text {, charring, } \\
\text { live/dead/snag }\end{array}$ & Logging tape & $\begin{array}{c}\text { Circle plot; Stevens-Rumann and } \\
\text { Morgan (2016) }\end{array}$ \\
\hline $\begin{array}{l}\text { Tree } \\
\text { establishment }\end{array}$ & $\begin{array}{l}\text { Increment cores extracted from } \\
\text { live trees; five per plot }\end{array}$ & $\begin{array}{l}\text { Handheld } \\
\text { increment borer }\end{array}$ & $\begin{array}{l}\text { Circle plot; Schoennagel et al } \\
\qquad(2011)\end{array}$ \\
\hline
\end{tabular}

If the predetermined plot location did not meet desired criteria, the plot was moved in 30m intervals, in a random cardinal direction, within the immediate patch, 
until conditions correctly matched the strata (Stevens-Rumann and Morgan 2016; Table 6). If no area inside a patch met desired conditions, plots were moved to another nearby patch of the same strata using the raster layers uploaded upon GPS unit. If a plot showed signs of management influence, the plot was moved appropriately using above methods. Although we traversed through areas with management influence present (i.e. planted trees, sawed stumps, and salvage logging), we did not encounter any signs of management presence within predetermined plot locations.

Table 6: Number and percentage of plots $(n=122)$ moved in the field due to mismatch between field and remotely-sensed conditions.

\begin{tabular}{lcc}
\hline Criteria & \# of Plots & \% of Plots \\
\hline Low burn severity & 5 & $4.1 \%$ \\
High burn severity & 6 & $4.9 \%$ \\
Unburned (no recent fire) & 0 & $0 \%$ \\
Topographic setting (aspect/slope) & 9 & $7.3 \%$ \\
Management influence (presence) & 0 & $0 \%$ \\
\hline
\end{tabular}

At each plot location, a 0.07 hectare $15 \mathrm{~m}$-radius circle plot was established by running two field tapes in cardinal directions (Figure 7). First, elevation, slope, and distance from plot center to the ten nearest live conifer trees of cone bearing age (seed source) was recorded (Kemp et al. 2016; Stevens-Rumann and Morgan 2016). The species of these ten seed source trees was also recorded. Next, seedling density inside each plot was estimated to inform choice of the variable width of seedling belt transects. Default dimensions of the belt transect were $14 \times 2 \mathrm{~m}$ (medium) extending $1 \mathrm{~m}$ beyond plot center in cardinal directions, but the width was adjusted to either $14 \times 1 \mathrm{~m}$ 
(small) if seedlings were very dense (i.e. $>200$ seedlings would be captured in default [medium] belts) or to the entire $15 \mathrm{~m}$-radius circle (large) if seedlings were very sparse (i.e. $<10$ seedlings would be captured in default [medium] belts) following Harvey et al. (2016). When using small belt transects, we stopped counting seedlings at 200 stems; any number beyond this indicated a very high regeneration response $(>35,708$ seedlings/ha). Seedlings were counted by species, but some inaccuracy may have occurred when differentiating among very young true-fir seedlings (grand fir, pacific silver fir, subalpine fir), which are difficult to differentiate below three years of age (Brown et al. 2013). Thus, the abundance and location of mature parent species in and surrounding each plot was considered as guidance when identifying very young true-fir seedlings.

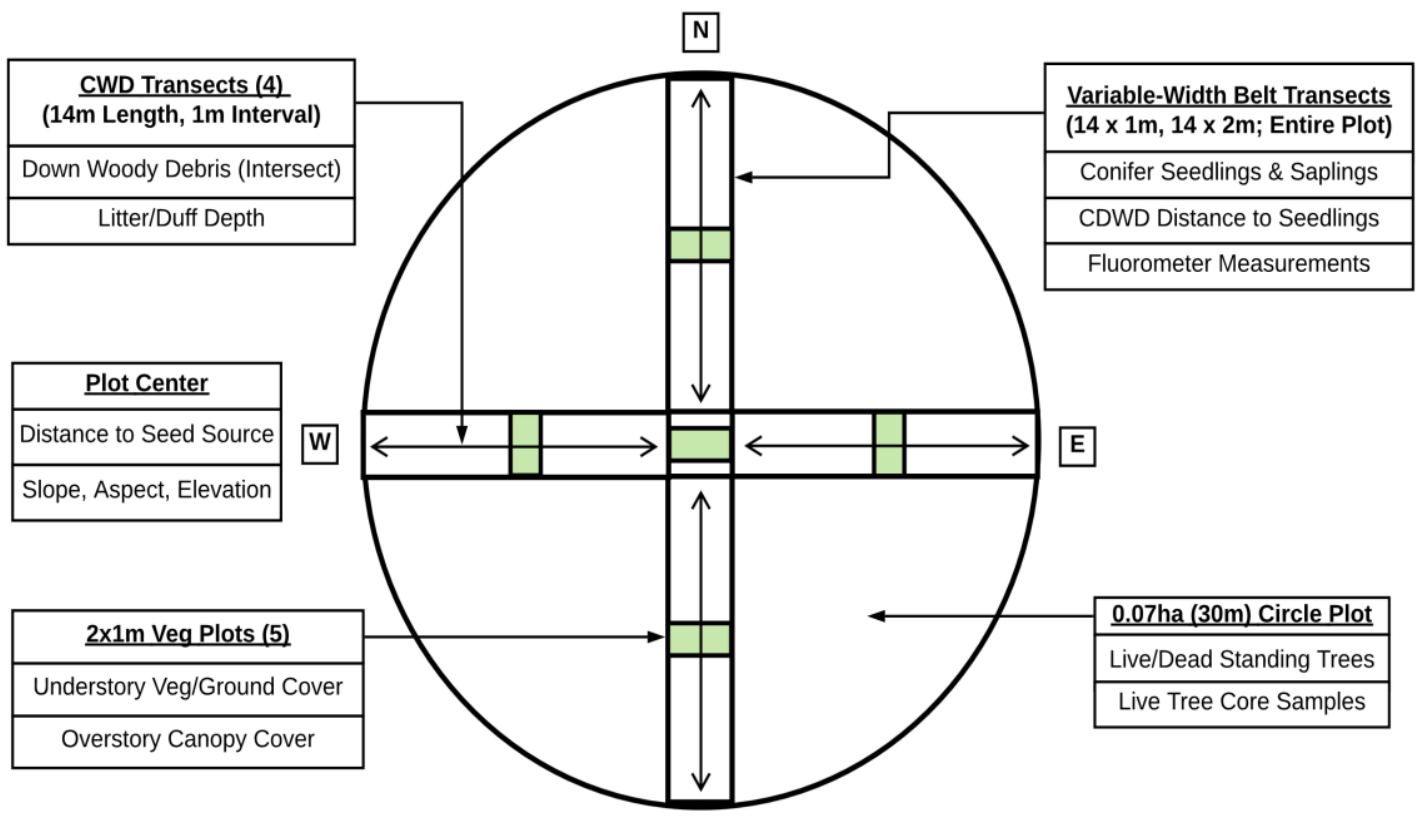

$\mathrm{s}$

Figure 7: Field sampling design diagram. 
Seedlings were counted only if they established post-fire or post-reburn. For this, relative seedling age was estimated by counting bud-scar nodes. Aging by bud scar loses accuracy as tree age increases, but it is a relatively minor factor for juveniles ( $<10 \mathrm{yrs}$ old) and is mostly a rapid and noninvasive sampling approach when high accuracy on age data is outside of the scope of the study (Hankin et al. 2018; Harvey et al. 2016; Millar et al. 2004; Urza and Sibold 2013). The earliest any post-fire seedling could have established was post-2003 (15 years of age) based on fire years within our study areas, and we did not encounter seedlings exhibiting node counts beyond this range except in unburned or low-severity plots. Additionally, time between fires for reburned plots was 7 or 11 years, which created a relatively large age-gap between seedlings that established after the initial fire and then later, post-reburn.

As complementary information to seedling abundance, dark-adapted hydraulic stress measurements were recorded (Murchie and Lawson 2013). For this, darkadapting left clips were applied to south-facing, one-year old needles (i.e. using the most recent bud scar as guideline) of the dominant tree species in up to 10 seedlings per plot. If fewer than 10 seedlings occurred within the plot, needles on seedlings from all present species were clipped. A timer was set for 30 minutes upon clipping the first seedling, and each clipped seedling was marked using a numbered survey flag for relocation and differentiation. After 30 minutes, optimal quantum yield measurements (i.e. Fv/Fm) were taken in the successive order of clipped seedlings using a fluorometer (OS5p, OptiSciences). The Fv/Fm test is a common technique to measure plant stress by 
dark-adapting leaves for photosystem II to reset, then stimulating fluorescence response in photosystem II with light pulses and comparing each measured fluorescence value (Fv) to a maximum fluorescence value $\left(\mathrm{Fm}\right.$; theoretical maximum value for $\mathrm{C}_{3}$ photosynthesis is ca. 0.83; Ritchie 2006). A lower Fv/Fm ratio correlates with higher plant stress, which can be caused by lack of moisture availability (Murchie and Lawson 2013).

Seedlings were also assessed for their proximity to dead/ down coarse woody debris (CWD), to test the hypothesis that CWD provides favorable nursery conditions (i.e. shading, moisture, soil nutrients) for seedlings. CWD was identified when downed wood had a diameter equal to or greater than $7.6 \mathrm{~cm}$ (i.e. $1000+$ fuel-hour class; Anderson 1982) and the proximal area of influence on seedlings was determined by CWD's diameter and distance to each seedling (Figure 8). When the diameter of nearby

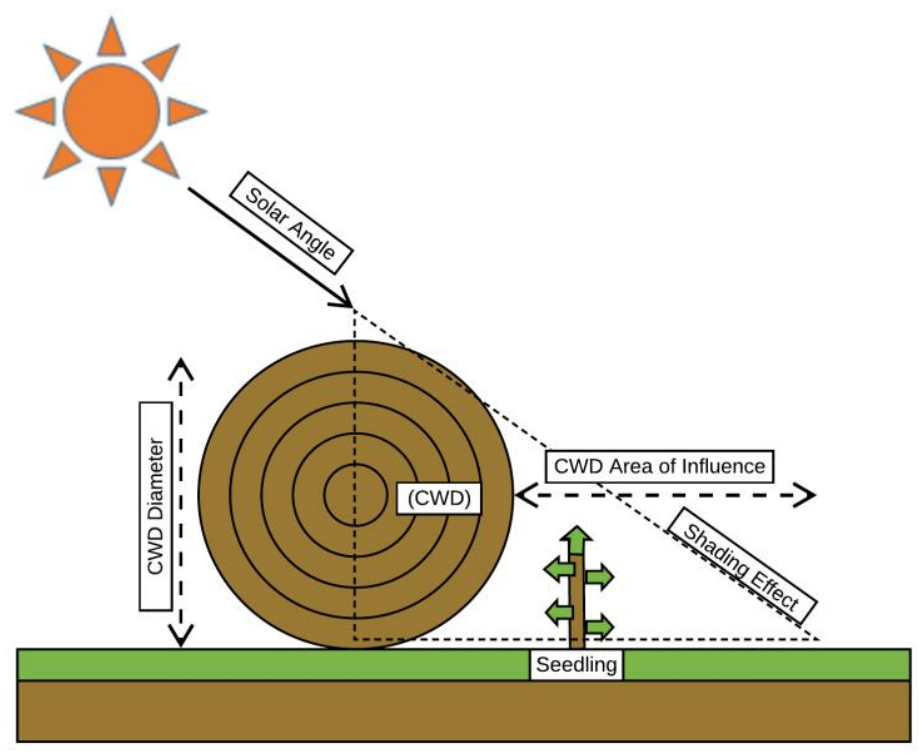

Figure 8: Conceptual diagram illustrating the shading effect coarse woody debris (CWD) can provide for establishing seedlings. 
CWD was equal or greater than the horizontal distance to the seedling, CWD diameter and distance to seedling were recorded, or otherwise ignored.

To quantify abundance of fine down woody debris (FWD, $<7.6$ diameter) and CWD, we used the planar intersect method sampling at $1 \mathrm{~m}$ intervals along each $14 \mathrm{~m}$ cardinal direction tapeline (i.e. skipping plot center; Figure 7; Brown 1974). Debris was classified by diameter using time-lag fuel hour notation, including additional categorical attributes to describe wood appearance; i.e. sound, rotten, and/or heavily charred (Anderson 1982). At each $1 \mathrm{~m}$ interval the presence and depth of a litter and duff layer was also measured using a ruler; litter and duff layers were grouped together to represent organic surface material. This sampling protocol resulted in 56 fine/coarse woody debris and litter/duff depth data points per plot (14 points x 4 transects).

Percent ground cover of understory plant communities was recorded in five $2 \times 1 \mathrm{~m}$ ground cover quadrats located at plot center and $7 \mathrm{~m}$ along each cardinal direction tapeline (Figure 7). Understory plant cover was recorded by broad functional vegetation types (grasses, forbs, and shrubs) and non-vegetation types (bare soil or litter/duff cover). Canopy cover density was also assessed at each quadrat location using a spherical densiometer (Lemmon 1956). A densiometer measurement was taken facing each cardinal direction and the four measurements averaged for each quadrat. The data from the five ground and canopy cover quadrats were then averaged to represent mean conditions for each circle plot. 
To estimate pre-fire forest composition, all standing trees within each $0.07 \mathrm{ha}$ circle plot equal to or greater than $7.8 \mathrm{~cm}$ in diameter at breast height (DBH) were identified at species level (but see below) and measured for $\mathrm{DBH}$; decay-stage (live, dead or snag) and tree charring was additionally noted. Charring was recorded as a binary response, defined as individual tree stems exhibiting black carbon biochar on more or less than $50 \%$ of their non-bark, woody surface area. In some reburned areas, heavily charred stumps were the only indicators of pre-fire tree composition. In such situations, stumps were counted as snags, measured for diameter at tree base and classified as charred to indicate loss of pre-fire biomass. Working in high-severity burns, especially reburns, meant many standing trees were difficult to identify by species as indicators had been completely removed by fire (needles, bark, structure, branch pattern, cones, etc.) and remaining indicators masked by charring. Where no discernable indicators could be identified, tree species was marked as unknown. Unknown trees were removed from future species composition analyses.

Within plots with live trees (low burn severity or unburned), five increment cores per plot were extracted by increment borer (Haglöf). Trees were selected randomly by flagging every 5 th tree measured within the plot until five trees had been selected. Very large trees $(\mathrm{DBH}>80 \mathrm{~cm})$ were avoided to focus on establishment during the past two centuries (e.g. recent history) and to improve tree age estimates - which can become increasingly convoluted in larger/older trees as pith and the shoot/root boundary become more difficult to obtain and identify. Trees were cored at a slight downward 
angle approximately $20 \mathrm{~cm}$ above the root collar, to reach the establishment date as best as feasible.

Upon extraction, cores were stored in plastic straws and labeled according to plot number and tree data. Once delivered to the lab, cores were mounted to wood troughs, sanded, and scanned following standard procedures (Stokes and Smiley 1968; Speer 2012). Scanned images were uploaded to CooRecorder V8.1 for ring counting and dating (Cybis Dendrochronology 2013). Although coring live trees increases the accuracy of potential tree establishment dates, some inherent error exists with regards to years missed due to coring height and missed pith. A correction for pith estimation for cores where pith was not obtained was implemented in CooRecorder using a function that uses the width of the last seven known rings to project a geometric model of the missing rings. The projection changes ring dimensions as the user moves the pith location, and so the user attempts to match known ring curvature to estimate distance and years to pith (Cybis Dendrochronology 2013). For our purposes of broad stand-age characterization, only estimated years to pith was necessary. 


\section{Data Analysis}

All statistical analyses were completed in R version 3.5.2 (R Core Team 2017) using standard core packages, unless otherwise noted.

\section{Post-Fire Forest Structure}

To identify potential differences in post-fire forest structure among sampled fire histories (recently unburned, low, high, low-high, and high-low burn severities), univariate and multivariate methods were utilized. For both analyses, post-fire forest structure was summarized by twelve variables including distance to seed source, percent canopy cover, coarse and fine down woody debris abundance, percent ground cover (litter/duff layer, exposed bare soil, grass, shrub, forb), and standing tree class proportions (live, snag, charred). Many variables had non-normal distributions and unequal variance, which informed our choice of nonparametric statistical methods, which also allowed for unequal sample sizes among fire histories. For the univariate analysis, a Kruskal-Wallis test (non-parametric ANOVA) was used to test for differences amongst fire histories. When differences were detected, a Games-Howell post-hoc test was used for pairwise comparisons utilizing the "userfriendlyscience" R package (Peters 2018). Resulting p-values were pre-adjusted using the Holm method to correct for increased Type I error introduced by multiple pairwise comparisons (Aickin and Gensler 1996).

For the multivariate (i.e. cumulative) analysis of stand structure, a permutational multivariate analysis of variance (PERMANOVA) was used in R with the "vegan" $R$ 
package (Oksanen et al. 2018). PERMANOVA is a highly flexible "semi-parametric" MANOVA design which uses a distribution-free permutation technique and chosen dissimilarity measure for detecting cumulative differences amongst groups (Anderson 2017). For our analysis, number of permutations was set to 999 and dissimilarity measure to Bray-Curtis distance (Faith, Minchin, and Belbin 1987). Like the univariate analysis, we also used the Holm method to adjust resulting $p$-values for multiple pairwise comparisons. Finally, a non-metric multidimensional scaling (NMDS) plot was developed for visual interpretation of the multivariate results among fire histories.

\section{Post-Fire Seedling Presence and Abundance}

To identify primary factors influencing conifer regeneration, the presence and abundance of post-fire conifer seedlings was modeled as a function of post-fire ecological legacies (e.g., distance to seed source, canopy cover), abiotic environmental conditions (e.g., heat load index, elevation, slope), temporality (e.g., time since a highseverity fire), and post-fire climate conditions (e.g., snow water equivalent, vapor pressure deficit); see Table 7. Fire history (i.e. burn severity class) was originally included in seedling models as a categorical variable - but was removed in favor of continuous variables which explained fire effects on forest structure in greater detail (i.e. many levels) and to minimize multicollinearity in subsequent models.

Two statistical model types were run-one to predict drivers of seedlings presence/ absence and another to predict drivers of seedling abundance. Specifically, generalized linear regression (GLM) with a logistic function was used for modeling the 
Table 7: Predictor variables included in all postfire seedling regeneration models and their methods of measurement.

\begin{tabular}{|c|c|c|c|c|c|}
\hline Category & Variable & Method of measurement & Units & Type & Range \\
\hline \multirow[t]{8}{*}{ Fire legacies } & $\begin{array}{l}\text { Live seed } \\
\text { source } \\
\text { distance }\end{array}$ & $\begin{array}{l}\text { Field measured (10 closest } \\
\text { mature trees; averaged) }\end{array}$ & $\mathrm{m}$ & Continuous & $\begin{array}{l}\text { Bounded } \\
{[15500]}\end{array}$ \\
\hline & $\begin{array}{l}\text { Seed source } \\
\text { censor }\end{array}$ & $\begin{array}{l}\text { Censor variable indicating } \\
\text { whether a seed source was } \\
\text { noted within } 500 \mathrm{~m} \text { of plot }\end{array}$ & Unitless & Constant & $\begin{array}{l}\text { Discrete } \\
\text { [0 or 1] }\end{array}$ \\
\hline & $\begin{array}{l}\text { Coarse woody } \\
\text { debris }\end{array}$ & Field measured (abundance) & Integer & Continuous & $\begin{array}{l}\text { Bounded } \\
\text { [0 56] }\end{array}$ \\
\hline & Canopy cover & $\begin{array}{c}\text { Field measured (5 plots, } \\
\text { averaged) }\end{array}$ & $\%$ & Continuous & $\begin{array}{l}\text { Bounded } \\
{\left[\begin{array}{ll}0 & 100]\end{array}\right.}\end{array}$ \\
\hline & $\begin{array}{l}\text { Bare soil } \\
\text { cover }\end{array}$ & $\begin{array}{c}\text { Field measured (5 plots, } \\
\text { averaged) }\end{array}$ & $\%$ & Continuous & $\begin{array}{l}\text { Bounded } \\
{\left[\begin{array}{ll}0 & 100\end{array}\right]}\end{array}$ \\
\hline & Shrub cover & $\begin{array}{c}\text { Field measured (5 plots, } \\
\text { averaged) }\end{array}$ & $\%$ & Continuous & $\begin{array}{l}\text { Bounded } \\
{\left[\begin{array}{ll}0 & 100\end{array}\right]}\end{array}$ \\
\hline & Forb cover & $\begin{array}{c}\text { Field measured (5 plots, } \\
\text { averaged) }\end{array}$ & $\%$ & Continuous & $\begin{array}{l}\text { Bounded } \\
{\left[\begin{array}{ll}0 & 100\end{array}\right]}\end{array}$ \\
\hline & Grass cover & $\begin{array}{c}\text { Field measured (5 plots, } \\
\text { averaged) }\end{array}$ & $\%$ & Continuous & $\begin{array}{c}\text { Bounded } \\
{[0 \text { 100] }}\end{array}$ \\
\hline Biotic & $\begin{array}{l}\text { Pre-fire tree } \\
\text { basal area }\end{array}$ & $\begin{array}{l}\text { Field measured ( } 15 \mathrm{~m} \text { radius } \\
\text { plot); live/dead standing trees }\end{array}$ & m2 ha-1 & Continuous & $\begin{array}{c}\text { Not Bounded } \\
{[0.6 \text { 157.1] }}\end{array}$ \\
\hline \multirow[t]{4}{*}{ Abiotic } & Elevation & Field measured & $\mathrm{m}$ & Continuous & $\begin{array}{l}\text { Bounded } \\
{[1215 \text { 1650] }}\end{array}$ \\
\hline & Slope & Field measured & Degrees & Continuous & Bounded [5 40] \\
\hline & $\begin{array}{l}\text { Heat load } \\
\text { index (HLI) }\end{array}$ & $\begin{array}{l}\text { Derived from field measured } \\
\text { slope, aspect and latitude } \\
\text { (McCune and Keon 2002) }\end{array}$ & Unitless & Continuous & $\begin{array}{c}\text { Not bounded } \\
{[0.381 .01]}\end{array}$ \\
\hline & $\begin{array}{l}\text { Topographic } \\
\text { wetness index } \\
\text { (TWI) }\end{array}$ & $\begin{array}{l}\text { Derived from a 30m DEM; } \\
\text { ArcGIS (Beven and Kirkby } \\
\text { 1979; Evens et al. 2014) }\end{array}$ & Unitless & Continuous & $\begin{array}{l}\text { Not bounded } \\
{[5.6714 .27]}\end{array}$ \\
\hline Temporality & $\begin{array}{l}\text { Time since a } \\
\text { high-severity } \\
\text { fire }\end{array}$ & $\begin{array}{c}\text { Derived by year of sampling } \\
\text { minus year of burn }\end{array}$ & Years & Continuous & $\begin{array}{l}\text { Discrete values } \\
{[3,4,6,10,11,15]}\end{array}$ \\
\hline \multirow[t]{3}{*}{$\begin{array}{l}\text { Post-fire } \\
\text { climate }\end{array}$} & $\begin{array}{l}\text { Snow water } \\
\text { equivalent } \\
\text { (SWE) }\end{array}$ & $\begin{array}{l}\text { March - May averaged SWE } \\
\text { (deviation from 15-year } \\
\text { normal) 0-3 years after a high- } \\
\text { severity fire; (SnoDAS } 1 \mathrm{~km} \text { ) }\end{array}$ & $\mathrm{mm}$ & Continuous & $\begin{array}{c}\text { Not bounded } \\
{[-534.16350 .14]}\end{array}$ \\
\hline & $\begin{array}{c}\text { Vapor } \\
\text { pressure } \\
\text { deficit (VPD) }\end{array}$ & $\begin{array}{c}\text { June - Sept averaged VPD } \\
\text { (deviation from 30-year } \\
\text { normal) 0-3 years after a high- } \\
\text { severity fire; (METDATA 4km) }\end{array}$ & $\mathrm{kPa}$ & Continuous & $\begin{array}{l}\text { Not bounded } \\
{[0.010 .18]}\end{array}$ \\
\hline & $\begin{array}{c}\text { Palmer } \\
\text { drought } \\
\text { severity index } \\
\text { (PDSI) }\end{array}$ & $\begin{array}{c}\text { June - Sept averaged PDSI } \\
\text { (deviation from 30-year } \\
\text { normal) 0-3 years after a high- } \\
\text { severity fire; (METDATA 4km) }\end{array}$ & Unitless & Continuous & $\begin{array}{l}\text { Not bounded } \\
{[-1.570 .38]}\end{array}$ \\
\hline
\end{tabular}


presence or absence of seedlings and GLM with a negative binomial distribution (logitlink) for predicting seedling counts following Kemp et al. (2016). Negative binomial models were developed using the "MASS" R package (Venables and Ripley 2002). All referenced variables from Table 7 were included within the preliminary full logistic and count models, prior to model simplification, except for percent litter/duff cover. Litter/duff cover was highly collinear $(\rho>0.70)$ with canopy cover and seed source distance upon inspection with Spearman's rank correlation. Upon fitting a full model, outlier data points were assessed using Cook's Distance when plotting Pearson's residuals against fitted values. Significant outliers, indicated as having Cook's Distance > 0.5 , were removed from each model to improve performance and meet assumptions (Cook 1979).

The above preliminary models were reduced to only significant variables $(p<$ 0.05) using a backward stepwise procedure in which each variable was assessed for model improvement through its removal using absolute decreases in $\mathrm{AICc}$ and ChiSquare probability. In a stepwise fashion, variables were removed that contributed the largest decrease in AICC and Chi-Square probability until only significant variables remained. Multicollinearity was assessed in the reduced models using the variance inflation factor (VIF) measure; final explanatory variables displayed VIF values $<3.0$, indicating minor collinearity detected within models (Zuur et al. 2010). 


\section{Logistic Regression Models for Seedling Presence/ Absence}

A total of nine logistic regression models were developed to predict the presence or absence of conifer seedlings; i.e. one for each of the eight most abundant conifer species (lodgepole pine, grand fir, Douglas fir, subalpine fir, pacific silver fir, mountain hemlock, ponderosa pine, and engelmann spruce) and another for all species combined. For species specific models, distance to seed source was calculated using only the recorded live, mature trees of the same species. Logistic model fit was assessed using the deviance residual and Hosmer-Lemeshow test (Hosmer et al. 2013; Zuur et al. 2010). These model fit statistics indicate a significant lack of fit to the data if the $p$-value generated from the deviance chi-squared test or Hosmer-Lemeshow statistic is $<0.05$ (alpha; Hosmer et al. 2013).

Model predictive performance was assessed using K-Fold cross-validation (Fushiki 2011), which partitions data into k equally sized segments. One fold is held out for validation while the other k-1 folds are used to train the model and then used to predict the response variable from testing data. This process is repeated $k$ times and prediction performance is recorded as model accuracy. For our models, we used k=10 and reported mean prediction accuracy with $95 \%$ confidence intervals around the mean. Additionally, we included the positive and negative predictive rates (PPR, NPR), which respectively indicate how well a model predicted seedling presence (positive) or absence (negative). 


\section{Negative Binomial Count Models for Seedling Abundance}

The distribution of our seedling density data was strongly right skewed with unequal variances, where variance was always far greater than the mean; this hinted at significant overdispersion (Figure 9). For modeling non-normal count data, a GLM with a

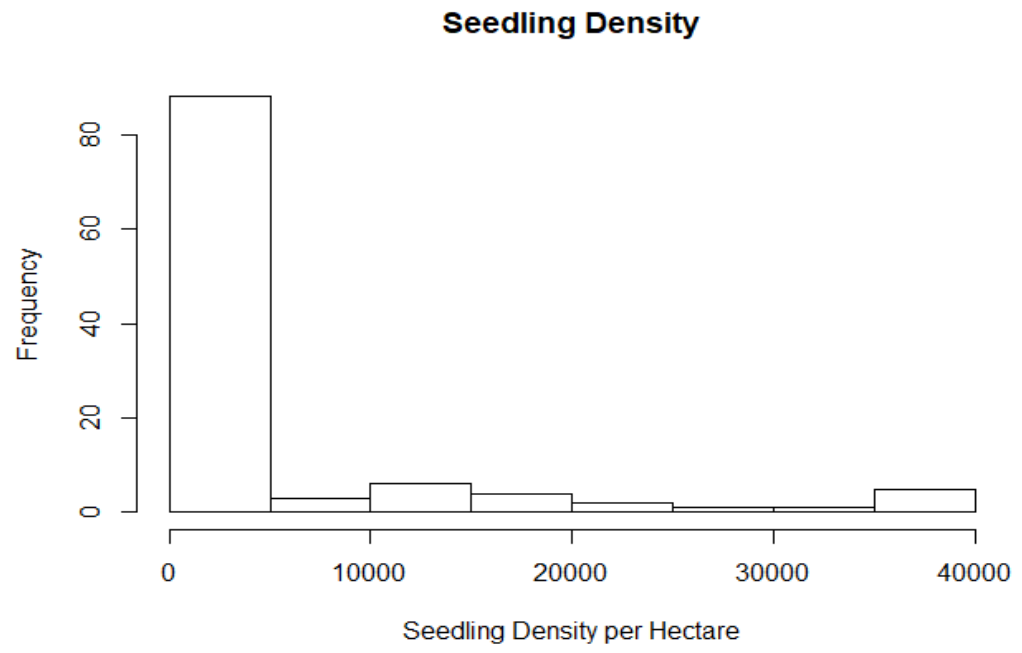

Figure 9: A histogram showing the distribution of seedling densities, per hectare, across burned plots $(n=111)$.

type of Poisson distribution is a commonly used approach (Zuur et al. 2012). When data displays significant overdispersion and/or a high number of zero responses, a negative binomial or zero-inflated negative binomial model can be an appropriate solution (Zuur et al. 2012). We originally attempted to develop count models for individual conifer species but were unable to successfully fit models for most species using oisson, negative binomial, or zero-inflated negative binomial distributions. Models we did fit performed poorly when assessing goodness of fit using residual plots and the Pearson's chi-squared test. Kemp et al. (2016) experienced similar issues with their seedling count 
models, a problem likely stemming from a high number of zeros for individual species across plots.

Thus, to minimize the number of zeros in our data, we grouped individual seedling species into two broad functional groups defined by shade tolerance. Three count models were developed in total for all species combined, shade-tolerant species, and shade-intolerant species. The ten conifer species we encountered were classified as shade-tolerant or intolerant using species information from the USFS Fire Effects Information System (Abrahamson 2018). Thus, grand fir, mountain hemlock, subalpine fir, pacific silver fir, and Engelmann spruce were grouped as shade-tolerant and lodgepole pine, Douglas fir, ponderosa pine, western white pine, and western larch as shade-intolerant.

After grouping species, we were successfully able to fit and validate the new count models. We found the negative binomial distribution best fit the data without sacrificing each model's ability to predict zeros. To account for the variable seedling transect sizes (0.0056ha, $0.0112 \mathrm{ha}, 0.0706 \mathrm{ha})$, an offset variable was included within model equations (Zuur et al. 2012). In addition to visual assessment of the plotted residuals against fitted values, a Pearson's chi-squared test was performed to assess each model's goodness of fit (Zuur et al. 2009). Prediction performance was assessed by comparing predicted and observed values from each model using Spearman's rank correlation ( $\rho)$. In this context, correlation indicates how close predicted seedling counts were to actual observed counts; a correlation of 1.0 indicates perfect prediction. 
Seedling Probability Curves: Distance to Seed Source and Fire History

To illustrate the impacts of seed source availability and fire history on seedling establishment, final reduced logistic and negative binomial GLM models were used to model the probability of seedling presence/ absence and abundance as a function of increasing distance to seed source. Model terms other than distance to seed source which explained fire effects on forest structure (e.g. canopy cover, ground/vegetation cover, woody debris, etc.) were kept at their median value for specific fire histories (i.e. low, high, low-high, high-low), while model terms which explained static site conditions or climate (e.g. elevation, slope, TWI, SWE, etc.) were kept at their median value for all plots that experienced recent fire ( $n=109$; Kemp et al. 2016) to avoid introducing bias that was not directly connected to fire effects. Since models were reduced to only significant terms, fire history probability curves may be biased toward and/or strongly influenced by specific forest structure variables.

\section{Seedling Composition and Establishment Across Fire Histories}

To broadly evaluate potential shifts in forest compositions and investigate impacts of reburns on seedling composition, several analyses were conducted. Pre-fire and post-fire conifer species composition, calculated as mean percent of plot density (i.e. number of stems), was compared across topographic settings and fire histories. To aid in visualizing and interpreting seedling composition results across fire histories, two nonmetric multidimensional scaling (NMDS) ordination plots were developed to represent species presence/ absence and abundance. 
NMDS is a highly flexible, iterative, non-parametric ordination technique commonly used in ecology for exploration of species composition (Kruskal 1964; Minchin 1987). NMDS uses dissimilarity distance measures to plot subjects in multidimensional, multivariate space, allowing for visual interpretation of associations and locations in space (Faith et al. 1987). Eight out of ten of the most abundant conifer species we encountered were included in the analysis; western larch and western white pine were excluded due to their lack of abundance across study areas $(<1 \%$ of trees and seedlings encountered). Plots with no seedlings detected $(n=21)$ were additionally removed from the analysis (i.e. total of $n=90$ plots out of $n=111$ analyzed). Bray-Curtis and Jaccard distance measures were used for seedling abundance and presence/absence, respectively. NMDS solutions were tried in $2^{\text {nd }}$ and $3^{\text {rd }}$ dimensions and the number of dimensions that best minimized NMDS stress scores were chosen. The "vegan" and "ggplot2" R packages were used to generate NMDS plot figures (Oksanen et al. 2018; Wickham 2016).

Finally, temporal seedling establishment (all species combined) was compared between the two studied reburn severity sequences (i.e. low-high, high-low) to determine if sequence of burn severity affects the timing of seedling establishment. Temporal seedling establishment was estimated using bud scar node counts to determine relative seedling age; seedlings were then sorted to have established after an initial fire or after a reburn occurred based on associated fire years within plots. 


\section{Distance from High-Severity to Lower Severity Patches}

To relate plot-specific results to the greater landscape, distances were calculated from forest patches burned at a high-severity to lower severity patches (e.g. unburned, low, moderate) following Kemp et al. (2016) within the extent of wildfire perimeters affecting our study areas. Using classified MTBS burn severity (RdNBR) raster datasets for each wildfire perimeter in ArcGIS, area burned at a high-severity during an initial wildfire and/or reburn was extracted and joined into a single raster layer. All other area that did not burn at a high-severity was similarly extracted and joined into a separate layer. These two raster layers were converted to point features, and the Near tool was used to compute the shortest distance from each high-severity point to a point burned at a lower severity (i.e. patches with potential live seed source). Due to the spatial resolution of the raster imagery, the minimum distance measured from a high-severity patch to lower severity patch was $30 \mathrm{~m}$. Patch distance statistics were then computed in $\mathrm{R}$ using an exported point feature table from ArcGIS.

Seedling Stress (Fv/Fm)

Prior to analysis, plant stress (Fv/Fm) values beyond the interquartile-range (IQR)

* 1.5 were identified as outliers and removed from the dataset. Thus, we retained 507 (out of 542) conifer seedling Fv/Fm measurements across all sampled plots for analysis. Seedling presence, and therefore number of Fv/Fm measurements, was skewed toward low-severity plots where conifer regeneration was abundant. Data distribution of Fv/Fm measurements was also notably non-normal (Figure 10). Thus, for comparing Fv/Fm 
across fire histories and species, we used a permutation ANOVA appropriate for nonnormal, heteroskedastic data and unbalanced designs. Correlations between Fv/Fm values and predictor variables were assessed using a correlation matrix and Spearman's Rank tests. In this analysis we considered predictor variables that could conceptually influence seedling stress, which included the topographic wetness index (TWI), heat load index (HLI), slope, elevation, canopy cover, presence of proximate coarse woody debris (CWD), pre-fire basal area (BA), and percent ground and vegetation cover types.

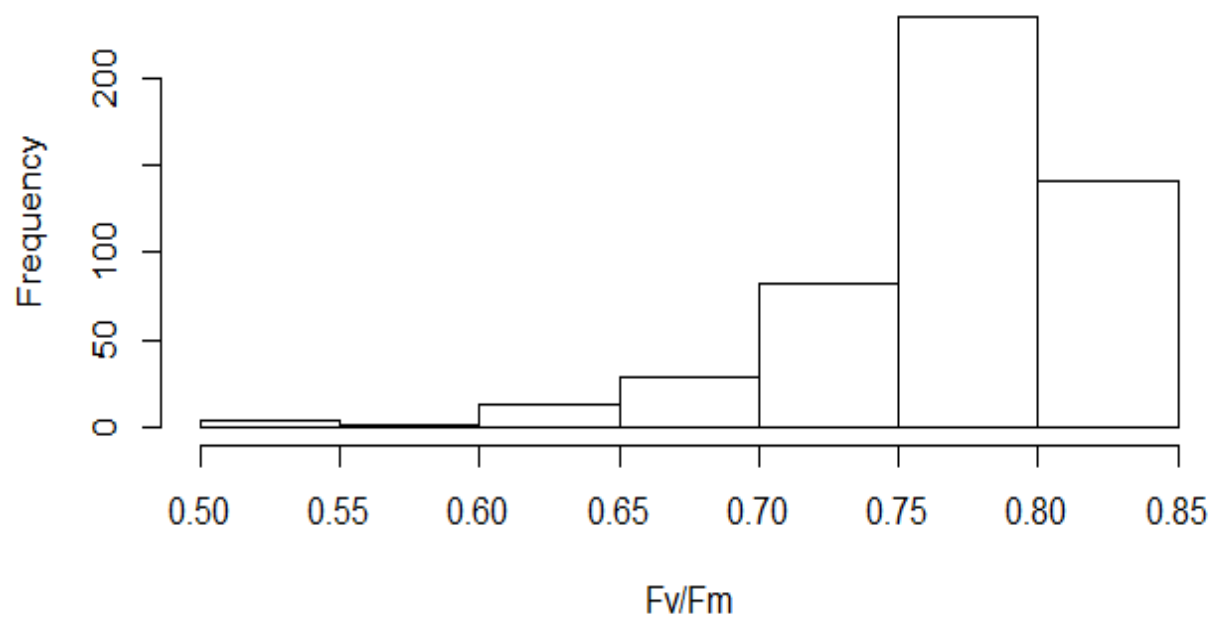

Figure 10: Histogram of the Fv/Fm data. 


\section{Results}

Fire Effects on Forest Structure

Individual components and cumulative forest structure varied across fire

histories. The multivariate PERMANOVA analysis found that cumulative forest structure was significantly different $(p=0.001)$ when compared between almost all fire histories

(Table 8; for visual interpretation via NMDS, see Figure 11). Exceptions were that stand structure compared between low-high reburns and high-low reburns was not significantly different $(p=0.263)$, nor was comparison between recently unburned and low-severity burned areas $(p=0.263)$

Table 8: Results from the multivariate analysis (permutation MANOVA) of forest structure* among sampled fire histories.

\begin{tabular}{|c|c|c|c|c|c|}
\hline \multirow{2}{*}{ Fire History } & \multirow{2}{*}{$\begin{array}{l}\text { Unburned } \\
\qquad(n=11)\end{array}$} & \multicolumn{2}{|c|}{ Burned once } & \multicolumn{2}{|c|}{ Reburned } \\
\hline & & $\begin{array}{c}\text { Low } \\
(n=28)\end{array}$ & $\begin{array}{l}\text { High } \\
(n=26)\end{array}$ & $\begin{array}{l}\text { Low-high } \\
\quad(n=29)\end{array}$ & $\begin{array}{l}\text { High-low } \\
(n=28)\end{array}$ \\
\hline Unburned & - & 0.263 & 0.001 & 0.001 & 0.001 \\
\hline Low & & - & 0.001 & 0.001 & 0.001 \\
\hline High & & & - & 0.001 & 0.001 \\
\hline Low-high & & & & - & 0.263 \\
\hline High-low & & & & & - \\
\hline
\end{tabular}

*Twelve forest-structure characteristics include: distance to seed source, percent canopy cover, coarse/fine woody debris, percent ground cover (litter/duff, bare soil, grass, shrub, forb), live trees, snag trees, and charred trees were assessed. Seedling density was excluded from this analysis. P-values are shown for pairwise comparisons of forest structure across sampled fire histories. P-values have been corrected for Type 1 error using the Holm adjustment method; $p<0.05$ is significant. Bolded values show significant pairwise differences in overall forest structure between fire histories. 

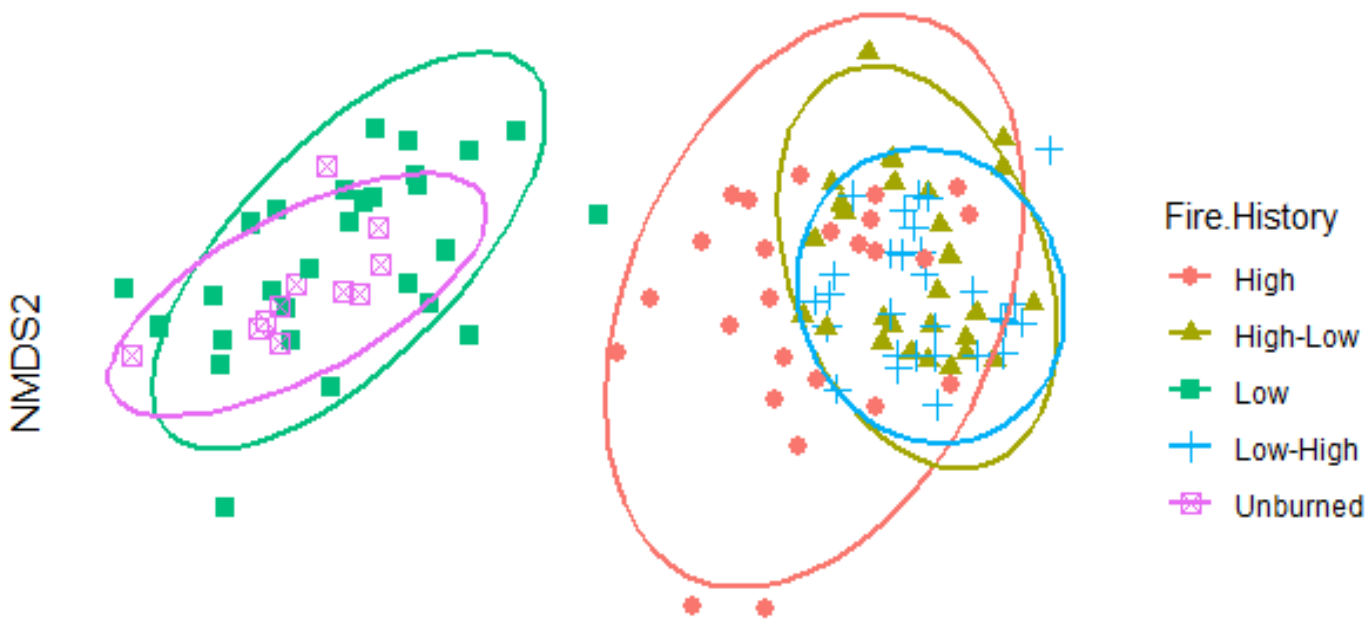

\section{NMDS1}

Figure 11: Non-metric multidimensional scaling (NMDS) ordination of multivariate forest structure amongst sampled fire histories. Dissimilarities measured using Bray-Curtis distance; stress $=0.082$, dimensions $=3$. Ellipses drawn using $95 \%$ confidence intervals. Substantially overlapping ellipses indicate similar forest structure under fire history effects.

No live trees were found within plots that experienced a high-severity fire as either an individual event or as the first or second fire within a reburned area, and median distance to a live seed source more than tripled after a reburn event when compared to a single high-severity fire (i.e. from $54 \mathrm{~m}$ to $180 \mathrm{~m}$ [high-low reburn] and from $54 m$ to 199m [low-high reburn]; Figure 12; Table 9). Eleven reburned plots (19\% of reburned plots) had seed source distances greater than $500 \mathrm{~m}$ away, while all highseverity plots had a seed source less than 500 m away. In contrast, low-severity plots always had a live seed source within $15 \mathrm{~m}$ of any location on a plot. 


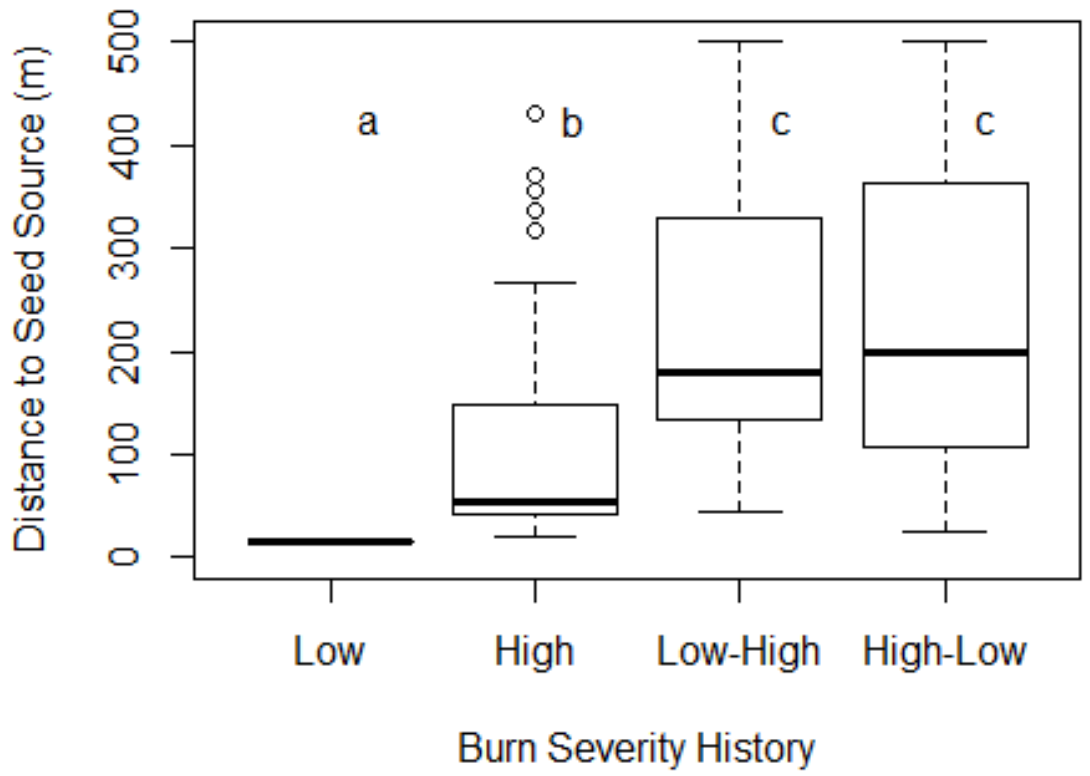

Figure 12: Relationship between the average distance to live seed source and sampled fire histories. Seed source was always present on low-severity sites, such that any location on the $15 \mathrm{~m}$ radius plot would have a seed tree within that distance. Letters indicate statistical differences between fire histories via Games-Howell test. Boxplot constructed using median and IQR; outliers are IQR * 1.5 .

The percentage of standing snags (in relation to all other standing trees within the plots) within single high-severity fire plots was $21.3 \%$ and in reburned plots increased up to $61.8 \%$ (low-high) and $70 \%$ (high-low). Severely charred trees, exhibiting black carbon biochar on more than $50 \%$ of their standing surface area, also increased from $17 \%$ to $53.3 \%$ (low-high)/ $74.2 \%$ (high-low) between high-severity fire and reburns (Figure 13; Table 9). Canopy cover sharply declined after a high-severity fire but was not different from a low-high reburn (29.5\% vs. 31\%). High-low reburns had the lowest canopy cover (15\%). 
Table 9: Median \pm SE (IQR) forest structure characteristics across sampled fire histories.

\begin{tabular}{|c|c|c|c|c|c|}
\hline \multirow{2}{*}{$\begin{array}{l}\text { Forest Structure } \\
\text { Characteristics }\end{array}$} & \multirow{2}{*}{$\begin{array}{l}\text { Unburned } \\
\quad(n=11)\end{array}$} & \multicolumn{2}{|c|}{ Burned Once } & \multicolumn{2}{|c|}{ Reburned } \\
\hline & & $\begin{array}{c}\text { Low } \\
(n=28)\end{array}$ & $\begin{array}{l}\text { High } \\
(n=26)\end{array}$ & $\begin{array}{l}\text { Low-high } \\
(n=29)\end{array}$ & $\begin{array}{l}\text { High-low } \\
(n=28)\end{array}$ \\
\hline \multicolumn{6}{|l|}{ Standing Canopy } \\
\hline $\begin{array}{l}\text { Live Tree Density } \\
\quad\left(\text { trees } / \mathrm{ha}^{-1} \text { ) }\right.\end{array}$ & $\begin{array}{l}* 297^{a} \pm 60 \\
(142-460)\end{array}$ & $\begin{array}{c}269^{\mathrm{a}} \pm 28 \\
(205-354)\end{array}$ & $\begin{array}{l}0^{b} \pm 0 \\
(0-0)\end{array}$ & $\begin{array}{l}0^{b} \pm 0 \\
(0-0)\end{array}$ & $\begin{array}{l}0^{b} \pm 0 \\
(0-0)\end{array}$ \\
\hline $\begin{array}{l}\text { Distance to Seed } \\
\text { Source }(\mathrm{m})\end{array}$ & $\begin{array}{c}15^{a} \pm 0 \\
(15-15)\end{array}$ & $\begin{array}{c}15^{a} \pm 0 \\
(15-15)\end{array}$ & $\begin{array}{l}54^{b} \pm 25.4 \\
(19-148)\end{array}$ & $\begin{array}{l}180^{c} \pm 27.5 \\
(133-330)\end{array}$ & $\begin{array}{l}199^{c} \pm 30.9 \\
(106-364)\end{array}$ \\
\hline Snag (\%) & $\begin{array}{c}19.9^{\mathrm{a}, \mathrm{b}} \pm 4.1 \\
(8.8-28.1)\end{array}$ & $\begin{array}{l}5.1^{\mathrm{a}} \pm 1.5 \\
(2.6-9.6)\end{array}$ & $\begin{array}{l}21.3^{b} \pm 3.5 \\
(7.4-28.6)\end{array}$ & $\begin{array}{l}70^{c} \pm 5.6 \\
(35-90)\end{array}$ & $\begin{array}{c}61.8^{c} \pm 5.2 \\
(37.9-85.7)\end{array}$ \\
\hline Charred (\%) & $\begin{array}{l}0^{a} \pm 0 \\
(0-0)\end{array}$ & $\begin{array}{c}1.9^{b} \pm 0.5 \\
(0-3.7)\end{array}$ & $\begin{array}{l}17.0^{c} \pm 4.6 \\
(5.4-48.0)\end{array}$ & $\begin{array}{c}74.2^{d} \pm 5.4 \\
(35.7-88.4)\end{array}$ & $\begin{array}{c}53.3^{d} \pm 5.2 \\
(32.7-76.8)\end{array}$ \\
\hline Canopy Cover (\%) & $\begin{array}{l}85^{a} \pm 2.3 \\
(67-87)\end{array}$ & $\begin{array}{c}83^{\mathrm{a}} \pm 1.4 \\
(76.5-86.0)\end{array}$ & $\begin{array}{c}29.5^{b} \pm 3.1 \\
(23-46)\end{array}$ & $\begin{array}{l}31^{b} \pm 2.6 \\
(21-36)\end{array}$ & $\begin{array}{c}15^{c} \pm 1.8 \\
(8.5-21.5)\end{array}$ \\
\hline \multicolumn{6}{|l|}{ Ground Cover } \\
\hline Bare Soil (\%) & $\begin{array}{c}4^{a} \pm 2.2 \\
(0-5)\end{array}$ & $\begin{array}{l}0^{\mathrm{a}} \pm 1.8 \\
(0-5)\end{array}$ & $\begin{array}{l}56^{b} \pm 3.7 \\
(45-70)\end{array}$ & $\begin{array}{l}70^{b} \pm 2.7 \\
(60-77)\end{array}$ & $\begin{array}{c}51.5^{b} \pm 4.9 \\
(30-70)\end{array}$ \\
\hline Litter/Duff (\%) & $\begin{array}{c}61^{\mathrm{a}} \pm 8.4 \\
(27.5-71)\end{array}$ & $\begin{array}{l}57.5^{a} \pm 4.6 \\
(49.5-78)\end{array}$ & $\begin{array}{l}0^{b} \pm 0 \\
(0-0)\end{array}$ & $\begin{array}{l}0^{b} \pm 0 \\
(0-0)\end{array}$ & $\begin{array}{l}0^{b} \pm 0 \\
(0-0)\end{array}$ \\
\hline Grass (\%) & $\begin{array}{l}1^{\mathrm{a}} \pm 2.7 \\
(0-4.5)\end{array}$ & $\begin{array}{l}0.5^{a} \pm 1.8 \\
(0-11.5)\end{array}$ & $\begin{array}{l}3^{a} \pm 3.1 \\
(0-23)\end{array}$ & $\begin{array}{l}0^{\mathrm{a}} \pm 2.4 \\
(0-11)\end{array}$ & $\begin{array}{c}6^{a} \pm 4.7 \\
(0-44.5)\end{array}$ \\
\hline Forb (\%) & $\begin{array}{c}9^{\mathrm{a}} \pm 4.2 \\
(4.5-29)\end{array}$ & $\begin{array}{c}9.5^{\mathrm{a}} \pm 3.1 \\
(3-22)\end{array}$ & $\begin{array}{l}7^{a} \pm 1.7 \\
(1-15)\end{array}$ & $\begin{array}{l}4^{a} \pm 1.8 \\
(2-9)\end{array}$ & $\begin{array}{l}5.5^{a} \pm 1.5 \\
(3-9)\end{array}$ \\
\hline Shrub (\%) & $\begin{array}{c}18^{\mathrm{a}} \pm 3.9 \\
(5-29)\end{array}$ & $\begin{array}{c}5^{\mathrm{a}} \pm 1.8 \\
(1.5-13.5)\end{array}$ & $\begin{array}{c}1^{\mathrm{a}} \pm 3.9 \\
(0-9)\end{array}$ & $\begin{array}{l}3^{a} \pm 2.5 \\
(0-14)\end{array}$ & $\begin{array}{l}5^{a} \pm 2.4 \\
(0-18)\end{array}$ \\
\hline \multicolumn{6}{|l|}{ Down Woody Fuels } \\
\hline Fine $-\leq 100 \mathrm{~h}(\#)$ & $\begin{array}{c}33^{\mathrm{a}} \pm 2 \\
(28.5-38.5)\end{array}$ & $\begin{array}{c}30.5^{\mathrm{a}} \pm 1.4 \\
(28-38)\end{array}$ & $\begin{array}{l}17^{b} \pm 1.7 \\
(12-25)\end{array}$ & $\begin{array}{l}9^{c} \pm 1.4 \\
(5-14)\end{array}$ & $\begin{array}{c}9^{c} \pm 1.1 \\
(6-13.5)\end{array}$ \\
\hline Coarse - 1000+h (\#) & $\begin{array}{c}8^{d, e, g, h} \pm 0.8 \\
(5-9.5)\end{array}$ & $\begin{array}{c}4^{b, f, g} \pm 0.5 \\
(2.5-6)\end{array}$ & $\begin{array}{c}5^{a, b, c, d} \pm 0.6 \\
(3-7)\end{array}$ & $\begin{array}{c}4^{c, f, h} \pm 0.5 \\
(2-6)\end{array}$ & $\begin{array}{c}8.5^{\mathrm{a}, \mathrm{e}} \pm 0.6 \\
(5.5-10)\end{array}$ \\
\hline $\begin{array}{l}\text { Charred Coarse } \\
\text { Fuel (\%) }\end{array}$ & $\begin{array}{l}0 \pm 0^{a} \\
(0-0)\end{array}$ & $\begin{array}{c}25^{b} \pm 7 \\
(0-58.3)\end{array}$ & $\begin{array}{c}42.8^{\mathrm{b}, \mathrm{c}} \pm 7.6 \\
(25-100)\end{array}$ & $\begin{array}{c}100^{c} \pm 4.5 \\
(100-100)\end{array}$ & $\begin{array}{c}68.3^{\mathrm{c}} \pm 5.5 \\
(47.2-88.8)\end{array}$ \\
\hline No Fuel (\%) & $\begin{array}{l}30.3^{\mathrm{a}} \pm 3.2 \\
(19.6-33)\end{array}$ & $\begin{array}{c}33^{\mathrm{a}} \pm 2.7 \\
(26.7-43.7)\end{array}$ & $\begin{array}{c}62.5^{\mathrm{b}} \pm 3.4 \\
(42.8-71.4)\end{array}$ & $\begin{array}{c}76.7^{c} \pm 2.6 \\
(64.3-82.1)\end{array}$ & $\begin{array}{c}69.6^{b, c} \pm 2.2 \\
(58-76.7)\end{array}$ \\
\hline
\end{tabular}


The percentage of standing snags (in relation to all other standing trees within the plots) within single high-severity fire plots was $21.3 \%$ and in reburned plots increased up to $61.8 \%$ (low-high) and $70 \%$ (high-low). Severely charred trees, exhibiting black carbon biochar on more than $50 \%$ of their standing surface area, also increased from $17 \%$ to $53.3 \%$ (low-high)/ $74.2 \%$ (high-low) between high-severity fire and reburns (Figure 13; Table 9). Canopy cover sharply declined after a high-severity fire but was not different from a low-high reburn (29.5\% vs. 31\%). High-low reburns had the lowest canopy cover (15\%).
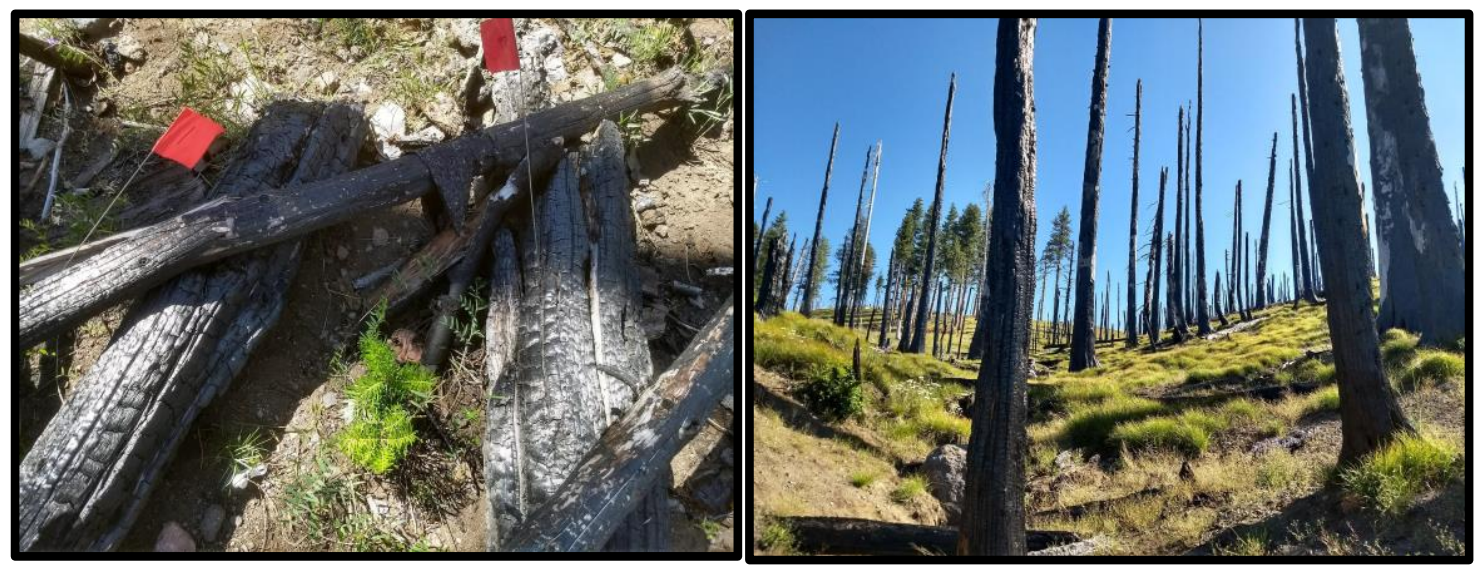

Figure 13: Black carbon biochar on down woody debris (left) and snag trees (right).

Functional vegetation groups (shrubs, forbs, and grasses) did not significantly differ across fire histories in terms of percent ground cover. While abundant in lowseverity plots, an organic litter/duff soil layer as ground cover was completely removed by high-severity and reburn histories. In place of this organic soil, charred bare soil represented the majority of ground cover in high-severity and reburn plots $(>50 \%)$ and did not significantly differ between these histories, but did between these and low severity and unburned classes. For fine down woody fuel abundance, high-severity and 
reburn (low-high or high-low) plots respectively experienced $44 \%$ and $71 \%$ lower fuel loads when compared to low-severity and unburned plots. The percentage of charred coarse woody debris did not significantly differ between high-severity and reburn plots, although median values were notably higher on reburned plots $(42.8 \%, 100 \%$, and 68.3\% for high, low-high, and high-low histories, respectively). Furthermore, reburns had the lowest overall down woody fuel loads, as indicated by total absences of debris (i.e. No Fuel; Table 9). See Figure 14 for visual field representations of post-fire forest structure among fire histories.

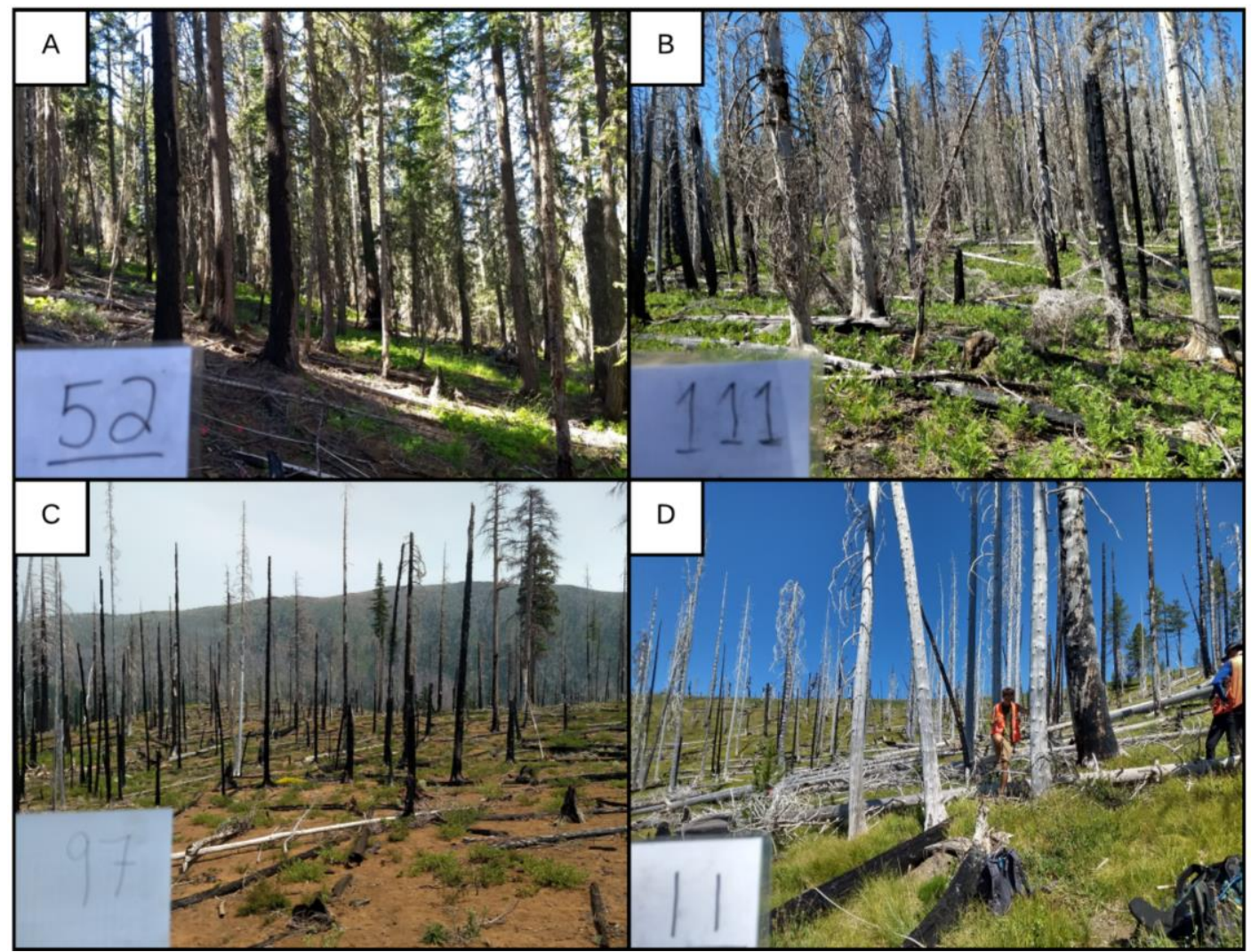

Figure 14: Field plots from the fire histories sampled on Mt. Adams and Mt. Jefferson: (A) low-severity, (B) high-severity, (C) low-high severity reburn, and (D) high-low severity reburn. Fires years associated with images were (A) 2012, (B) 2014, (C) 2003/2014, (D) 2008/2015. 


\section{Pre and Post-Fire Species Composition}

We counted over 4,200 standing trees (i.e. pre-fire composition) and over 4,000 seedlings (i.e. post-fire composition) of ten different conifer species across 111 recently burned plots with varying fire histories and topographic settings. Pre-fire tree densities varied between plots in wet and dry topographic settings (derived from HLI); wet sites hosted a higher median [IQR] density (609 [403 - 920] trees/ha) than dry sites (382 [269 - 509] trees/ha). Pre-fire species composition, expressed as the mean percent of plot density $[ \pm$ SE] across plots, was also affected by topographic setting (Table 10). Lodgepole pine, grand fir, mountain hemlock, and Engelmann spruce trees were most abundant on wet plots, whereas Douglas fir and ponderosa pine trees on dry plots both prior and following fire. Across all burned plots $(n=111)$, pre-fire composition was dominated by subalpine fir (25.7\%) and grand fir (20.6\%), with smaller components of ponderosa pine (11.2\%), lodgepole pine (9.7\%), and Douglas fir (7.2\%). While present on the landscape, Engelmann spruce (2.2\%), western white pine (0.1\%), and western larch (0.4\%) made up small proportions of the mature trees we encountered (Table 10).

Across all burned plots, lodgepole pine (22.1\%) and grand fir (21.6\%) were the dominant components of post-fire seedling composition. Post-fire seedlings followed similar compositional trends to pre-fire trees with regards to topographic setting. Lodgepole pine, grand fir, subalpine fir, and Engelmann spruce seedlings dominated wet plots and lodgepole pine, grand fir, Douglas fir and ponderosa pine seedlings dominated dry plots. Despite status as a shade-tolerant species, grand fir seedlings were a greater 


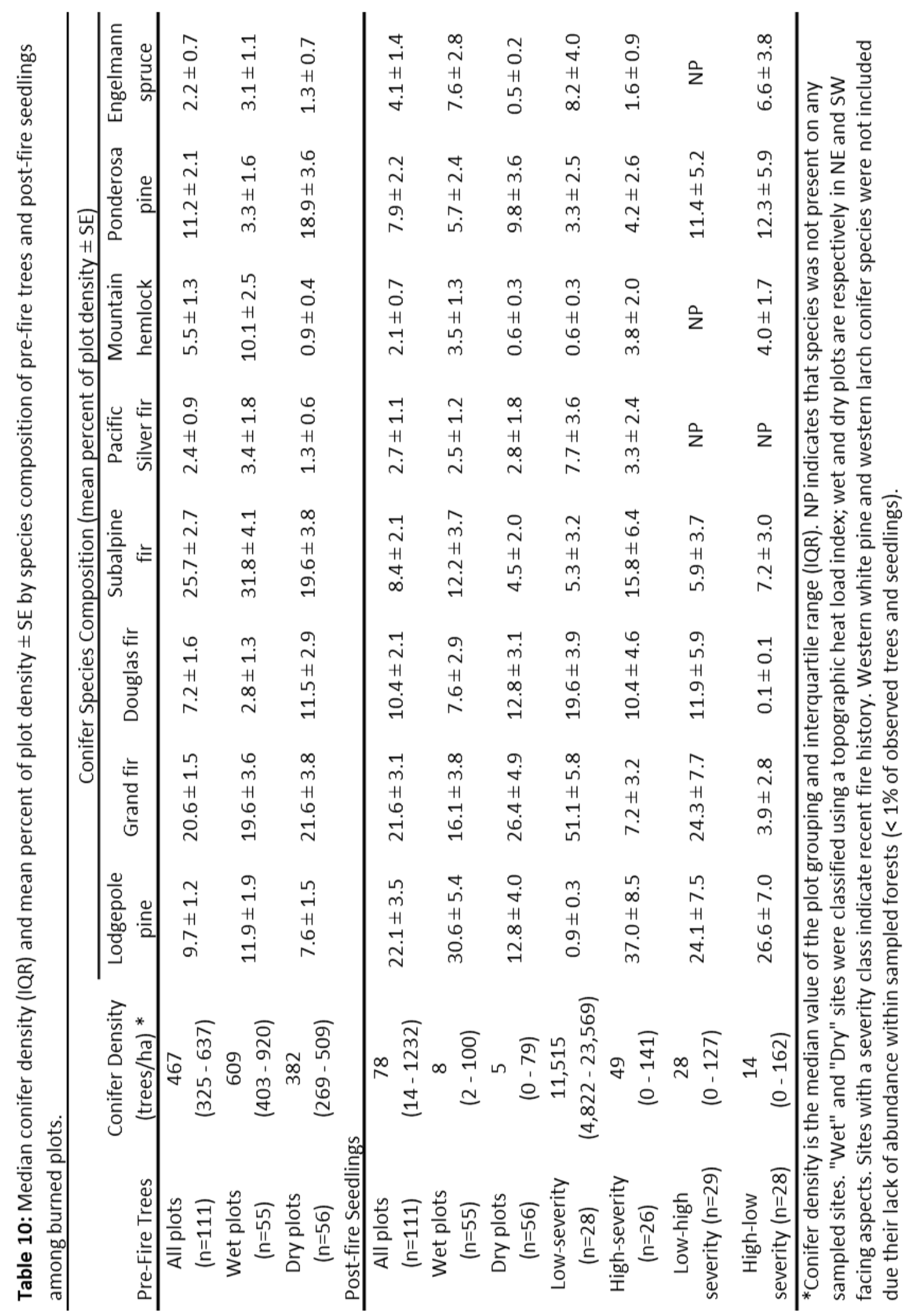


component of dry plots (26.4\%) than wet sites (16.1\%). Conversely, lodgepole pine established on a greater proportion of wet plots (30.6\%) than dry sites (12.8\%). When comparing pre-fire to post-fire composition across all burned plots, there was a substantial increase in lodgepole pine $(9.7 \%$ up to $22.1 \%)$ and smaller increases in Douglas fir (7.2\% up to $10.4 \%$ ) and Engelmann spruce (2.2\% up to $4.1 \%)$. A substantial decrease in subalpine fir ( $25.7 \%$ down to $8.4 \%$ ) and smaller decreases in mountain hemlock (5.5\% down to $2.1 \%$ ) and ponderosa pine (11.2\% down to $7.9 \%$ ) were also observed (Table 10).

Fire history strongly affected post-fire species composition. Plots that experienced low-severity fire were primarily composed of grand fir seedlings (51.1\%) with smaller components of Douglas fir (19.6\%), Engelmann spruce (8.2\%), and pacific silver fir (7.7\%). Across high-severity and reburned plots, lodgepole pine seedlings were the most dominant species (high 37\%, low-high 24.1\%, high-low 26.6\%). Subalpine fir experienced a lower compositional density in reburns (low-high 5.9\%, high-low 7.2\%) than high-severity plots (15.8\%). Alternatively, ponderosa pine was more abundant in reburns (low-high $11.4 \%$, high-low $12.3 \%$ ) than high-severity plots (4.2\%).

\section{Seedling Density and Establishment Across Fire Histories}

Seedling density varied across fire histories with large variance, but a clear difference emerged between densities after low-severity vs. those in other fire histories. Low-severity plots experienced very high conifer regeneration with a median density of 11,515 seedlings/ha. In contrast, high, low-high, and high-low histories exhibited very 
low median seedling densities of 49, 28, and 14 per hectare, respectively (Figure 15;

Table 10). We were unable to find any conifer seedlings in 20 out of the 83 sites (24\%)
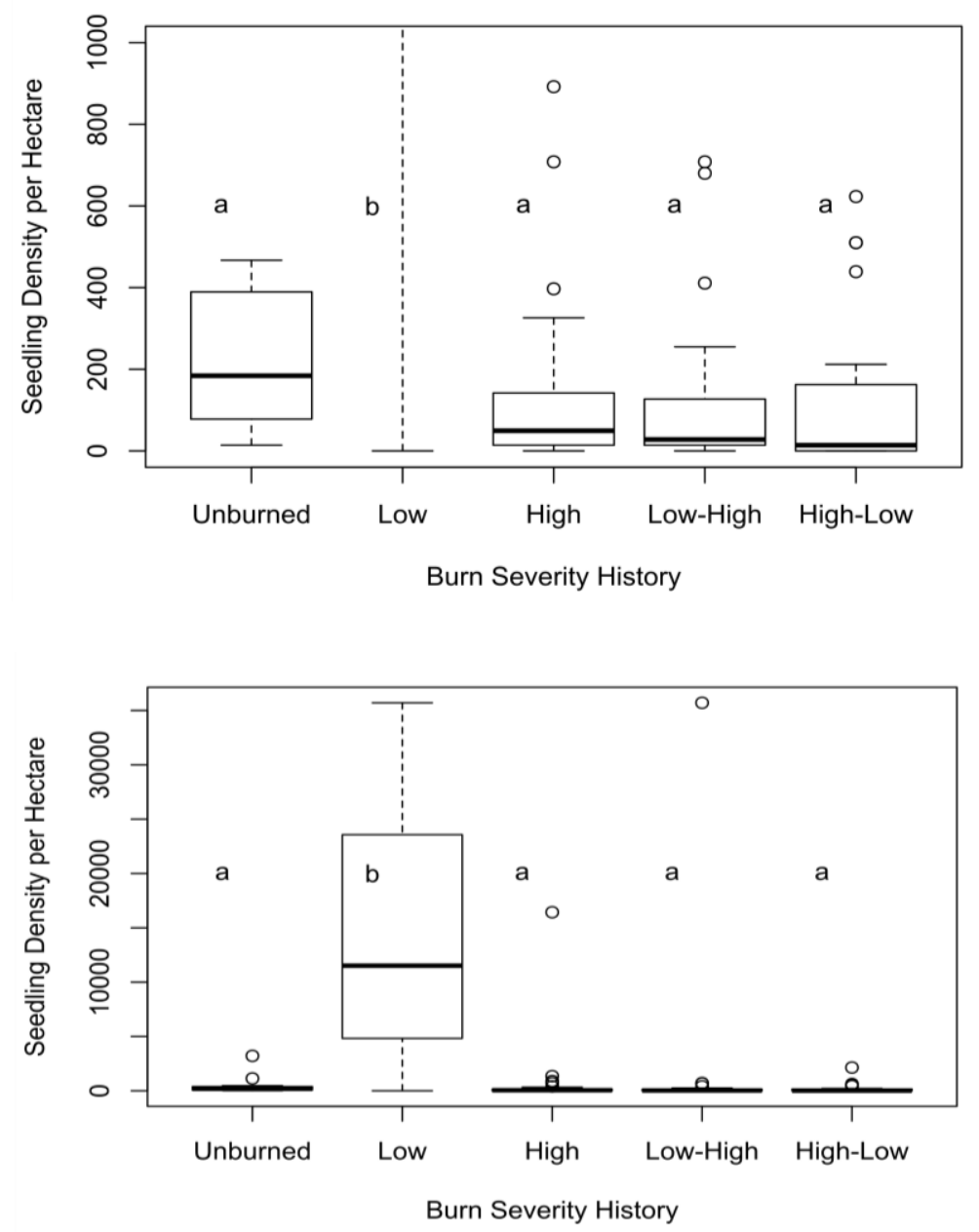

Figure 15: Conifer seedling density per hectare among sampled fire histories. Boxplots are identical - but are shown at two scales for illustration $(35,000,1,000)$. Letters indicate statistical differences between fire histories via pairwise comparisons using the Games-Howell test.

that experienced a high-severity fire or reburn. These median-density seedling values correspond to ca. $0.1-0.4 \%$ of those observed within low-severity burned plots, and to ca. $3 \%-10 \%$ of median pre-fire tree density values across all plots (i.e. 467 trees/ ha; Table 10). There were no significant differences in seedling densities between recently 
unburned, high, high-low, and low-high fire histories as indicated by the Games-Howell test (Figure 15).

Temporality, or time since a high-severity fire occurred, did not appear to influence seedling density in a linear fashion (Figure 16); seedling density generally declined 6-11 years post-fire and increased at 15 years post-fire - the latter of which may be biased toward those specific plots having nearer seed source. Additionally, we did not detect any significant differences in seedlings densities due to variations in time since a high-severity fire occurred ( 3 - 15 years).

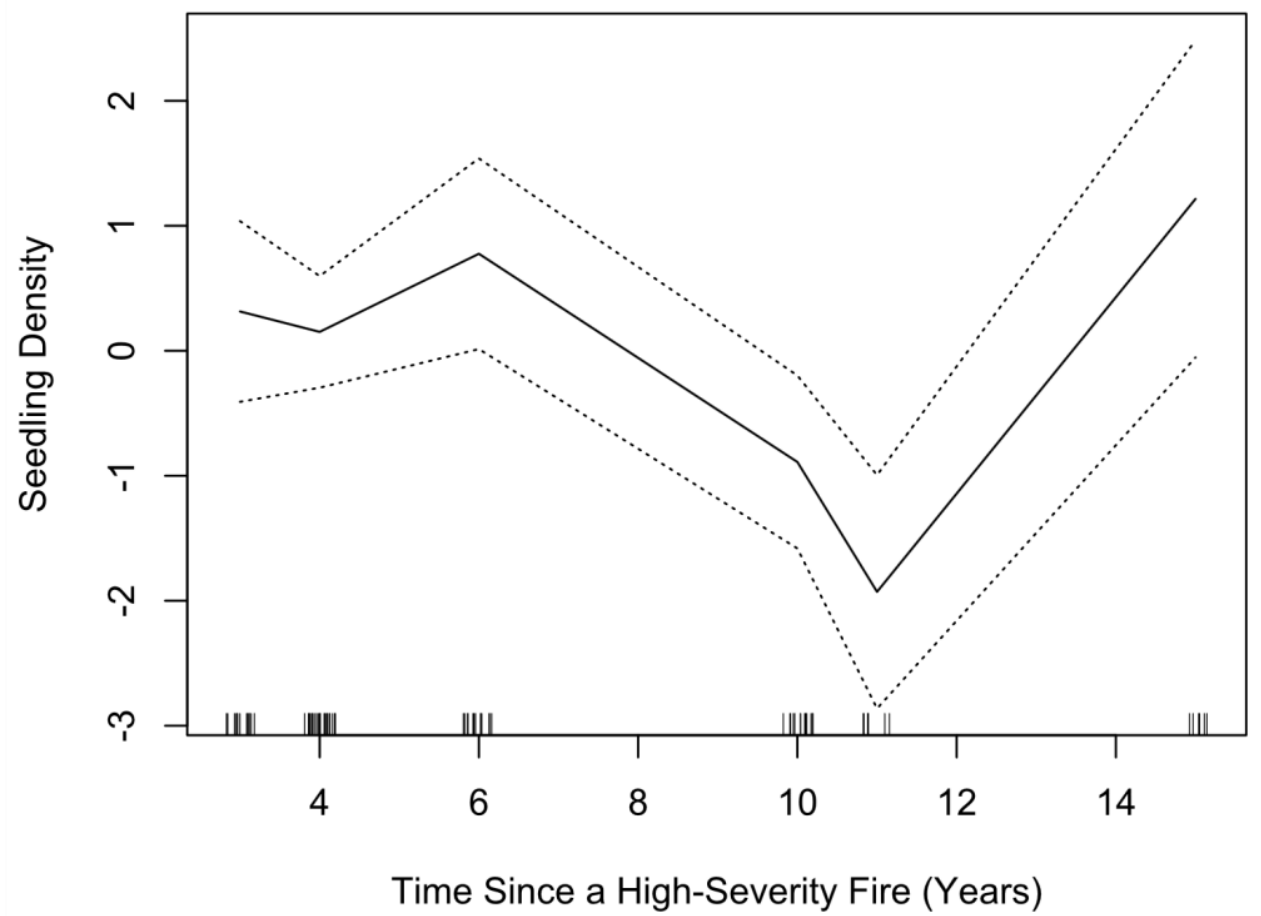

Figure 16: Non-linear relationship between seedling density and time since a high-severity fire occurred among plots that experienced a high-severity fire $(n=83)$. Relationship was modeled using a generalized additive model (GAM) with smoothing function. Dotted lines are $95 \%$ confidence intervals.

Interpretation of the NMDS ordinations revealed several important observations regarding seedling establishment across fire histories, including subtle differences in 
ordination space distances between species' abundance and presence/ absence. In the ordination plots, fire history space is represented by ellipses (drawn using $95 \%$ confidence intervals). NMDS stress for both plots was $<0.10$, indicating that the configuration spaces were close to actual dissimilarities (Clarke 1993). For the presence/ absence ordination, shade-tolerant species primarily occurred within low-severity space, except for Douglas fir (Figure 17). Lodgepole pine, ponderosa pine, and subalpine fir were the furthest from this grouping of shade-tolerant species and notably outside the low-severity space, showing a greater likelihood of presence after a high-severity fire or reburn. Based on distance proximity, Engelmann spruce and mountain hemlock occupied similar post-fire ecological niches, also grand fir and Douglas fir.

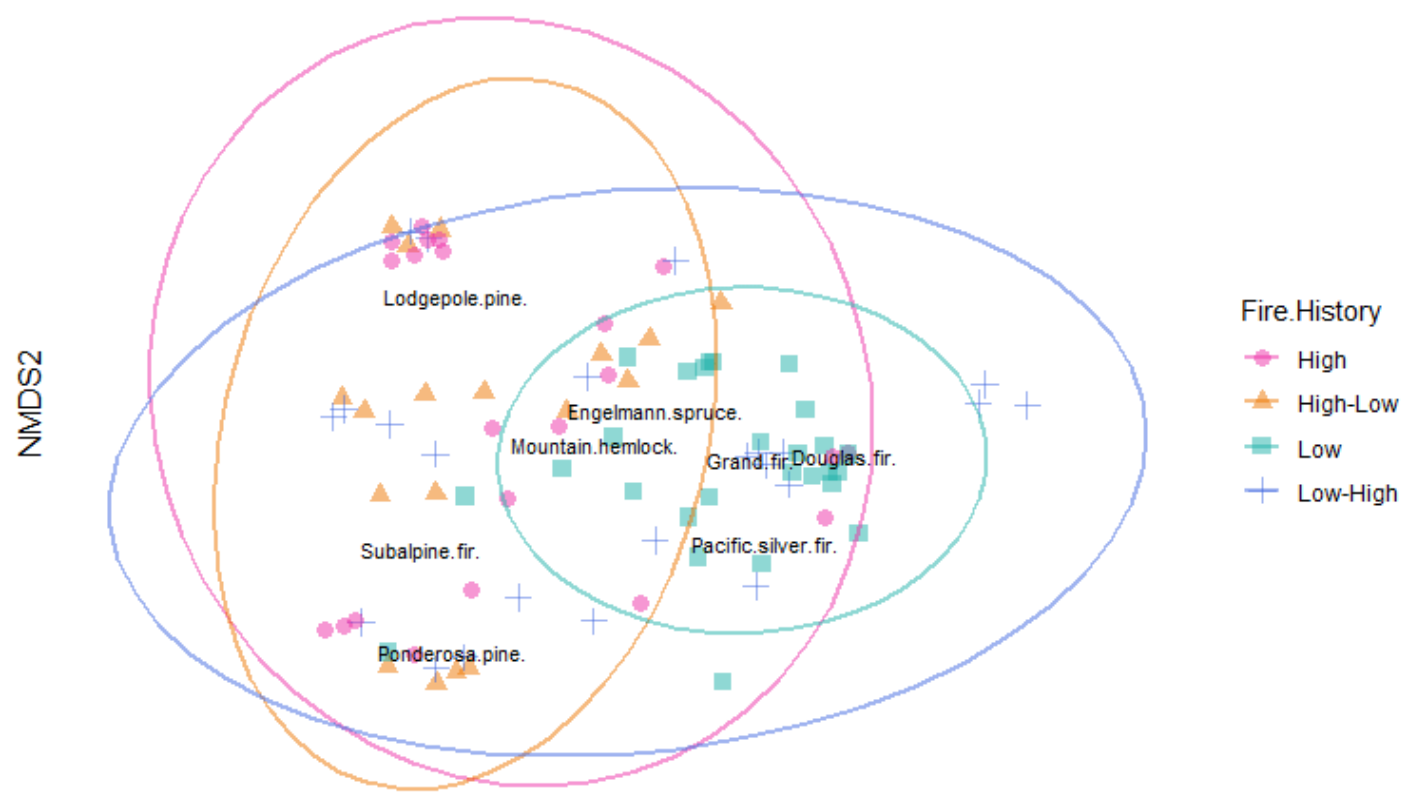

NMDS1

Figure 17: NMDS ordination of post-fire seedling presence-absence, by species, amongst sampled fire histories. Dissimilarities measured using Jaccard distance; stress $=0.074$, dimensions $=3$. Ellipses drawn using 95\% confidence intervals. Sample size (n) among fire histories used in analysis: Low (27), High (22), Low-high (23), High-low (18). 
In the abundance ordination, high and high-low-severity spaces become more constrained, with high-low reburns only promoting the abundance of lodgepole pine, ponderosa pine, and subalpine fir by a small margin (Figure 18). In contrast, the lowhigh reburn space remains the same as the presence/ absence ordination and supports the greatest diversity of species. Notably, subalpine fir shifts closer to shade-tolerant species in the abundance ordination and becomes contained within the low-severity space. Subalpine fir and ponderosa pine develop closer associations, as well as Douglas fir and pacific silver fir.

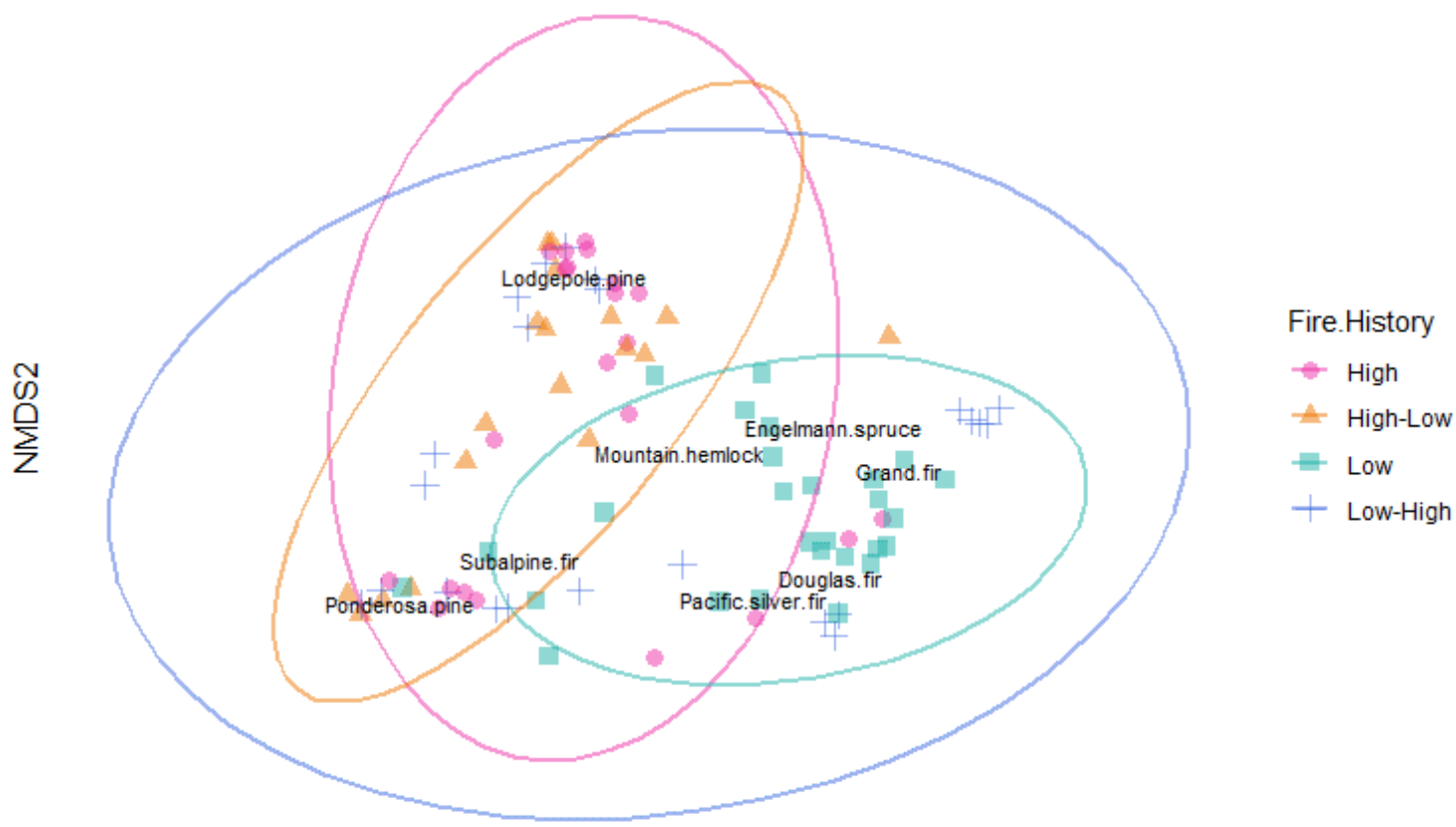

NMDS1

Figure 18: NMDS ordination of post-fire seedling abundance, by species, amongst sampled fire histories. Dissimilarities measured using Bray-Curtis distance; stress $=0.088$, dimensions $=3$. Ellipses drawn using 95\% confidence intervals. Sample size ( $n$ ) among fire histories used in analysis: Low (27), High (22), Lowhigh (23), High-low (18). 
For sites that experienced repeated fire, sequence of burn severity affected whether seedlings established post-fire or post-reburn (Figure 19). In the case of lowhigh severity reburns, the vast majority of establishment occurred after the second highseverity wildfire. By contrast in high-low severity reburns, a large pulse of establishment occurred after the first high-severity fire, followed by a lesser pulse of establishment after the second low-severity fire. In the case of high-low severity reburns, many seedlings (identified primarily as lodgepole and ponderosa pine) were able to survive a secondary low-severity fire with 7-11 years between fire events.

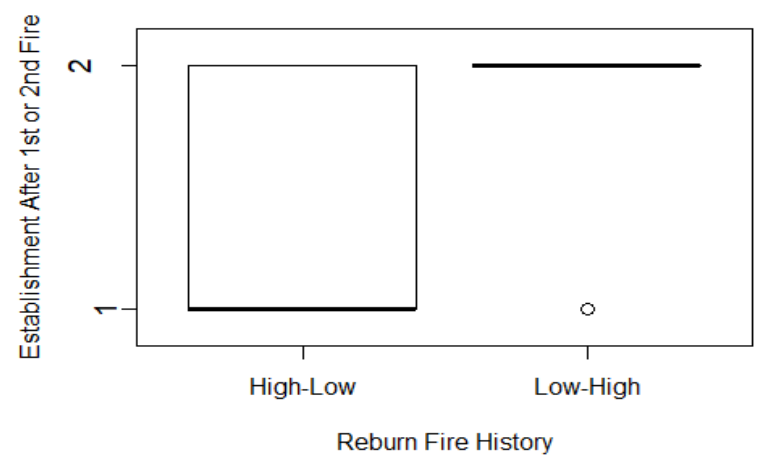

Figure 19: Boxplot showing establishment of conifer seedlings post-fire or post-reburn among the two reburn histories sampled (high-low, low-high).

Drivers of Post-Fire Conifer Regeneration: Binary Models

Reduced logistic and negative binomial regression models were used to identify the significance of predictor variables in explaining the presence/ absence and abundance of post-fire conifer seedlings, respectively (Table 11 and Table 13). For illustration, the following terms relate to the significance level of predictor variables in the associated binary and count models: mild $\left(p<0.05^{*}\right)$, moderate $\left(p<0.01^{* *}\right)$, and strong $\left(p<0.001^{* * *}\right)$. 


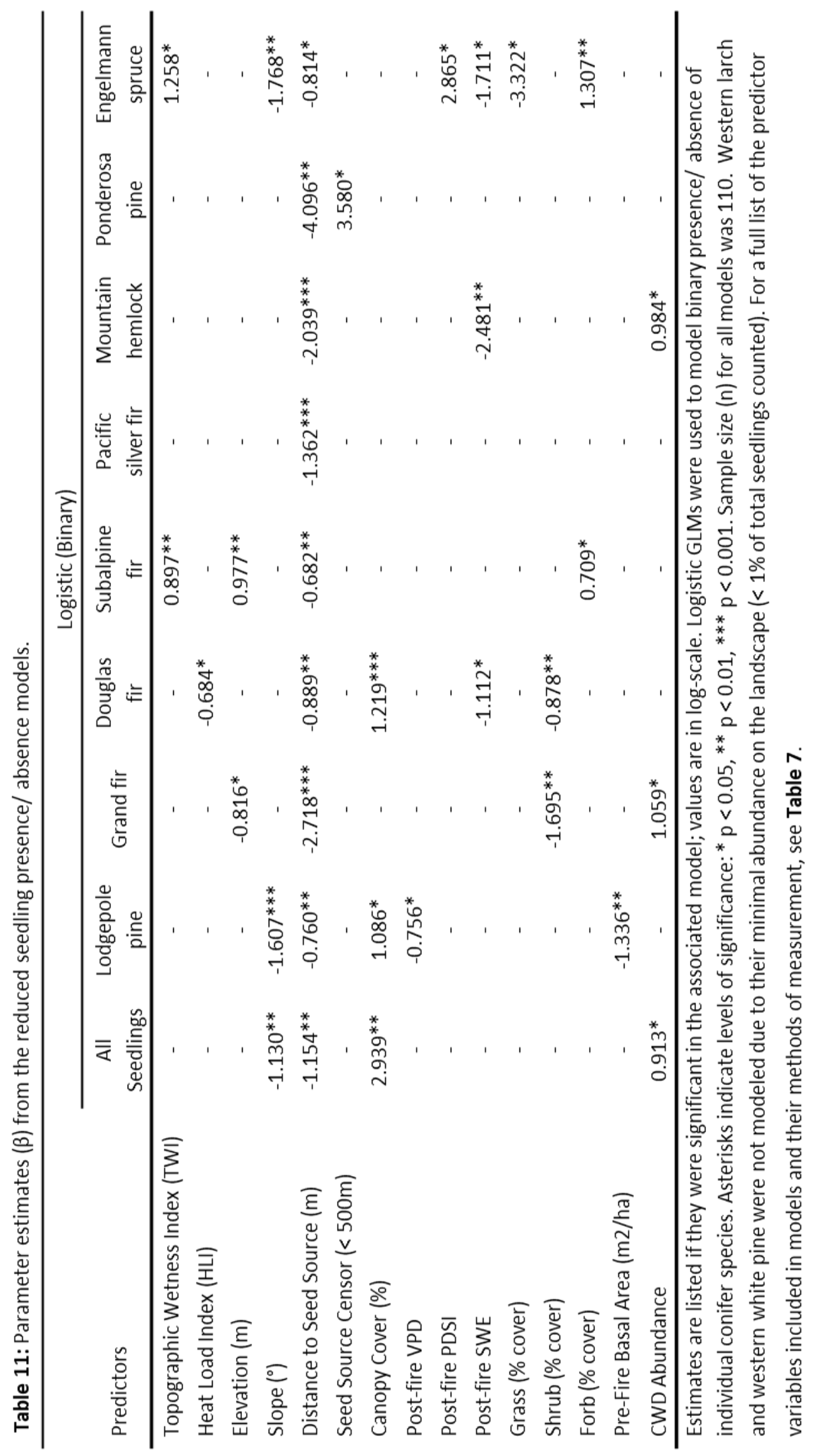


For the all species-combined binary model, distance to seed source, slope, and canopy cover were moderately important predictors, while CWD abundance and forb cover were mildly important; canopy cover had the greatest leverage on establishment probability ( $\beta=2.939)$. Cooler summer climate conditions, indicated by VPD and PDSI, mildly increased the presence of lodgepole pine and Engelmann spruce. High snowpack and cooler spring conditions - indicated by SWE, mildly and moderately limited the presence of Douglas fir, Engelmann spruce, and mountain hemlock. Seedling presence decreased mildly to strongly with an increasing distance to seed source for all species (Table 11).

Increasing shrub and grass cover (i.e. competition) moderately decreased grand fir, Douglas fir, and Engelmann spruce presence, while forbs respectively facilitated the presence of subalpine fir and Engelmann spruce mildly and moderately. Elevation mildly limited the presence of grand fir, and moderately increased the presence of subalpine fir. Wetter soils - indicated by TWI, moderately and mildly improved the presence of subalpine fir and Engelmann spruce, respectively. Steeper slopes strongly decreased the presence of lodgepole pine; dense or old-growth pre-fire stands - indicated by tree basal area, also moderately decreased its presence (i.e. too shady). CWD abundance was mildly important for the presence of grand fir and mountain hemlock.

Our binary logistic models fit seedling distributions well. P-values associated with the deviance residual and Hosmer-Lemeshow tests were well above $(>0.242)$ the alpha threshold of $0.05 ; p$-values below this threshold would indicate a significantly poor fit 
(Hosmer and Lemeshow 1980). K-fold cross-validation of the models also showed relatively strong predictive power (Table 12 ). Mean predictive accuracy ranged $81.8 \%$ to 94.5\%, and models correctly predicted seedling presence (PPR) $50 \%$ - 95\% of the time, and absence (NPR) $83 \%$ - 93\% of the time.

Table 12: Performance metrics among the reduced logistic models.

\begin{tabular}{|c|c|c|c|c|c|c|c|}
\hline \multicolumn{8}{|c|}{ Logistic GLM (Binary) } \\
\hline & \multicolumn{2}{|c|}{$\begin{array}{l}\text { Deviance } \\
\text { Residual }\end{array}$} & \multicolumn{2}{|c|}{$\begin{array}{c}\text { Hosmer- } \\
\text { Lemeshow }\end{array}$} & \multicolumn{3}{|c|}{ K-Fold Cross-Validation } \\
\hline & $x^{2}$ & $\mathrm{p}$ & $x^{2}$ & $\mathrm{p}$ & Accuracy $[95 \% \mathrm{Cl}]$ & PPR & NPR \\
\hline All Species & 58.9 & 0.999 & 6.0 & 0.642 & $0.875[0.759-0.948]$ & 0.88 & 0.83 \\
\hline Lodgepole pine & 104.8 & 0.457 & 10.3 & 0.242 & 0.818 [0.691-0.909] & 0.76 & 0.85 \\
\hline Grand fir & 59.7 & 0.999 & 9.0 & 0.341 & 0.909 [0.800-0.969] & 0.95 & 0.87 \\
\hline Douglas fir & 72.2 & 0.992 & 6.2 & 0.623 & $0.875[0.759-0.948]$ & 0.89 & 0.84 \\
\hline Subalpine fir & 90.4 & 0.860 & 4.1 & 0.851 & $0.854[0.733-0.935]$ & 0.91 & 0.84 \\
\hline Pacific silver fir & 34.3 & 1.000 & $<0.1$ & 1.000 & $0.945[0.848-0.988]$ & 0.71 & 0.98 \\
\hline Mountain hemlock & 47.2 & 0.999 & 3.2 & 0.921 & 0.891 [0.777-0.959] & 0.50 & 0.94 \\
\hline Ponderosa pine & 89.6 & 0.903 & 2.1 & 0.976 & $0.872[0.755-0.947]$ & 0.71 & 0.90 \\
\hline Engelmann spruce & 43.9 & 0.999 & 1.9 & 0.985 & 0.891 [0.777-0.959] & 0.75 & 0.93 \\
\hline
\end{tabular}

Model fit statistics (Deviance Residual, Hosmer-Lemeshow) indicate a significant lack of model fit to data distribution if $\mathrm{p}$-values are $<0.05$. Predictive accuracy is represented by K-Fold Cross-Validation. PPR and NPR are the positive and negative predictive rates; they respectively indicate how well the model predicted seedling presence (positive) or absence (negative).

Increasing distance to seed source reduced the probability of seedling presence among individual species and all species combined, with some notable variations due to fire history (Figures 20/21). Post-fire forest structure under low-severity fire effects generally improved seedling probabilities - except for lodgepole pine (PICO). Grand fir (ABGR) showed the highest probability of seedling presence with increasing distance to source, likely indicating strong dispersal ability and environmental adaptability within 

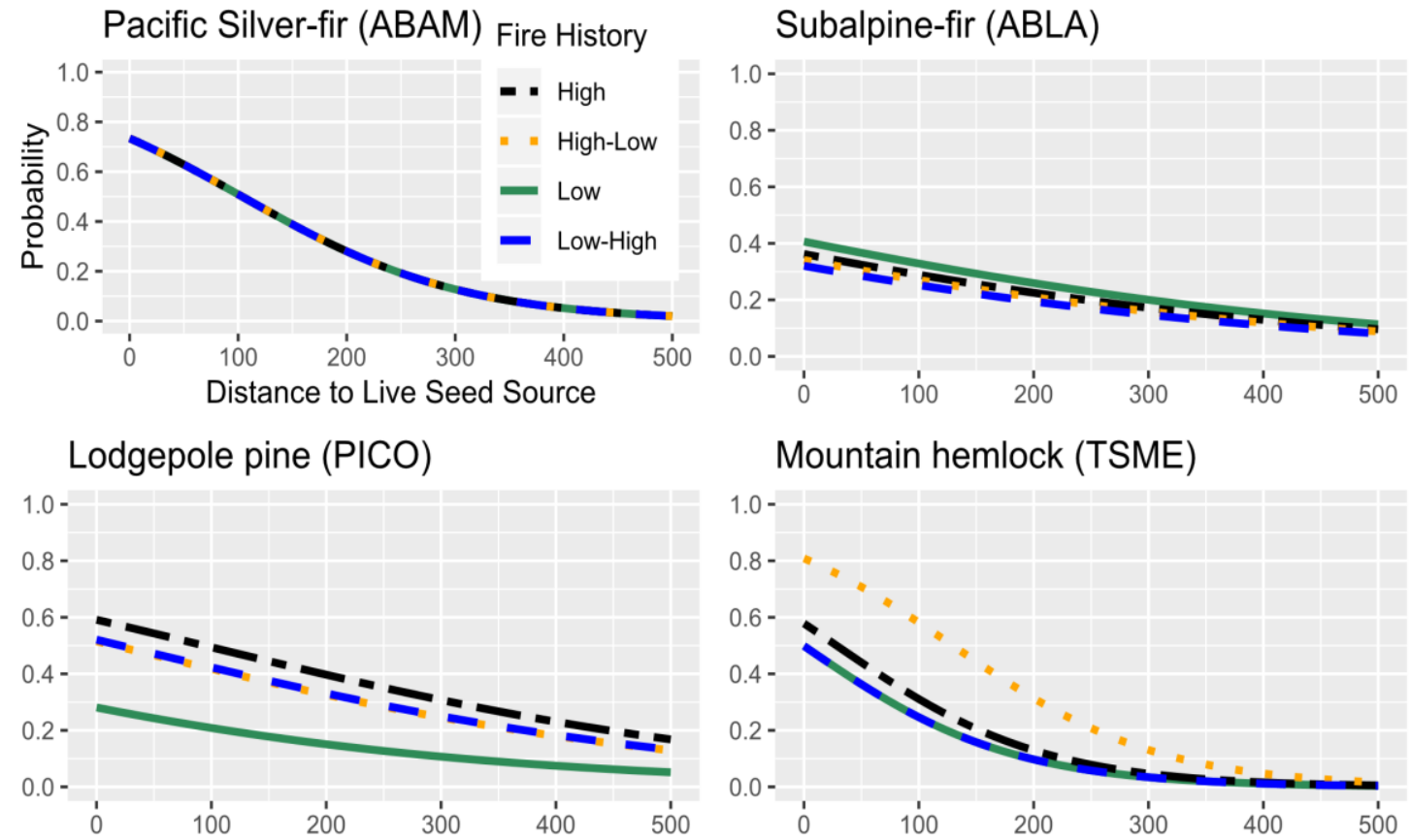

\section{Mountain hemlock (TSME)}

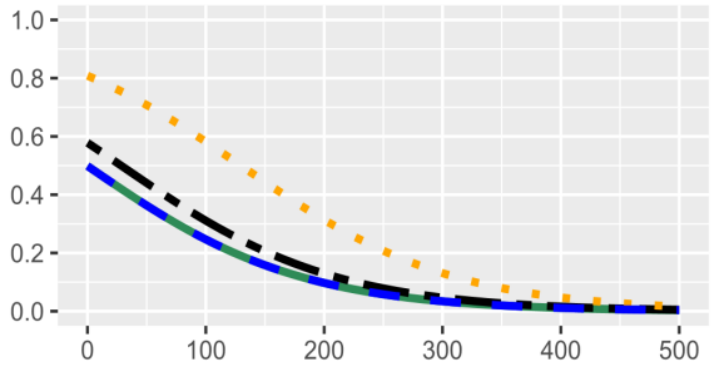

Grand-fir (ABGR)

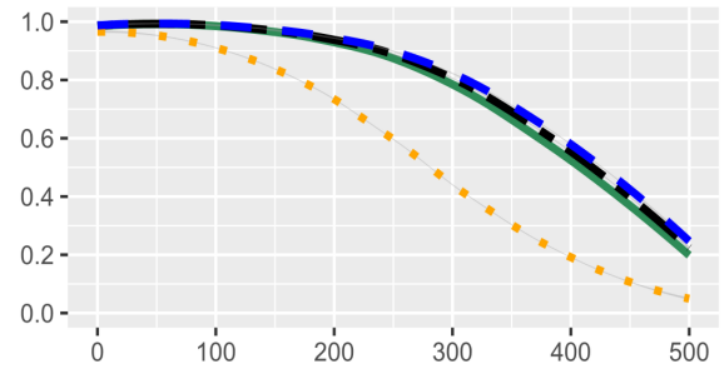

Douglas-fir (PSME)

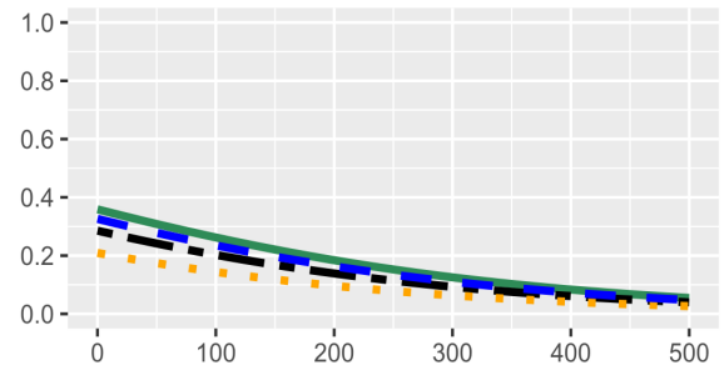

Ponderosa pine (PIPO)

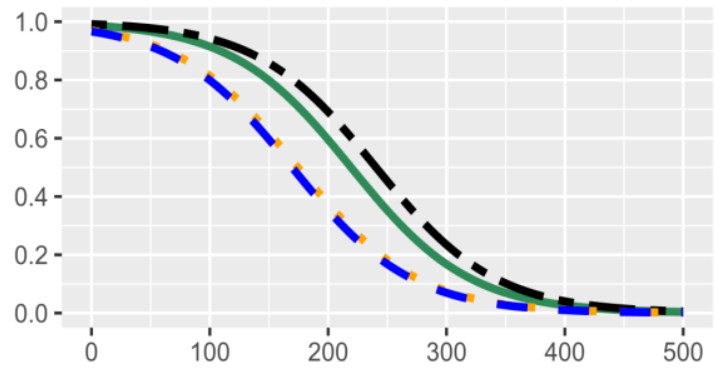

Engelmann spruce (PIEN)

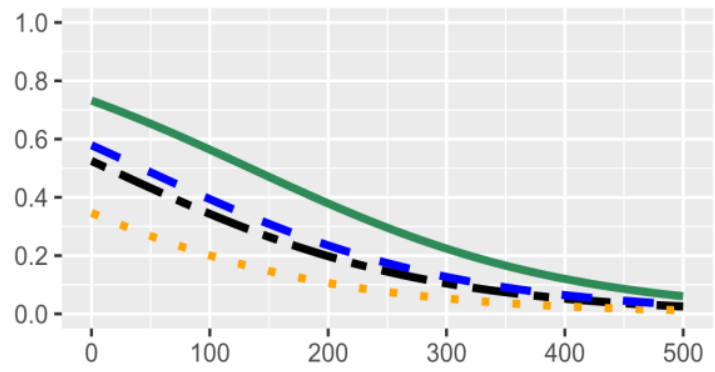

Figure 20: Probability of seedling presence (individual conifer species) as a function of distance to seed source among fire histories. Final reduced species-specific logistic models were used to model probabilities when model terms were kept at their median values - respective to fire history (see Data Analysis). While seed source was always present within $15 \mathrm{~m}$ under low-severity conditions, the lowseverity curve illustrates the impacts of forest structure on establishment probability within models. The Pacific silver fir (ABAM) model did not have other significant terms beside distance to seed source, thus, fire history curves present the same. 
the moisture gradient of the study areas. Grand fir, however, suffered the most under high-low reburn effects on forest structure.

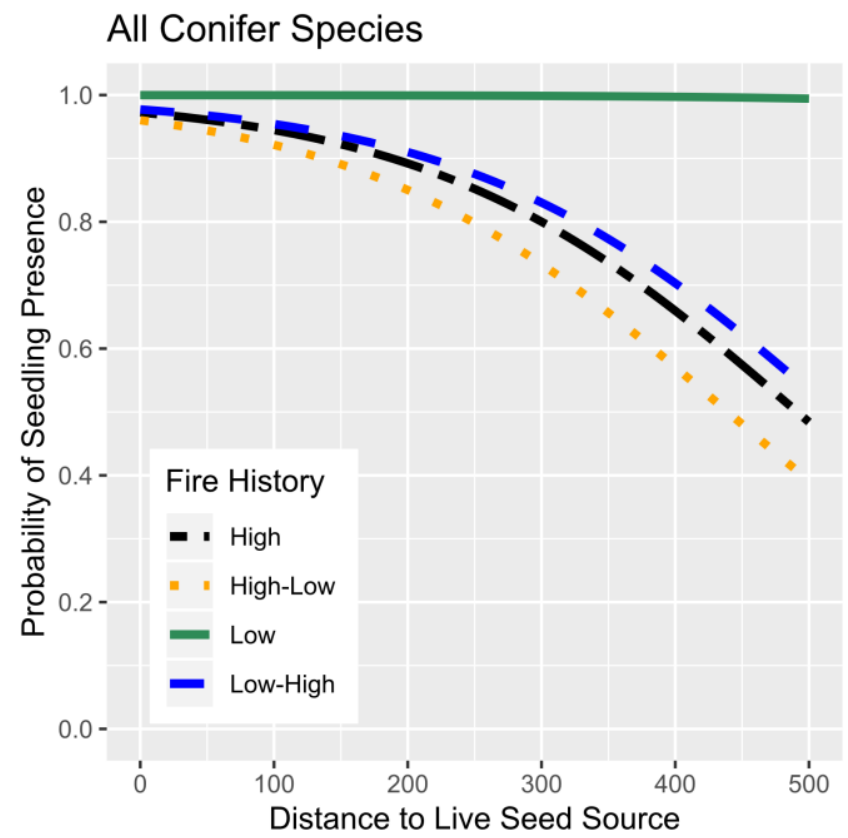

Figure 21: Probability of seedling presence (any species) as a function of distance to seed source among fire histories. The final reduced All Species logistic model was used to model probabilities when model terms were kept at their median values - respective to fire history (see Data Analysis). While seed source was always present within $15 \mathrm{~m}$ under low-severity conditions, the low-severity curve illustrates the impacts of forest structure on establishment probability within the model.

Drivers of Post-Fire Conifer Regeneration: Count Models

For all seedling species combined, distance to seed source $(\beta=-0.018, p=4.12 e-$ 10) and canopy cover $(\beta=0.017, p=<2 e-16)$ were the strongest predictors of seedling abundance (Table 13). Although there was some overlap in significant predictors (TWI, CWD, and distance to seed source), a clear divergence occurred between shade-tolerant and intolerant species. Distance to seed source $(\beta=-0.040, p=9.94 e-15)$, canopy cover $(\beta=0.030, p=1.75 e-09)$, and TWI $(\beta=0.020, p=5.61 e-09)$ were the most important predictors for shade-tolerant species; bare soil cover $(\beta=-0.053, p=6.75 e-12)$, post-fire 
SWE $(\beta=-0.054, p=1.56 e-10)$, and shrub cover $(\beta=-0.029, p=0.000305)$ for shadeintolerant species. Steeper slopes moderately decreased abundance for all seedlings combined but was not significant in shade-tolerant and intolerant models (Table 13).

Table 13: Parameter estimates $(\beta)$ from the reduced seedling count models.

\begin{tabular}{lccc}
\hline & \multicolumn{3}{c}{ Negative Binomial (Count) } \\
\cline { 2 - 4 } Predictors & All Seedlings & Shade-tolerant & Shade-intolerant \\
\hline Topographic Wetness Index (TWI) & $0.007^{* *}$ & $0.020^{* * *}$ & $0.017^{*}$ \\
Heat Load Index (HLI) & $-0.007^{* *}$ & $-0.010^{* *}$ & - \\
Slope $\left(^{\circ}\right)$ & $-0.007^{* *}$ & - & - \\
Distance to Seed Source (m) & $-0.018^{* * *}$ & $-0.040^{* * *}$ & $-0.025^{* *}$ \\
Canopy Cover (\%) & $0.025^{* * *}$ & $0.030^{* * *}$ & - \\
Post-Fire PDSI & - & $-0.013^{* *}$ & - \\
Post-Fire SWE & $-0.009^{* *}$ & - & $-0.054^{* * *}$ \\
Bare Soil (\% cover) & - & - & $-0.053^{* * *}$ \\
Shrub (\% cover) & - & - & $-0.029^{* * *}$ \\
Pre-fire Basal Area (m2/ha) & - & $0.013^{* *}$ & - \\
CWD Abundance & $0.008^{* *}$ & $0.011^{* *}$ & $0.016^{*}$ \\
\hline
\end{tabular}

Estimates are listed if they were significant in the associated model; values are in log-scale. Negative binomial GLMs were used to model seedling counts. Asterisks indicate levels of significance: $* p<0.05, * *$ $p<0.01, * * * p<0.001$. Sample size $(n)$ for the reduced count models was 109 . For a full list of the predictor variables included in models and their methods of measurement, see Table 5.

The abundance of coarse woody debris moderately and mildly improved regeneration for shade-tolerant and intolerant species, respectively. Shrub cover strongly reduced abundance for shade-intolerant species but did not affect shadetolerant; grass and forb cover were not influential in the models. High snowpack and cooler springtime conditions - indicated by SWE, strongly reduced abundance of shadeintolerant species. Meanwhile drier and warmer summertime post-fire climate conditions - indicated by PDSI, moderately increased regeneration for shade-tolerant species. Pre-fire tree basal area moderately improved regeneration of shade-tolerant 
species but had no effect on other models. Finally, sites that were in cooler topographic positions - as indicated by $\mathrm{HLI}$, moderately improved shade-tolerant regeneration - but not shade-intolerant.

The seedling abundance count models passed model fit validation, as indicated by $p$-values $>0.05$ from the Pearson's goodness of fit chi-squared test (Table 14).

Observed vs. predicted seedling counts, evaluated using Spearman's Rank correlation, ranged $\rho=0.701$ for the shade-intolerant model, $\rho=0.727$ for the shade-tolerant model, and $\rho=0.745$ for the all species model.

Table 14: Performance metrics among the reduced negative binomial GLM models.

\begin{tabular}{|c|c|c|c|}
\hline \multicolumn{2}{|c|}{ Negative Binomial GLM (Count) } & & \\
\hline & Spearman's Rank & \multicolumn{2}{|c|}{ Pearson's Statistic } \\
\hline & $\rho$ & $x^{2}$ & $\mathrm{p}$ \\
\hline All Species & 0.745 & 150.8 & 0.079 \\
\hline Shade Tolerant & 0.727 & 116.1 & 0.408 \\
\hline Shade Intolerant & 0.701 & 125.6 & 0.171 \\
\hline \multicolumn{4}{|c|}{$\begin{array}{l}\text { Model fit (Pearson's Statistic) indicates a significant lack of model fit to data } \\
\text { distribution if p-values are }<0.05 \text {. Predictive accuracy is represented by } \\
\text { Spearman's Rank, which describes the distance between predicted and } \\
\text { observed seedling counts; } 1.0 \text { represents no difference between predicted } \\
\text { and observed estimates. }\end{array}$} \\
\hline
\end{tabular}

As indicated by count models, seedling abundance declined sharply with increasing distances to seed source (Figure 22). Fire history primarily altered abundance probability for shade-intolerant species and generally became less influential as seed source distance increased. Shade-intolerant species maintained a very low but steady abundance up to $450-500 \mathrm{~m}$ from seed source, while shade-tolerant species abundance plummeted past $50 \mathrm{~m}$ and reached zero abundance at $200 \mathrm{~m}$ from seed source. This may 
be indicative of both dispersal abilities and post-fire environmental tolerances between shade-tolerant and intolerant species within our study areas.
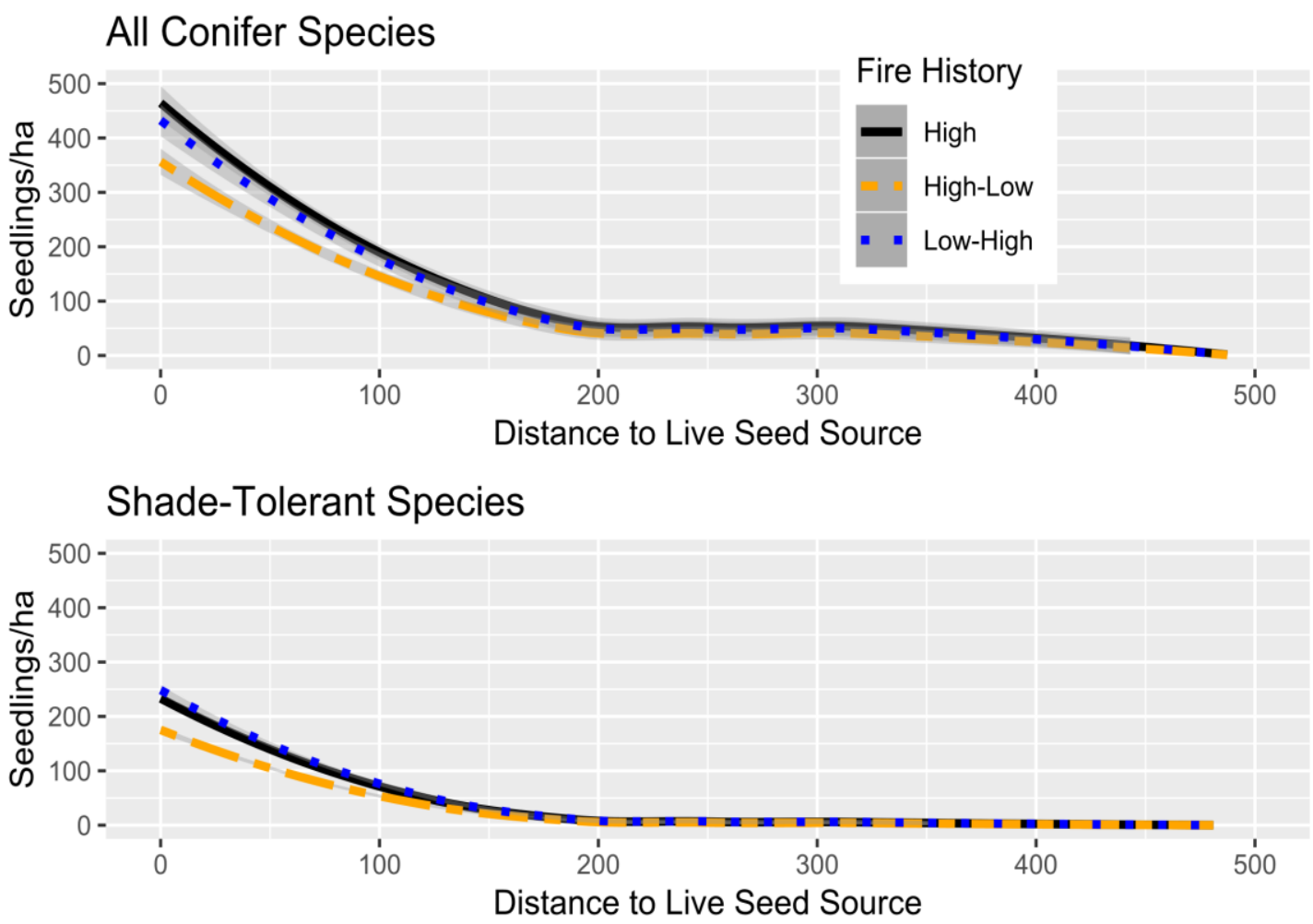

\section{Shade-Intolerant Species}

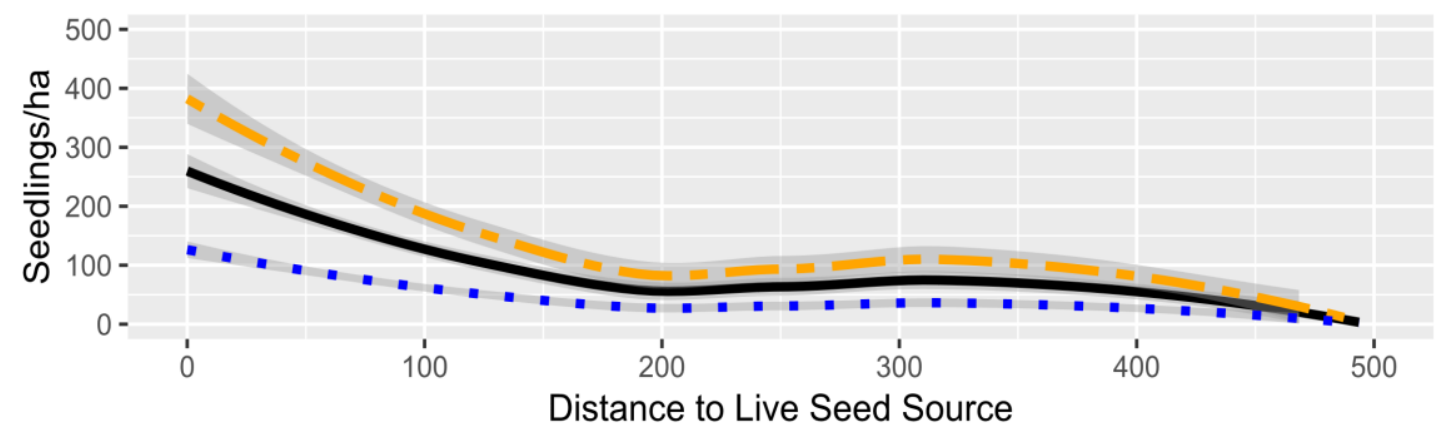

Figure 22: Seedling abundance probability as a function of distance to seed source $(\mathrm{m})$ among reburn and high-severity fire histories. Final reduced negative binomial count models were used to model probabilities when model terms were kept at their median values - respective to fire history (see Data Analysis). 


\section{Distance from High-Severity to Lower Severity Patches}

The patch distance analysis indicated differences in high-severity patch size between the two study areas (Figure 23). The Mt. Adams area experienced a greater total percentage of area burned at a high-severity (Table 2; Figure 5) and thus also experienced larger high-severity patches than Mt. Jefferson, where the center of such patches ranged up to $1400 \mathrm{~m}$ from a lower-severity patch; up to $600 \mathrm{~m}$ for Mt. Jefferson. Consequently, the Mt. Adams area experienced a larger proportion of area burned at a high-severity which was greater than $100 \mathrm{~m}$ from lower-severity patches (i.e. concentrated seed source; Table 15).

Mt. Adams Area

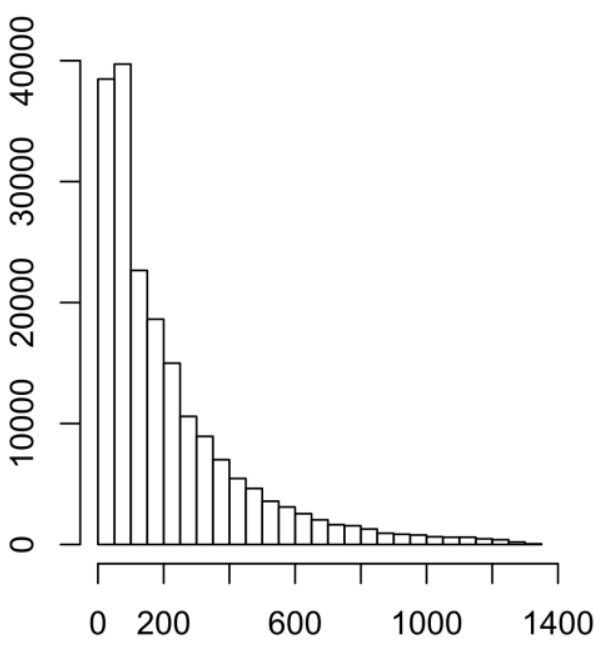

Distance $(m)$ from Lower-Severity Patch
Mt. Jefferson Area

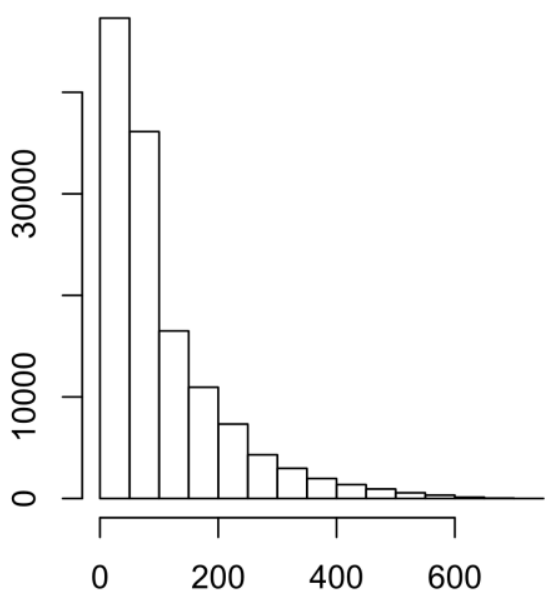

Distance $(\mathrm{m})$ from Lower-Severity Patch

Figure 23: Histogram distributions of forest burned at a high-severity and their distance $(\mathrm{m})$ to lowerseverity patches among the two study areas. The area of each datapoint was 900 sqm (i.e. the spatial resolution $[30 \mathrm{~m}]$ of the burn severity dataset) and the minimum possible distance to lower-severity patch $30 \mathrm{~m}$. 
Table 15: Percentage of study areas burned at a high-severity with varying distances to lower-severity patches (i.e. seed source).

\begin{tabular}{lccc}
\hline & \multicolumn{2}{c}{$\%$ of High-Severity Patches } & \\
\cline { 2 - 3 } Patch Distance Statistic & Mt. & Mt. & \\
\hline$<100 m$ to Lower-Severity Patch & $40 \%$ & $64 \%$ & $175-500+$ Seedlings/ha \\
$100-200 m$ to Lower-Severity Patch & $21 \%$ & $21 \%$ & Expected Seedling Density \\
\hline 200 m to Lower-Severity Patch & $39 \%$ & $15 \%$ & $50-175$ Seedlings/ha \\
\hline
\end{tabular}

Percentages were calculated using remotely sensed burn severity (RdNBR) rasters from study area wildfires. Expected seedling densities were calculated from the All Species seedling abundance probability model (Figure 22). Median pre-fire tree densities across sampled plots was 467 trees/ha.

\section{Conifer Seedling Stress (Fv/Fm)}

Over 500 conifer seedlings were measured for plant stress levels (Fv/Fm) within sample plots where seedlings existed. No significant differences in Fv/Fm were detected between fire histories or among species when a permutation ANOVA was conducted ( $p$ $<0.05)$. Two significant, but weak correlations were detected between $\mathrm{Fv} / \mathrm{Fm}$ data and environmental predictor variables. Using Spearman's Rank correlation, TWI $(\rho=0.095, p$ $=0.032)$ and slope $(\rho=-0.092, p=0.036)$ showed a weak influence on seedling stress across all plots. An unbalanced sampling design, including variable time of day and year when measurements were taken, may have masked more significant or observable results. Ideally, measurements would have been taken altogether in late summer (September) when plant stress would be at its greatest level from lack of moisture availability. 


\section{Discussion}

Our results highlight the impacts of spatially large, severe, and rapidly repeated wildfires on conifer regeneration within mid-to-high elevation temperate forests that have, in recent history, experienced climate-limited wildfire regimes. Poor conifer regeneration, occurring semi-equally across forests rapidly reburned and single-burned involving a high-severity fire, was primarily explained by a lack of live seed-bearing trees remaining on the landscape post-fires, and secondarily by unfavorable post-fire environmental conditions for locally dominant, shade-tolerant conifer species. Rapidly reburned stands exhibited lower woody fuel loads than single-burned stands, indicating the potential to act as buffers to future fire spread and/or high-severity fire.

Chronological sequence of burn severity (i.e. low-high vs. high-low) among reburned stands also altered the timing and composition of conifer seedling establishment.

Overall, our results suggest that wet temperate conifer forest resilience may be negatively impacted by increasingly large, severe, and frequent wildfires. Considering current seedling densities, lack of seed source, and anticipated shortening of fire-returnintervals within our study areas, forest patches affected by expansive high-severity and/ or repeated fire may transition into a patchy, low-density forest state. By incorporating fire-adapted species, lower tree densities, and lower fuel loads, this new state may be more resilient to frequent fire and shifting climate conditions than previous forest types. If future wildfire patterns manifest as expected in the Cascade Range, recovering mid- 
to-high elevation forests may begin resembling their drier, low-elevation mixed-conifer counterparts in structure and composition.

Fire Severity and Frequency Alter Seed Source Availability, Conifer Regeneration The presence of live seed sources and the distance to them can strongly moderate conifer regeneration post-wildfire (Donato et al. 2009; Harvey et al. 2016; Kemp et al. 2016; Owen et al. 2017). Within forest patches affected by high-severity fire, the degree of live tree mortality and geometry of patches may be primary filters on regenerative capacity (Donato et al. 2009 a/b; Kemp et al. 2016; Haire and McGarigal 2010). High-severity fire is generally classified as causing $\geq 90 \%$ mortality of live trees within affected patches (including this study) but may also range as low as $70 \%$ mortality (Eidenshink et al. 2007; Morgan et al. 2014, Whittier and Gray 2016). Although a $10 \%$ range appears small when considering a $\geq 90 \%$ mortality bracket, the degree to which live seed tree mortality is closer to $90 \%$ or $100 \%$ may create substantial differences in post-fire conifer regeneration. Within our study areas, fire severity in "high-severity" patches was very severe - causing live tree mortality near $100 \%$; we did not observe any live trees within field plots that experienced a high-severity fire. The $90 \%$ to $100 \%$ contrast is the difference between some legacy trees to serve as seed sources, enabling forest regeneration, and no legacy trees leading to complete conversion away from forest for a prolonged period. 
In addition to very high tree mortality in our study areas, the spatial extent of forest affected by contiguous high-severity fire was expansive, with patches spanning roughly up to 1000-ha (Figure 5). This was especially pronounced for rapidly reburned forests, where patches burned during the first fire at low or moderate severities often reburned at a high-severity, increasing the contiguity and size of patches with few or no live seed sources (Figure 24).

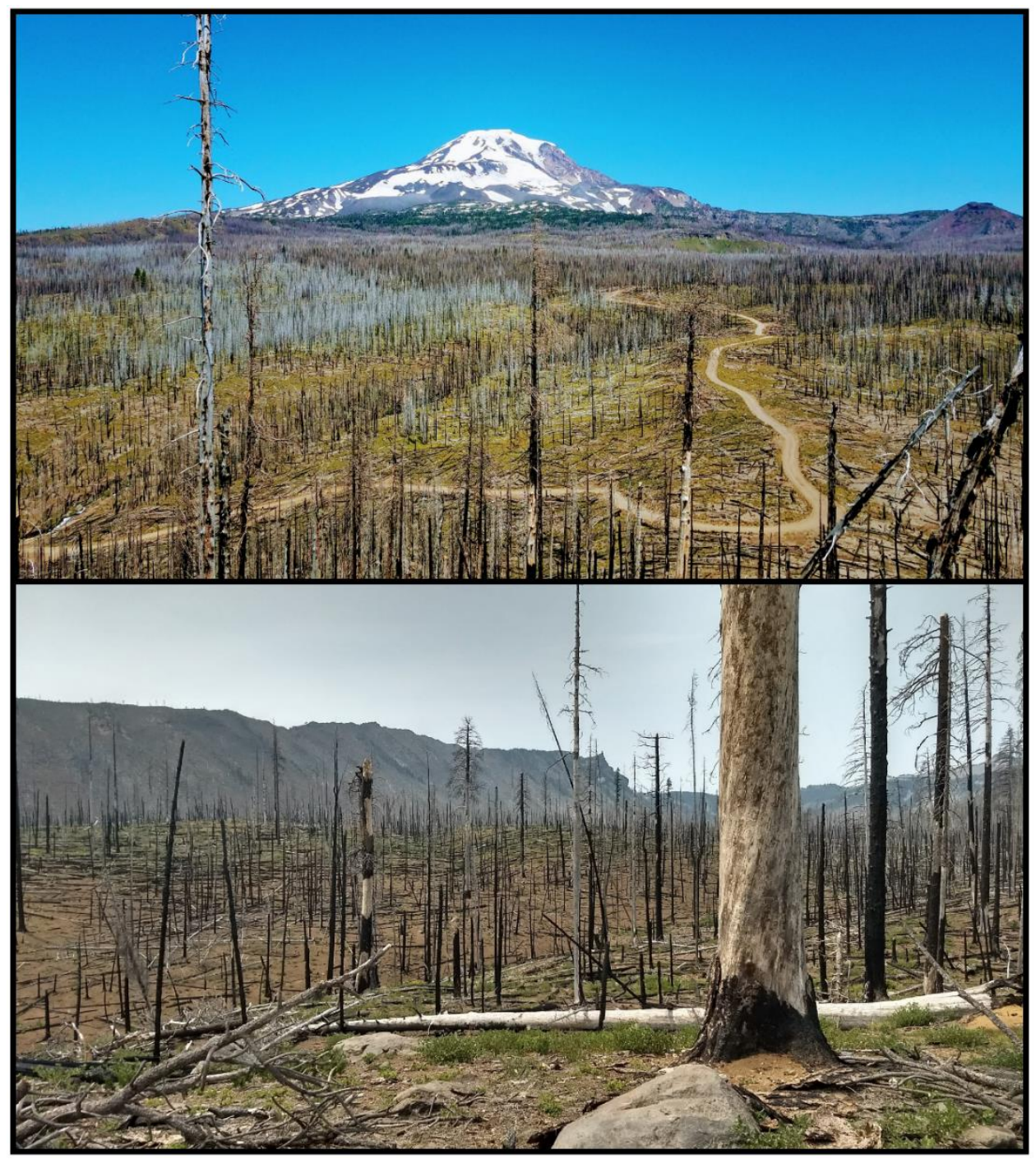

Figure 24: Subalpine forests on Mt. Adams (top) and Mt. Jefferson (bottom) affected by SIFs involving a high-severity fire. Vast areas exist on the landscape where only a handful of live trees remain. 
These fire severity dynamics frequently resulted in live, contiguous tree patches (e.g. refugia or forest edges) that were more than 500-1000 meters away from our reburned sample plots. Stevens-Rumann and Morgan (2016) also noted that SIFs progressively removed seed source from the landscape, although the spatial extent of high-severity patches in their case was far more limited ( $<150 \mathrm{~m}$ to seed source), generally resulting in more moderate to abundant conifer regeneration among their sample plots (200 - 14,000 seedlings/ha).

In two other recent studies assessing seed source distance as a driver of conifer regeneration, mixed-severity fire patterns generally limited high-severity patch sizes in the study areas, which resulted in greater conifer regeneration than this study. For example, Kemp et al. (2016) reported that $75 \%$ of forest burned at a high-severity was within $95 \mathrm{~m}$ of lower-severity patches in dry mixed-conifer forest of the Northern Rockies (0-36,000+ seedlings/ha), and Donato et al. (2009 a,b) reported 58\% and 81\% of forest burned at high-severity was respectively $\leq 200 \mathrm{~m}$ and $\leq 400 \mathrm{~m}$ from live forest edges in coastal evergreen forest of the Klamath-Siskiyou Range (298-6086 seedlings/ha). The study area of Donato et al. $(2009 a, b)$ was less sensitive to seed source distances, likely a consequence of (1) very moist coastal forest providing ideal environmental conditions for seedling establishment, (2) the way in which seed source was calculated (i.e. contiguous tree patches vs. individual trees), and (3) highly complex landscape topography. 
Following methods by Kemp et al. (2016), our analysis of distances from highseverity to lower severity patches revealed large variations between our studies areas, with Mt. Adams having burned more severely and extensively across fire perimeters than Mt. Jefferson (Table 15; Figure 23). Over 60\% of the area burned at a high-severity was $>100 \mathrm{~m}$ from a lower-severity patch for Mt. Adams and 36\% for Mt. Jefferson. Our seedling regeneration models indicated conifer seedling abundance between 100 200m from seed source was low (50 - 175 seedlings/ha) and seedling abundance was very low past $200 \mathrm{~m}$ ( $<50$ seedlings/ha); median pre-fire tree density across study areas was 467 trees/ha. Consequently, widescale conifer regeneration in the Mt. Adams area may be much poorer than the Mt. Jefferson due to large sizes of the landscape burned at high-severity in one or more recent fires.

Despite having a significantly different average distance to a live seed source, conifer seedling abundance was not statistically different between our sites that rapidly reburned and those that experienced a single recent high-severity fire (Figure 15). Seedling abundance was equally poor under these fire histories, with median densities ranging 14 - 28 seedlings/ha in reburns and 49 seedlings/ha in high-severity plots. Additionally, twenty out of the eighty-three sites (24\%) that experienced a high-severity fire or reburn had no conifer seedlings. These results suggest that fire effects which removed live seed source, whether it be SIFs or simply expansive high-severity fire, were the primary control on post-fire conifer regeneration. 
While distant seed sources ultimately led to poor conifer regeneration among our plots that experienced a high-severity fire or reburn, modeled probabilities of seedling abundance fell within the expected range of tree dispersal abilities, although with important differences between shade-tolerant and intolerant species (Figure 22). In high-severity patches, Kemp et al. (2016) found conifer seedling probability declined sharply past $95 \mathrm{~m}$ to seed source in dry mixed-conifer forests, and Harvey et al. (2016) found $75 \%$ of post-fire seedling establishment occurred within $150 \mathrm{~m}$ of seed source in subalpine forests. Under high-severity fire effects, including reburns, in this study, modeled seedling abundance reached the lower end of pre-fire forest densities in our study areas between $50-100 \mathrm{~m}$ from seed source and maintained a low-density state (i.e. 50 seedlings/ha) between 200-400m, dropping to complete seedling absence near $500 \mathrm{~m}$ from seed source. Shade-tolerant species abundance rapidly declined past $50 \mathrm{~m}$, reaching near zero probability past $200 \mathrm{~m}$. Alternatively, shade-intolerant species abundance maintained a low-density state between 200-400m from seed source.

\section{Secondary Controls on Conifer Regeneration}

Post-fire environmental growing conditions, climate, animal predation, seed production, and competition for niche space further compound the issue of poor seed source (Agee 1993; Franklin and Hemstrom 1981; Minore and Laacke 1992). While seeds may reach a given location with wind or animal assistance, a lack of shade, organic soil, or moisture may limit establishment, especially for shade-tolerant species. Successful seedling establishment can then be thought of as a probability equation, where more 
seeds are necessary for establishment when environmental conditions do not favor species survival, and vice versa.

Assuming seed source is available, seedling establishment may fluctuate with time since a fire occurred, as species specific seed production, dispersal cycles, and climate conditions can dictate pulses of establishment (Agee 1993; Rochefort et al. 1994; Freund et al. 2014). Within subalpine forest affected by high-severity fire, Harvey et al. (2016) noted seedling establishment followed a linear trend of increasing establishment over time - peaking between 2-8 years post-fire and then rapidly declining. Donato et al. (2016) also noted seedling establishment peaked 5-15 years postfire within dry mixed-conifer forest. In our case, we did not detect any significant differences in seedlings densities due to variations in time since a high-severity fire occurred (3 - 15 years), a linear relationship between these variables (Figure 16), nor was time since a high-severity fire ever chosen as a significant predictor in seedling abundance or presence/ absence models. This may indicate that under severe fire effects and without proximate long-term seed source, regeneration primarily occurs after a high-severity fire event, before remaining seed sources are removed from the landscape via delayed mortality (Figure 19).

Beyond seed source availability, our seedling regeneration models suggested that topographic, biotic, and abiotic factors which increased site shading and moisture availability (i.e. canopy cover, coarse woody debris, aspect/slope, topographic wetness) increased shade-tolerant species' abundance, in addition to warmer post-fire 
summertime conditions (i.e. PDSI). Alternatively, shade-intolerant species' abundance appeared to be primarily limited by post-fire years with above average spring snowpack (i.e. SWE), greater abundance of highly charred bare soils, and competition with shrubs. Depending upon geographic location, successful subalpine establishment has been climatically linked with warmer spring conditions, lower spring snowpack, and cooler or warmer summer conditions (Agee and Smith 1984; Andrus et al. 2018; Little et al. 1994). For shade-intolerant species within our study areas, high post-fire snowpack may be shortening the temporal period for establishment, disrupting dispersal and germination mechanisms, leading to lesser abundance.

Environmental factors which improve moisture availability, as in the case of our shade-tolerant species model, are theoretically and empirically backed by a wide body of research (e.g. Agee 1993; Donato et al. 2016; Harvey et al. 2016, Andrus et al. 2018). Post-fire climate can also be crucial for seedling establishment by augmenting site moisture availability, and in the case of post-fire drought, has recently been shown to negatively impact conifer establishment across mixed-conifer and some subalpine forest types (e.g. Davis et al. 2019; Harvey et al. 2016; Kemp et al. 2019; Stevens-Rumann et al. 2017). Our results generally contrast these findings, which may be explained by differences in annual precipitation - or moisture gradients between study areas (Figure 25). With the exception of Donato et al. (2009 a,b), who assessed forest regeneration after high-severity fire and SIFs in very wet coastal evergreen forest, our study areas are substantially wetter and experience comparable or somewhat cooler summer 
temperatures than recent studies citing drought as a limiting force (Figure 25). Thus, growing season length (constrained by snowpack) and cooler summers may actually be limiting establishment within our study areas. Thus, warmer future climate conditions may allow for increased conifer regeneration assuming seed source is present, but drier forest fuels may create higher burn-severity conditions and shortened fire-returnintervals (Abatzoglou and Williams 2016; Abatzoglou et al. 2017) prohibitive to subalpine forest development (Turner and Romme 1994).

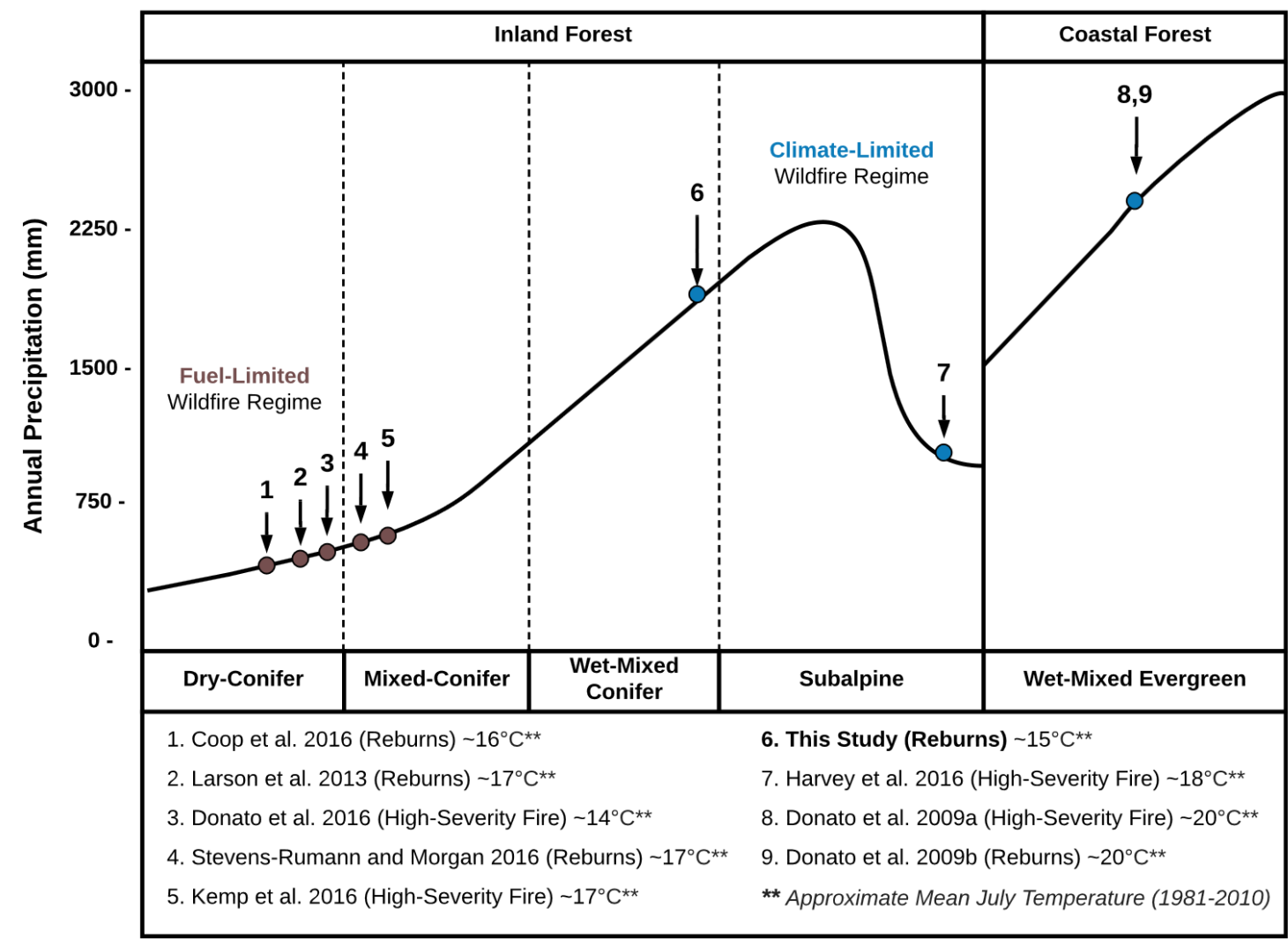

Figure 25: Related recent studies assessing conifer regeneration after high-severity fire and/ or reburns in the Western United States. Studies have been placed according to relative moisture gradients (i.e. annual precipitation) and forest types identified within study areas. 


\section{Mechanisms Promoting Persistent Seed Source: Refugia}

Two mechanisms we observed, occurring separately within upper-montane and subalpine forest types, may help promote persistent fire refugia and conifer legacies (i.e. contiguous live seed trees) on the landscape despite high-severity fires and SIFs. Throughout our study area, forests that burned at low severities and thereby maintained live seed trees experienced one of two dynamics. First, at lower elevations, persistent old-growth grand fir and Douglas fir forest suppressed general seedling establishment. High canopy cover and low light availability helped prevent the accumulation of ladder fuel trees and mature trees were widely spaced enough to prevent canopy fire. Old-growth trees had additionally developed very thick fireresistant bark (including grand fir), which further prevented canopy tree mortality. Meigs and Krawchuk (2018) found in a study of refugial extent in the PNW that among closed-canopy forests, those with the largest trees facilitated lower burn severities than those with small or medium tree classes. Widely spaced, closed-canopy, old-growth stands should help maintain persistent fire refugia in upper-montane stands despite increases in fire frequency - assuming old-growth trees do not experience rapid mortality from non-fire effects (Reilly and Spies 2016).

The second dynamic was observed within higher-elevation stands which, unlike our first example, maintained high fuel connectivity and tree densities typical of subalpine forests. These stands were commonly located within extremely wet floodplains or perennial creek channels, which provided enough year-round moisture to 
limit the ignition of fuels - resulting in low burn-severity. These locations were easily identifiable by their high TWI values in a Geographic Information System (GIS), which corroborates findings from recent research assessing predictors of refugial persistence (Krawchuk et al. 2016; Rogeau et al. 2018). This suggests a completely different kind of refugium, a coupled hydrological-fire refugium

Across elevation gradients and forest types, rocky ridgeline outcroppings were also a common bastion of refugia on the landscape, which primarily hosted large fireresistant ponderosa pine (Figure 26). Low fuel connectivity created by these landscape features may enable long-term persistence of species whom can handle the exposed conditions (Blomdahl et al. 2019; Kolden et al. 2017). These ridges were ideal for seed dispersal, where wind and topography could increase dispersal distances beyond normal expected ranges.

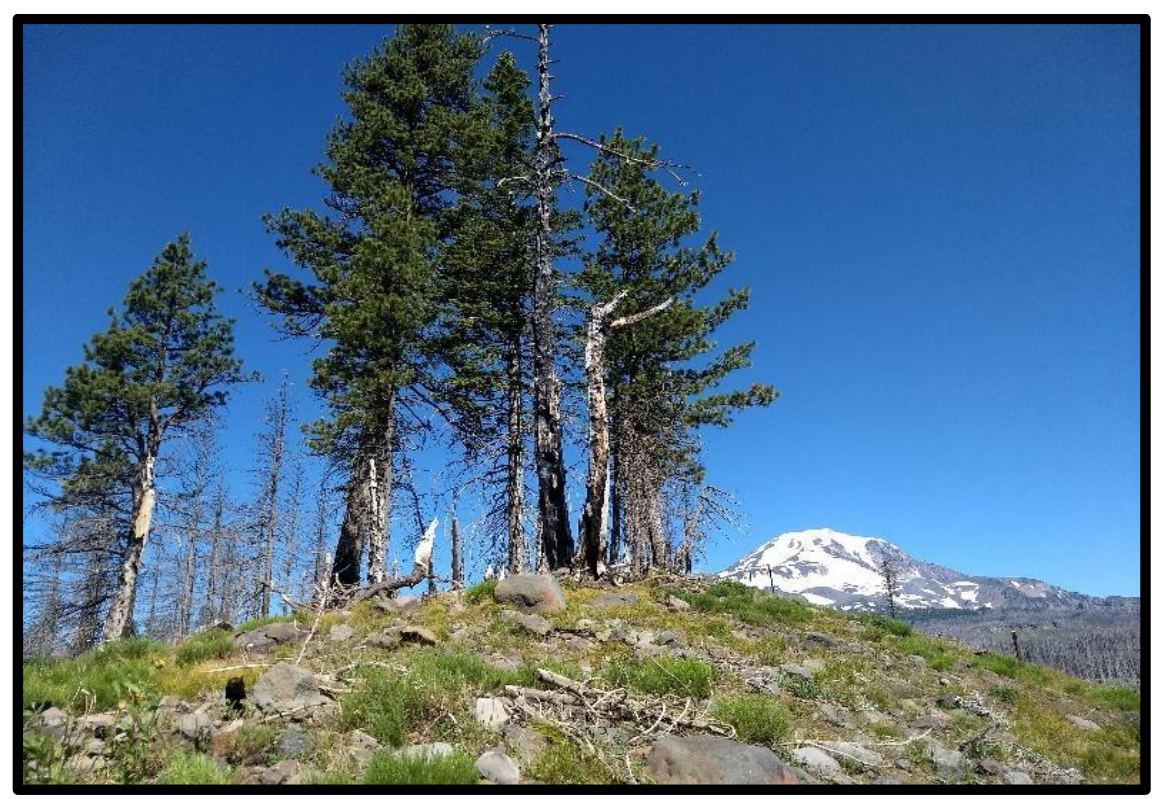

Figure 26: Rocky ridgelines created small bastions of refugia on an otherwise torched landscape for fireresistant ponderosa pine and some other species. 


\section{Repeated Wildfire Alters Stand Structure, Species Composition}

In terms of individual and overall post-fire forest structure, our results primarily agree with and expand upon Stevens-Rumann and Morgan (2016), who compared forest structure and conifer regeneration after SIFs using a similar sampling design in dry mixed-conifer forests. We found that reburned stands in both severity sequences (i.e. low-high, high-low) were structurally different from forest exposed to a single highseverity fire - but not from each other (Table 8). These differences are best explained by lower fine fuel abundance (also supported by Larson et al. 2013), greater percentage of heavily charred snags, and further distance to seed source among reburned plots (Table 9; Figure 13). High-low severity reburns specifically exhibited greater loadings of coarse woody debris and lower canopy cover than other fire histories, which may be explained by greater time elapsed since a high-severity fire occurred - allowing more time for snags to become down woody debris. Post-fire ground cover of functional vegetation groups (i.e. grasses, shrubs, and forbs) did not differ between fire histories following Stevens-Rumann and Morgan (2016), however, our plots that experienced a highseverity fire (including reburns) exhibited greater median percentages ( $6 \%$ to $45 \%$ more) of ground cover as exposed bare ground than the above study. This may indicate that general fire behavior within our study areas was more extreme than Stevens-Rumann and Morgan (2016), which is not surprising considering forest tree density differences between studies (low to moderate vs. high-density) and the general lack of live trees within high-severity patches we surveyed. 
Pre-fire and legacy forests within our study areas were largely dominated by shade-tolerant species; grand fir at lower elevations (upper-montane forest) and subalpine fir at higher elevations (subalpine forest) with a smaller component of lodgepole pine and ponderosa pine mixed across elevation gradients (Table 10). Douglas fir was generally restricted to lower elevations and dry aspects, while mountain hemlock and Engelmann spruce were more common at higher elevations and in wet shady drainages. Tree density characteristically followed variations in topographic moisture availability expressed through the HLI and TWI; wetter and shadier sites hosted higher pre-fire tree densities primarily composed of shade-tolerant species.

Plots that experienced a low-severity fire and thereby retained seed source regenerated abundantly (median density of 11,515 seedlings/ha) with locally proximate shade-tolerant species, mirroring pre-fire composition. In the Western Cascades, Brown et al. (2013) found post-fire conifer seedling regeneration respectively on the order of 60,000 and 14,000 seedlings/ha within pacific silver fir and western hemlock zones when seed source was present. Agee and Smith (1984) found seedling regeneration on the order of several thousand per hectare within subalpine forest on the Olympic Peninsula, with the highest densities closest to forest edges. In terms of temperature, elevation, growing season length, and moisture gradients, the regenerative capacity of our study areas fit somewhere between the margins of these two studies when seed source was present. 
Post-fire seedling composition within plots affected by a single high-severity fire, which were biased toward subalpine compositions (see Table 4), were characteristic of some stand-replacing fire regimes in the Western U.S. (i.e. Yellowstone NP; Turner and Romme 1994) where lodgepole pine was the dominant species (37\%). Pre-fire species were present within plots affected by a single high-severity fire - but at lower percentages and densities than lodgepole pine (Table 10). Harvey et al. (2016) found similar results in subalpine stands affected by high-severity fire with the exception of Engelmann spruce, which was dominant in their Glacier NP sites - perhaps a consequence of greater pre-fire compositional dominance than in our study areas (i.e. Engelmann spruce was only $2 \%$ of the pre-fire trees we encountered). Harvey et al. (2016) additionally noted that while pre-fire forests were generally dominated by subalpine fir, subalpine fir seedling abundance did not mirror pre-fire composition and suffered greatly with increasing distance to seed source.

We observed notable differences in post-fire species composition between single high-severity plots and reburned plots. Although lodgepole pine seedlings largely dominated these three fire histories (i.e. high, high-low, low-high), reburns lowered this species' compositional dominance within sample plots from $37 \%$ after a single highseverity fire to about $25 \%$ in reburns. Meanwhile, ponderosa pine was more dominant among reburned plots, increasing from $4 \%$ after a single high-severity fire to $12 \%$ in reburns. Reburns appeared to negatively affect the dominance of subalpine fir, lowering composition from $16 \%$ in high-severity plots to about $6.5 \%$ in reburns. 
For serotinous species like lodgepole pine, concerns have been expressed around shrinking fire-return-intervals disrupting reproductive strategies (Buma et al. 2013). We did not check for the presence of serotiny among the mature lodgepole pine we encountered (nor were they often still alive to check), and so there is no information about the degree of serotinous cones in our study area. Geographically, both the nonserotinous (var. murrayana) and serotinous (var. latifolia) variations of lodgepole pine are understood to be present within the Central Cascade Range (Krugman and Jenkinson 1974; Atzet and McCrimmon 1990). Var. latifolia is known to have varying levels of serotiny based on environment, tree age, and fire history, where high-elevation stands with infrequent fire tend to favor the production of open, non-serotinous cones (Critchfield 1978; Lotan 1976; Lotan and Perry 1983). While reburns reduced the abundance of lodgepole pine in post-fire stands, it remained at a low-density across the landscape - indicating some sustained resilience against SIFs. Within several plots that experienced a high-severity fire in 2003 , followed by a low-severity fire in 2014 , surviving lodgepole pine saplings greater than 10 years of age were successfully developing cones by 2018 (Figure 27). Assuming there was pronounced serotiny within mature trees, its possible severe fire conditions destroyed canopy seedbanks - leading to lower than normal densities of the species within areas not reburned (Anderson and Romme 1991; Lotan 1976). 


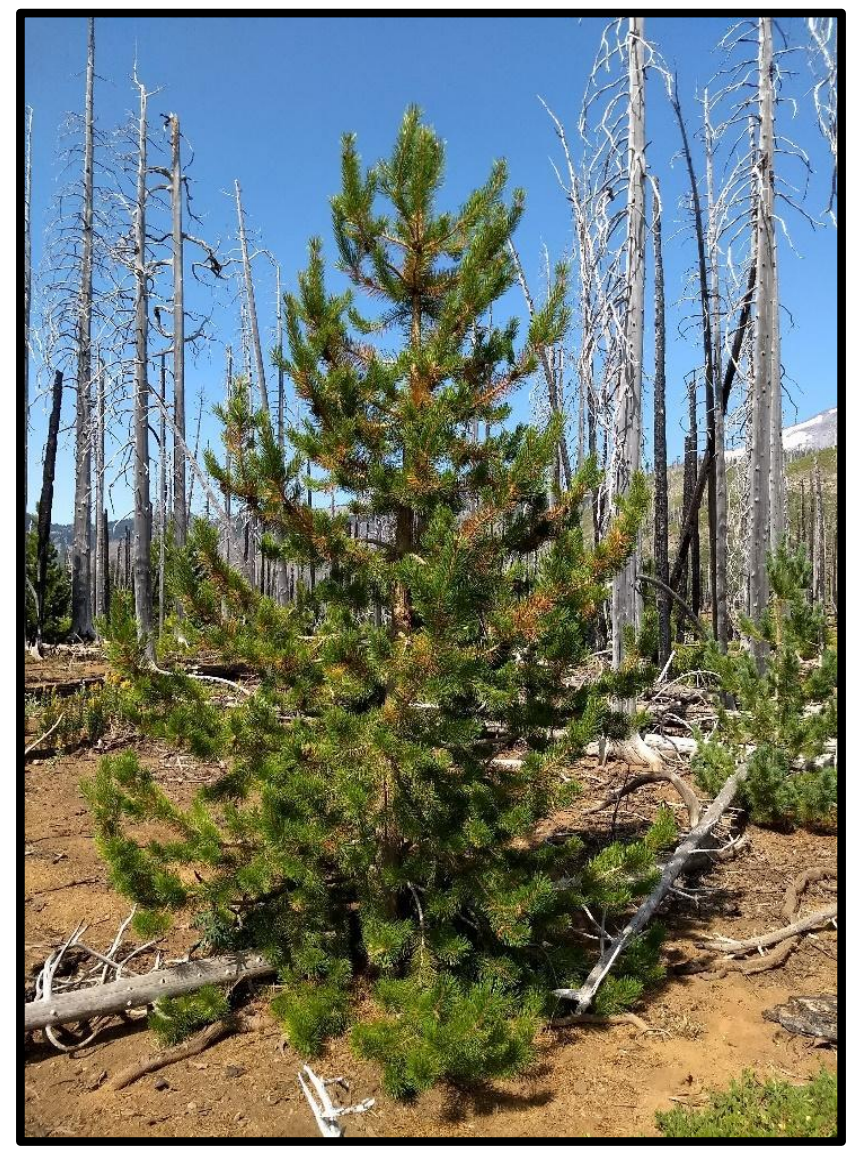

Figure 27: A lodgepole pine sapling that established after a 2003 high-severity fire, whom survived a 2014 low-severity fire (11 years between events) and was producing cones in 2018.

As indicated by the NMDS ordinations (Figures 17/18), low-high severity reburns appeared to the support establishment of the widest diversity of species, while high-low reburns primarily supported lodgepole pine and ponderosa pine. Although both reburns equally removed live seed sources from affected patches, the sequence of this removal may be important - as indicated by Stevens-Rumann and Morgan (2016). Ultimately, a low-high-severity reburn mimics a single stand-replacing fire, in contradiction to the possible hypothesis that the second fire, although high-severity, might be fuel-limited. Instead, some understory is removed during the first fire, but most canopy trees survive; 
then, when the second fire ensues, mass mortality of live trees and establishing seedlings occurs although some trees may experience delayed mortality and disperse final offspring post-fire before succumbing. Unless a third fire occurs, those seeds can successfully establish and remain relatively undisturbed.

Alternatively, in a high-low-severity reburn, the stand experiences mass mortality and ejects final offspring upon the first, high-severity fire. By the time the second fire occurs, delayed mortality has taken its course. The secondary low-severity fire kills unprotected or poorly adapted seedlings, and no nearby seed source is left to reseed the stand after the fire. Therefore, only the seedlings that grow fast and are large or tough enough to survive a low-severity fire remain. In this case, lodgepole pine and ponderosa pine appear to be the most successful under a high-low reburn sequence with 7-11 years between fires, while grand fir and Douglas fir suffered the most. Although Stevens-Rumann and Morgan (2016) saw more extreme differences in seedling densities between high-low and low-high reburn sequences within mixedconifer forest, the same trend of lower species diversity and abundance under a highlow sequence was present.

Across all burned sites, we saw a substantial decrease in subalpine fir $(25.7 \%$ down to $8.4 \%$ ) and substantial increase in lodgepole pine (9.7\% up to $22.1 \%)$. These patterns of establishment indicate that much of the forest landscape affected by highseverity and repeated fire is undergoing stand re-initiation at low tree densities, 
dominated by lodgepole and ponderosa pine at longer distances (i.e. $>100 \mathrm{~m}$ ) from live seed sources.

Forest Ecosystem Transitions, Migrations, and Future Resilience

Post-fire forest regeneration can take many successional pathways, and pathways may shift or emerge decades after a wildfire. For this reason, quantifying regeneration shortly after fire events may provide poor snapshots of long-term forest development (Tepley et al. 2014; Gill et al. 2017). Several important components indicated within this study, however, reinforce the likelihood that regeneration trends seen now may not deviate significantly in the future. Conifer legacies stored on the landscape as live seed trees have primarily been removed within the high-severity and reburned patches we sampled. Without those legacies intact, few mechanisms exist to reseed forests beyond marginal wind and animal dispersal - that is until surviving seedlings reach sexual maturity. Surviving seedlings could begin to reseed immediate areas around them, eventually creating enough shade and moisture to facilitate shadetolerant species' establishment. Left undisturbed, this process could eventually lead to the re-establishment of prior forest compositions.

If climate change impacts are considered, however, greater forest fuel aridity points to more frequent wildfire (Abatzoglou and Williams 2016; Abatzoglou et al. 2017) and potentially larger, more severe fires (Cansler and McKenzie 2014). Within the subalpine zone, frequent fire (as has occurred recently) would generally prevent the reestablishment of characteristically subalpine species like mountain hemlock, 
Engelmann spruce, and subalpine fir (Hansen et al. 2018; Johnstone et al. 2016; Turner and Romme 1994). Frequent fire would also promote the same low forest densities presently observed (Tepley et al. 2013).

Donato et al. (2012) proposed that spatiotemporal wildfire characteristics and environmental stress could create multiple successional pathways in temperate forests. Within this model, some forests can maintain high structural complexity across seral stages, and may even skip traditional developmental stages, such as competitive exclusion. This may result in a forest with abnormally low tree density over time, but structurally complex attributes, nonetheless. We posit that within our study areas affected by expansive high-severity and repeated wildfire, previously high-density subalpine and upper-montane forests may have transitioned into now persistently altered low-density states in response to the changed climate and fire regimes. Using the framework described by Donato et al. (2012), we believe these forests may be following a homologous precocity successional pathway (Figure 28). 

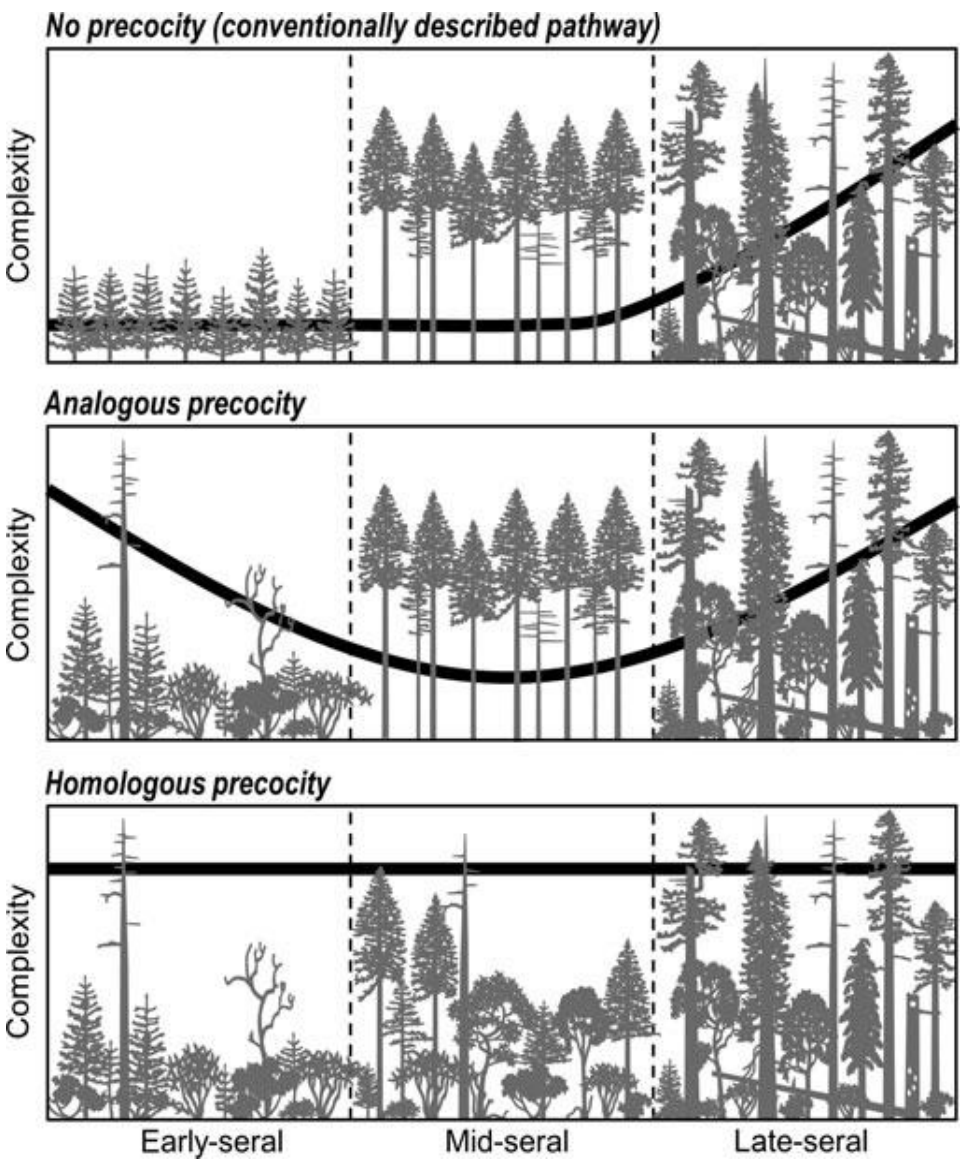

Figure 28: Three alternate successional pathways for forest development, showing the relative levels of structural complexity exhibited in each seral stage. In the conventional successional model, both earlyand mid-seral conditions are dominated by a relatively even-aged tree cohort, and structural complexity does not arise until the latest stage of development. In the case of analogous precocity, early-successional stands exhibit structural complexity in some ways similar to that in old stands, but canopy closure results in reduced complexity during mid-succession. In the case of homologous precocity, the lack of a tree canopy-closure phase results in a continuity of complexity throughout forest development. From Donato et al. 2012.

Where prior forests lacked resilience against frequent fire, new compositions will have multiple components that reinforce mixed-severity fire regimes. Alternative forests will be dominated by fire-adapted species, experience lower fine fuel loads, maintain patchier connectivity of fuels, and exhibit lower conifer densities - promoting fewer expansive stand-replacing crown fires (Coop et al. 2016; Larson et al. 2013; StevensRumann and Morgan 2016; van Wagtendonk et al. 2012). If we can expect increasing 
summertime fuel aridity within the PNW region (Abatzoglou and Williams 2016;

Abatzoglou et al. 2017; Westerling et al. 2006), altered forest compositions will maintain greater resilience in the face of climate change by adapting to new fire regimes (Johnstone et al. 2016; Turner et al. 1993).

Additionally, in response to these changes, we expect forest compositions to begin migrating over the next century within the Central Cascade Range (Davis et al. 2019; Kemp et al. 2019; Stevens-Rumann et al. 2017; Figure 29). As dense forests within the upper-montane and

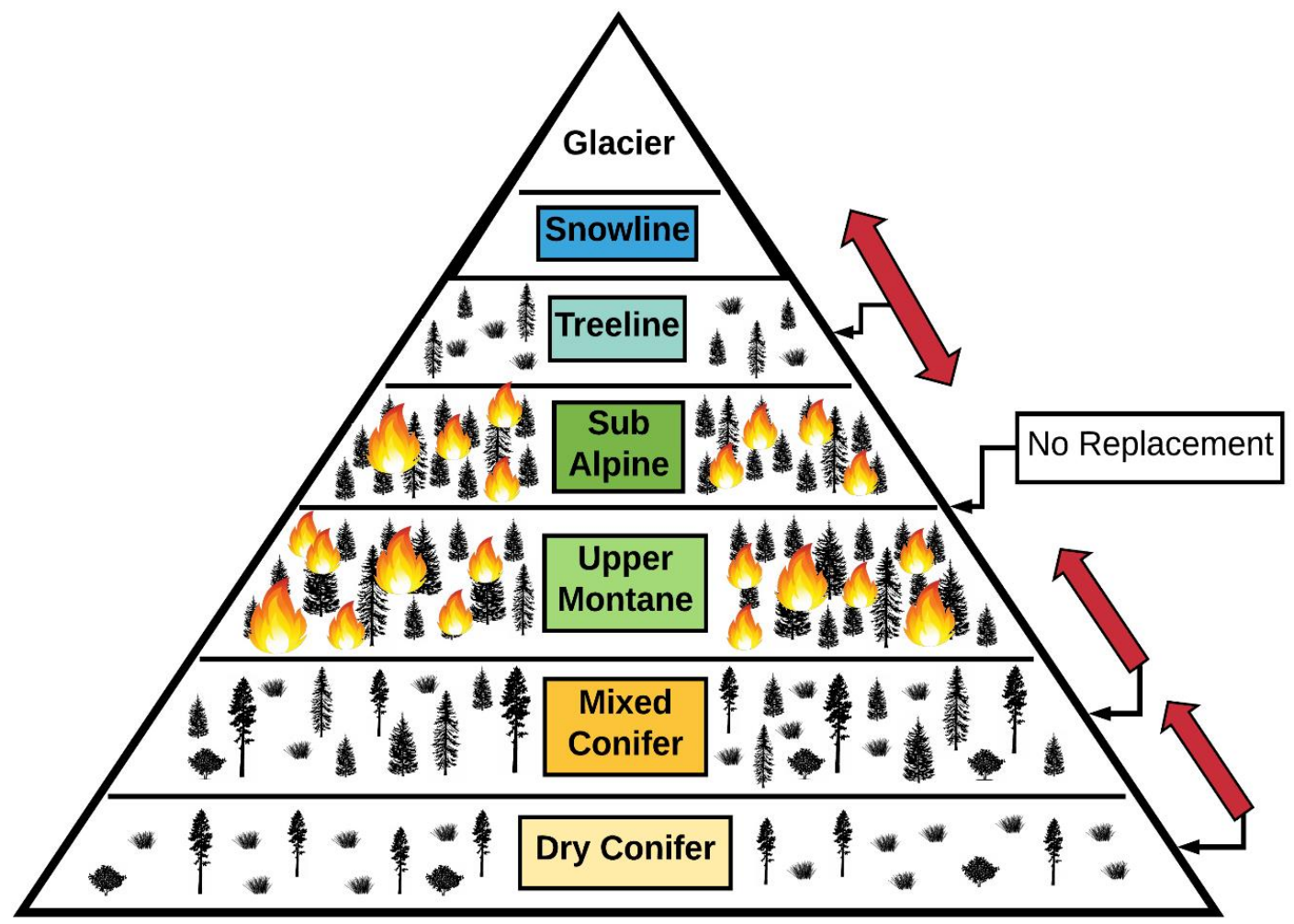

Figure 29: Conceptual diagram of anticipated forest composition shifts due to increased fire frequency and climate change impacts within the Central Cascade Range. A general upward shift in forest types is anticipated, except where large high-severity fire patches and short-interval fires remove live conifer legacies (seed source). Adapted from Cansler et al. 2018. 
subalpine zones begin to burn more frequently and in greater extent, high-severity patches may lack proximate seed sources except at fire perimeter edges or in small islands of refugia (Kemp et al. 2016; Harvey et al. 2016; Hansen et al. 2018). At high and low elevation points within affected perimeters in upper-montane/ subalpine zones, alpine treeline species will push downward into the subalpine zone, and mixed-conifer species upward into the upper-montane zone (Cansler et al. 2018). Within large patches burned at a high-severity, the center of affected perimeters may have minimal conifer replacement, and thereby transition into low-density forests with large patches of grass and shrubland (Harvey et al. 2016; Kemp et al. 2016; Serra-Díaz et al. 2018; Tepley et al. 2018; van Wagtendonk et al. 2012).

In the short-term, this belt of sparse fuels may act as a barrier to future fire spread, protecting the subalpine-treeline transition zone from fires. As summit snowlines recede in elevation, an upward migration of forest types will occur, starting from dry conifer forests east of the Cascade crest, to alpine treeline species advancing on receding snowlines. The speed of such potential forest changes and migrations is theorized to be accelerated by the occurrence of large-scale natural disturbances especially wildfires (Enright et al. 2015; Johnstone et al. 2016; Turner et al. 1993). If so, post-reburned areas might turn out to adapt more quickly to direct (i.e. warmer and drier conditions) and indirect (e.g. increased frequency of fires) climate change impacts in these mid-to-high elevation forests. 


\section{Management Implications}

For wildfire, forest, timber, and recreation managers operating in the Central Cascade Range, altered wildfire regimes and forests present dynamic challenges. Productive upper-montane forest stands are ideal for timber harvest, but under climate change are at risk of spatially extensive high-severity fires which leave little marketable timber left for extraction (Abatzoglou and Williams 2016; Abaztoglou et al. 2017; McKenzie and Littell 2017). As forests develop lower densities after experiencing highseverity and repeated wildfires, affected stands may lose some economic viability for harvest (Stine et al. 2014). Meanwhile, human development and recreation lands intersecting high-elevation areas may be at greater risk of expansive wildfire until forest fuel densities decline. In the aftermath, burned forests in scenic recreation areas may illicit lower perceived value from guests - reducing tourism and public access to landscapes (Englin et al. 2001; Hesseln et al. 2004; Kline et al. 2004; Loomis et al. 2001; Stine et al. 2014). Affected areas may also remain closed until infrastructure can be repaired and post-fire erosion concerns addressed.

To mitigate forests transitions and control wildfire patterns, fewer effective management practices have been identified in forests with climate-limited wildfire regimes when compared to fuel-limited regimes (Halofsky et al. 2018; Stine et al. 2014). Halofsky et al. (2018) identified climate adaptation options for forests which facilitate stand-replacing fire regimes. These options incorporate practices which (1) maintain live seed tree legacies on landscapes, (2) minimize high-severity fire extent, and (3) utilize 
fire suppression to maintain existing forest compositions. In the long-term, fire suppression may be a poor management option. Increasingly drier forests with large historical, even multi-century, fuel accumulations will stimulate expansive high-severity fires sooner or later - unless stands are truthfully wet enough to resist short-term climate change impacts.

If forest ecosystems are fundamentally ill-adapted to frequent fires and a warming climate, we would recommend management practices that allow ecosystems to begin transitioning - but at fundamentally slower rates than unmitigated wildfire may create. This could involve creating systematic firebreak buffers within dense forests to limit high-severity fire extent, buffering refugia islands to protect persistent seed sources, and/or encouraging wildfires during wetter, cooler climatic periods which limit high-severity fire extent. Additionally, planting seedlings in and around live conifer legacies and fire refugia may help reinitiate components of prior forest compositions. To increase seedling survival, planting efforts may be focused in areas with favorable topographic features which increase moisture availability (i.e. TWI, HLI). Such strategies could help retain existing conifer legacies within affected forests, preventing potentially rapid ecosystem transitions from conifer regeneration failure. 


\section{Limitations and Future Directions}

Seed Source Distance and Delayed Mortality

Distance to seed source has been identified as a primary control on conifer regeneration post-disturbance by numerous recent studies (e.g. Donato et al. 2009a,b; Donato et al. 2016; Kemp et al. 2016; Harvey et al. 2016) - but the method(s) in which seed source distance is calculated varies by study. Common methods involve measuring (1) distance to the nearest single live tree, (2) averaged distance to the nearest 10 live trees, and (3) distance to the nearest contiguous live tree patch (i.e. forest edge or refugia). Since methods vary, interpretations of critical seed source distance thresholds may also vary between studies, as individual live trees vs. contiguous live tree patches may have differential capacities to reseed burned areas (i.e. greater quantity of seeds reaching plots). While we used method (2) in this study, incorporating method (3) may have revealed differences in the effectiveness of scattered vs. clumped seed source and improved seedling regeneration models.

Delayed mortality of trees post-fire may additionally confuse seed source distance measurements, where seed trees may have been alive post-fire, but not during the time of field sampling. When attempting to model seedling regeneration as a function of seed source, delayed mortality can confuse results (i.e. seed source was present on sample plot, but not detected). Many studies have used iterations of MTBS' remotely-sensed burn severity data to select field sites and/or conduct spatial analyses (including this study), which is built on determining fire-severity approximately one-year 
post-fire (Eidenshink et al. 2007). Thus, forest burned at "moderate-severity" as captured by MTBS may experience delayed mortality, resulting in "high-severity" conditions within several years. Assuming enough time has passed since a fire occurred ( 2+ years postfire), future studies may benefit from comparing one-year post-fire imagery to several years post-fire imagery (i.e. subtract images) to quantify tree mortality from fire effects more accurately.

\section{Compound Disturbance Interactions: Insect Outbreak}

As noted in the study methodology section, we attempted to limit the influence of recent insect outbreak within our sample plots from Western Spruce Budworm (WSB) and Mountain Pine Beetle (MPB). Forests within both study areas (Mt. Jefferson and Mt. Adams) have experienced extensive recent insect outbreaks from these species (Hummel and Agee 2003; Meigs et al. 2015b), which may kill live trees and/or reduce their resilience to future disturbance (Hummel \& Agee 2003; Meigs et al. 2015a; Raffa et al. 2008). While we minimized effects from insects within our sample plots, we did not consider or remove influence from areas surrounding our plots (i.e. where live trees providing seed source were often located). Tree mortality from insects may have combined with fire effects to limit the amount of live seed source near our plots, both within immediate patches which matched plot burn-severity and from clusters of nearby live trees burned at lower severities (i.e. refugia).

While MPB is primarily known for causing tree mortality, WSB can also reduce cone and seed production in host trees (Brooks et al. 1987). Considering the compound 
stress created by insect and fire effects, it's possible that seed production capacity of live trees near our sample plots was negatively affected - resulting in fewer seeds reaching sample plots and poorer subsequent conifer regeneration. In the case of an alpine treeline environment, Jameson et al. (2015) found insect outbreak reduced treeline expansion by limiting viable conifer seeds and cone production. As warming climate conditions increase the potential for compound disturbances like repeated wildfire and insect outbreaks, future research could assess the impacts of disturbance interactions on conifer seed production, dispersal, and establishment - thus improving scientific understanding of post-disturbance forest regeneration outcomes.

\section{Impacts of Woody Charring on Snowmelt}

Winter snowpack and the timing of snowmelt are important mechanisms controlling forest fuel aridity within high-elevation forests (Fyfe et al. 2017; Gergel et al. 2017; Mote 2006; Westerling et al. 2006). Snowmelt timing may also be important for post-fire conifer establishment, where melt timing may facilitate or impede establishment of different conifer species - as indicated by our seedling regeneration models (Andrus et al. 2018; Little et al. 1994). A lack of canopy cover may increase snow deposition, but it might also speed up the melting of snow in the spring. In addition, charred forests have been shown to alter the albedo of snow, potentially increasing the rate at which snowpack melts (Gleason et al. 2013; Gleason and Nolan 2016; Harpold et al. 2014). 
Among our sample sites, rapidly reburned plots exhibited a significantly greater percentage of both heavily charred coarse woody debris and dead, standing trees when compared to single high-severity plots (Table 9; Figure 14). Ward et al. (2017) also noted that reburned forest exhibited significantly more black carbon charring on down woody debris than sites which experienced only a single high-severity fire. With a greater cumulative surface area of heavily charred biomass, it's possible that reburned stands may further decrease snow albedo for the duration charred trees remain standing, increasing local snowmelt rates over stands affected by a single high-severity fire. Consequently, conifer regeneration could be differently impacted within reburned stands because of this dynamic. Existing research has assessed snow ablation after highseverity fires, but not short-interval fires (Gleason et al. 2013; Gleason and Nolan 2016; Harpold et al. 2014). Future research could assess the validity of this hypothesis by comparing snowmelt rates between forest stands burned once and rapidly reburned at a high-severity.

\section{Soil Moisture and Post-Fire Forest Regeneration}

Landscape-level ecological assessments often use climate data or modeled climate products as a proxy for local bioclimatic conditions, including this research. Field measurement of soil hydrology and moisture availability for local flora are often time consuming, must be recorded over continuous periods, and corresponding result can be very heterogenous over space as soil and vegetation compositions change (Vereecken et al. 2015). Conversely, climate data exists widely across the earth at semi-fine spatial 
resolutions and perhaps most importantly, is available for the late and early $20^{\text {th }} / 21^{\text {st }}$ centuries. Regardless of the inherent difficulties of field sampling and the ease and availability of climate data, climate data and modeled products are still only a proxy for ground conditions - an important limitation of this study. Within forest stands affected by low and high-severity fires, for example, actual soil moisture availability for regenerating vegetation may be wildly different - even though climatic data is the same. Varying post-fire forest structures facilitate varying levels of moisture retention and availability (Boisramé et al. 2018, Cardenas and Kanarek 2014).

As remote-sensing techniques for measuring soil-moisture improve, soilmoisture may be a more accurate measure of climatic effects on post-fire forest regeneration than climate data alone at the plot and landscape level (Bourgeau-Chavez et al. 2007; Elsner et al. 2011; Mohanty et al. 2017). Especially during periods of drought, soil moisture availability may determine the success of germinating seeds and survival of young conifer seedlings (Andrus et al. 2018; Harvey et al. 2016; Kemp et al. 2019; Stevens-Rumann et al. 2018). Existing methods work effectively for monitoring soil moisture over homogenous landscapes (e.g. agricultural crops) but are much less reliable over complex terrain and heterogenous vegetation types (Mohanty et al. 2017; Zhang et al. 2017). We recommend (1) the promotion of technologies and methods which improve the accuracy and accessibility of remotely-sensed soil moisture data over topographically complex forested landscapes, and (2) the utilization of this data in future studies assessing post-fire forest regeneration or mortality. Linking soil moisture 
availability to forest regeneration at the plot and landscape level may improve the accuracy of ecological models and help decipher the impacts of climate change on affected forest systems.

\section{Improving Seedling Stress Sampling Protocols}

Although we detected two mildly influential variables (TWI and slope), our analysis of conifer seedling stress using the Fv/Fm method yielded mostly inconclusive results. When considering the primary factors that influence plant stress, it's likely that our sampling protocol dampened the ability to detect stronger correlations and observe differences among groups. In the context of our study area and burned plots, seedling stress manifests primarily from a lack of moisture availability to mitigate overexposure to sunlight and heat (Pearson et al. 2013). Considering the early-to-mid summer period we sampled field plots (late-June to mid-August), it is very possible that seedlings generally experienced sufficient moisture availability across fire histories and topographic settings - dampening potential differences. To improve the strength and effectiveness of an Fv/Fm sampling protocol, field measurements should ideally occur at the end of summer (mid-late September) when forests experience the greatest moisture deficit. Measurements should also ideally be taken at the same time of day, during the same time period (i.e. a single week), and when weather conditions do not fluctuate significantly. 


\section{References}

Abatzoglou, J. T. 2013. Development of gridded surface meteorological data for ecological applications and modelling. gridMET. Int. J. Climatol., 33: 121-131.

Abatzoglou, J. T., and A. P. Williams. 2016. Impact of anthropogenic climate change on wildfire across western US forests. Proceedings of the National Academy of Sciences 113 (42):11770-11775.

Abatzoglou, J. T., C. A. Kolden, A. P. Williams, J. A. Lutz, and A. M. S. Smith. 2017. Climatic influences on interannual variability in regional burn severity across western US forests. International Journal of Wildland Fire 26 (4):269.

Abrahamson, Ilana. Fire Effects Information System (FEIS). Available online at https://www.feis-crs.org/feis/.

Agee, J. 1993. Fire Ecology of Pacific Northwest Forests. Island Press. Washington D.C.

Agee, J. 1998. The Landscape Ecology of Western Forest Fire Regimes. Northwest Science 72:24-34.

Ager, A. A., M. A. Day, C. W. McHugh, K. Short, J. Gilbertson-Day, M. A. Finney, and D. E. Calkin. 2014. Wildfire exposure and fuel management on western US national forests. Journal of Environmental Management 145:54-70.

Ager, A. A., R. M. Houtman, M. A. Day, C. Ringo, and P. Palaiologou. 2019. Tradeoffs between US national forest harvest targets and fuel management to reduce wildfire transmission to the wildland urban interface. Forest Ecology and Management 434:99109.

Aickin, M., and H. Gensler. 1996. Adjusting for multiple testing when reporting research results: the Bonferroni vs Holm methods. American Journal of Public Health 86 (5):726728.

Anderson, H. E. 1982. Aids to determining fuel models for estimating fire behavior. Gen. Tech. Rep. INT-122. Ogden, Utah: US Department of Agriculture, Forest Service, Intermountain Forest and Range Experiment Station. 22p. 122.

Anderson, Jay E.; Romme, William H. 1991. Initial floristics in lodgepole pine (Pinus contorta) forests following the 1988 Yellowstone fires. International Journal of Wildland Fire. 1(2): 119-124. 
Anderson, M. J. 2017. Permutational Multivariate Analysis of Variance (PERMANOVA). In Wiley StatsRef: Statistics Reference Online, eds. N. Balakrishnan, T. Colton, B. Everitt, W. Piegorsch, F. Ruggeri, and J. L. Teugels, 1-15. Chichester, UK: John Wiley \& Sons, Ltd http://doi.wiley.com/10.1002/9781118445112.stat07841 (last accessed 9 January 2019).

Andrus, R. A., B. J. Harvey, K. C. Rodman, S. J. Hart, and T. T. Veblen. 2018. Moisture availability limits subalpine tree establishment. Ecology 99 (3):567-575.

Atzet, Thomas; McCrimmon, Lisa A. 1990. Preliminary plant associations of the southern Oregon Cascade Mountain province. Grants Pass, OR: U.S. Department of Agriculture, Forest Service, Siskiyou National Forest. 330 p.

Balch, J. K., B. A. Bradley, J. T. Abatzoglou, R. C. Nagy, E. J. Fusco, and A. L. Mahood. 2017. Human-started wildfires expand the fire niche across the United States.

Proceedings of the National Academy of Sciences 114 (11):2946-2951.

Bawa, R. S. 2017. Effects of wildfire on the value of recreation in western North America. Journal of Sustainable Forestry 36 (1):1-17.

Beven, K. J., and M. J. Kirkby. 1979. A physically based, variable contributing area model of basin hydrology. Hydrological Sciences Bulletin 24 (1):43-69.

Blomdahl, E. M., C. A. Kolden, A. J. H. Meddens, and J. A. Lutz. 2019. The importance of small fire refugia in the central Sierra Nevada, California, USA. Forest Ecology and Management 432:1041-1052.

Boisramé, G., S. Thompson, and S. Stephens. 2018. Hydrologic responses to restored wildfire regimes revealed by soil moisture-vegetation relationships. Advances in Water Resources 112:124-146.

Bourgeau-Chavez, L. L., E. S. Kasischke, K. Riordan, S. Brunzell, M. Nolan, E. Hyer, J. Slawski, M. Medvecz, T. Walters, and S. Ames. 2007. Remote monitoring of spatial and temporal surface soil moisture in fire disturbed boreal forest ecosystems with ERS SAR imagery. International Journal of Remote Sensing 28 (10):2133-2162.

Boyd, R. 1999. Indians, Fire, and the Land in the Pacific Northwest. Oregon State University Press.

Brookes, M.H., Colbert, J.J., Mitchell, R.G., Stark, R.W., 1987.Western spruce budworm. USDA For. Serv. Tech. Bull. 1694, p.108 
Brown, J. K. 1974. Handbook for inventorying downed woody material. USDA Forest Service General Technical Report (INT-16):32.

Brown, M. J., J. Kertis, and M. H. Huff. 2013. Natural tree regeneration and coarse woody debris dynamics after a forest fire in the western Cascade Range. Portland, OR: U.S. Department of Agriculture, Forest Service, Pacific Northwest Research Station. https://www.fs.usda.gov/treesearch/pubs/43434 (last accessed 30 November 2018).

Buma et al., B. 2013. The Impacts of Changing Disturbance Regimes on Serotinous Plant Populations and Communities. BioScience 63 (11):866-876.

Buja, K. and Menza, Charles (2013) Sampling design tool for ArcGIS: Instruction manual.[for ESRI ArcGIS 10.0 Service Pack 3 or higher]. Silver Spring, MD, NOAA/National Centers for Coastal Ocean Science, $16 \mathrm{pp}$.

Cansler, C. A., and D. McKenzie. 2014. Climate, fire size, and biophysical setting control fire severity and spatial pattern in the northern Cascade Range, USA. Ecological Applications 24 (5):1037-1056.

Cansler, C. A., D. McKenzie, and C. B. Halpern. 2018. Fire enhances the complexity of forest structure in alpine treeline ecotones. Ecosphere 9 (2):e02091.

Cardenas, M. B., and M. R. Kanarek. 2014. Soil moisture variation and dynamics across a wildfire burn boundary in a loblolly pine ( Pinus taeda ) forest. Journal of Hydrology 519:490-502.

Clarke, K. R. 1993. Non-parametric multivariate analyses of changes in community structure. Australian Journal of Ecology 18 (1):117-143.

Collins, B. M., R. G. Everett, and S. L. Stephens. 2011. Impacts of fire exclusion and recent managed fire on forest structure in old growth Sierra Nevada mixed-conifer forests. Ecosphere 2:51

Cook, R. D. 1979. Detection of Influential Observation in Linear Regression. 19 (1):5.

Comer, P., D. Faber-Langendoen, R. Evans, S. Gawler, C. Josse, G. Kittel, S. Menard, M. Pyne, M. Reid, K. Schulz, K. Snow, and J. Teague. 2003. Ecological Systems of the United States: A Working Classification of U.S. Terrestrial Systems. NatureServe, Arlington, Virginia. 
Coppoletta, M., K. E. Merriam, and B. M. Collins. 2016. Post-fire vegetation and fuel development influences fire severity patterns in reburns. Ecological Applications 26 (3):686-699.

Critchfield, W. B. 1978. The distribution, genetics, and silvics of lodgepole pine. In: Proceedings, International Union of Forestry Research Organizations (IUFRO) joint meeting of working parties. Vol. 1: Background papers and Douglas fir provenances. 1978; Vancouver, BC. Victoria, BC: British Columbia Ministry of Forests: 65-94. [8317]

Davis, K. T., S. Z. Dobrowski, P. E. Higuera, Z. A. Holden, T. T. Veblen, M. T. Rother, S. A. Parks, A. Sala, and M. P. Maneta. 2019. Wildfires and climate change push low-elevation forests across a critical climate threshold for tree regeneration. Proceedings of the National Academy of Sciences :201815107.

Dennison, P. E., S. C. Brewer, J. D. Arnold, and M. A. Moritz. 2014. Large wildfire trends in the western United States, 1984-2011: Geophysical Research Letters 41 (8):29282933.

Donato, D. C., J. B. Fontaine, J. L. Campbell, W. D. Robinson, J. B. Kauffman, and B. E. Law. 2009a. Conifer regeneration in stand-replacement portions of a large mixedseverity wildfire in the Klamath-Siskiyou Mountains. Canadian Journal of Forest Research 39 (4):823-838.

Donato, D. C., J. B. Fontaine, W. D. Robinson, J. B. Kauffman, and B. E. Law. 2009b. Vegetation response to a short interval between high-severity wildfires in a mixedevergreen forest. Journal of Ecology 97 (1):142-154.

Donato, D. C., J. L. Campbell, and J. F. Franklin. 2012. Multiple successional pathways and precocity in forest development: can some forests be born complex? ed. M. Palmer. Journal of Vegetation Science 23 (3):576-584.

Donato, D. C., J. B. Fontaine, and J. L. Campbell. 2016. Burning the legacy? Influence of wildfire reburn on dead wood dynamics in a temperate conifer forest ed. F. Biondi. Ecosphere 7 (5):e01341.

Donato, D. C., B. J. Harvey, and M. G. Turner. 2016. Regeneration of montane forests 24 years after the 1988 Yellowstone fires: A fire-catalyzed shift in lower treelines?

Ecosphere 7 (8):e01410.

Eidenshink, J., B. Schwind, K. Brewer, Z.-L. Zhu, B. Quayle, and S. Howard. 2007. A Project for Monitoring Trends in Burn Severity. Fire Ecology 3 (1):3-21. 
Elsner, M.M, A.F. Hamlet, R.D Woodsmith, J.S Littell, E. Istanbulluoglu. 2011. The Effects of Soil Moisture Stress on Forest Recovery in the Entiat River Basin after Stand Replacing Fire. American Geophysical Union

Englin, J.; Loomis, J.; Gonzalez-Caban, A. 2001. The dynamic path of recreational values following a forest fire: a comparative analysis of states in the Intermountain West. Canadian Journal of Forestry Research. 31: 1837-1844.

Enright, N. J., J. B. Fontaine, D. M. Bowman, R. A. Bradstock, and R. J. Williams. 2015. Interval squeeze: altered fire regimes and demographic responses interact to threaten woody species persistence as climate changes. Frontiers in Ecology and the Environment $13(5): 265-272$.

Evans JS, Oakleaf J, Cushman SA, Theobald D (2014) An ArcGIS Toolbox for Surface Gradient and Geomorphometric Modeling, version 2.0-0.

Fischer, A. P., T. A. Spies, T. A. Steelman, C. Moseley, B. R. Johnson, J. D. Bailey, A. A. Ager, P. Bourgeron, S. Charnley, B. M. Collins, J. D. Kline, J. E. Leahy, J. S. Littell, J. D. Millington, M. Nielsen-Pincus, C. S. Olsen, T. B. Paveglio, C. I. Roos, M. M. Steen-Adams, F. R. Stevens, J. Vukomanovic, E. M. White, and D. M. Bowman. 2016. Wildfire risk as a socioecological pathology. Frontiers in Ecology and the Environment 14 (5):276-284.

Murchie, E. H., and T. Lawson. 2013. Chlorophyll fluorescence analysis: a guide to good practice and understanding some new applications. Journal of Experimental Botany 64 (13):3983-3998.

Forrestel, A. B. F., D. L. Fry, and S. L. Stephens. 2017. Fire History and Forest Structure Along an Elevational Gradient in the Southern Cascade Range, Oregon, USA. Fire Ecology $13(1): 1-15$.

Franklin, J. F., and C. T. Dyrness. 1973. Natural Vegetation of Oregon and Washington. PNW-8: U.S. Dept. of Agriculture, Forest Service, Pacific Northwest Research Station.

Freund, J. A., J. F. Franklin, A. J. Larson, and J. A. Lutz. 2014. Multi-decadal establishment for single-cohort Douglas fir forests. Canadian Journal of Forest Research 44 (9):10681078.

Fushiki, T. 2011. Estimation of prediction error by using K-fold cross-validation. Statistics and Computing 21 (2):137-146. 
Gergel, D. R., B. Nijssen, J. T. Abatzoglou, D. P. Lettenmaier, and M. R. Stumbaugh. 2017. Effects of climate change on snowpack and fire potential in the western USA. Climatic Change 141 (2):287-299.

Gill, N. S., D. Jarvis, T. T. Veblen, S. T. A. Pickett, and D. Kulakowski. 2017. Is initial postdisturbance regeneration indicative of longer-term trajectories? Ecosphere 8 (8):e01924.

Gleason KE, Nolin AW, Roth TR. 2013. Charred forests increase snowmelt: effects of burned woody debris and incoming solar radiation on snow ablation. Geophysical Research Letters 40: 4654-4661. DOI:10.1002/grl.50896

Gleason, K. E., and A. W. Nolin. 2016. Charred forests accelerate snow albedo decay: parameterizing the post-fire radiative forcing on snow for three years following fire: Charred Forests Accelerate Snow Albedo Decay. Hydrological Processes 30 (21):38553870.

Grabinski, Z. S., R. L. Sherriff, and J. M. Kane. 2017. Controls of reburn severity vary with fire interval in the Klamath Mountains, California, USA. Ecosphere 8 (11):e02012.

Haffey, C., Sisk, Thomas, Allen, Craig D, Thode, Andrea E., and Margolis, Ellis. 2018. Limits to ponderosa pine regeneration following large high-severity forest fires in the United States Southwest. Fire Ecology 14 (1):21.

Hagmann, R. K., J. F. Franklin, and K. N. Johnson. 2014. Historical conditions in mixedconifer forests on the eastern slopes of the northern Oregon Cascade Range, USA. Forest Ecology and Management 330:158-170.

Haire, S. L., and K. McGarigal. 2010. Effects of landscape patterns of fire severity on regenerating ponderosa pine forests (Pinus ponderosa) in New Mexico and Arizona, USA. Landscape Ecology 25 (7):1055-1069.

Halofsky, J. S., D. C. Donato, J. F. Franklin, J. E. Halofsky, D. L. Peterson, and B. J. Harvey. 2018. The nature of the beast: examining climate adaptation options in forests with stand-replacing fire regimes. Ecosphere 9 (3):e02140.

Hansen, W. D., K. H. Braziunas, W. Rammer, R. Seidl, and M. G. Turner. 2018. It takes a few to tango: changing climate and fire regimes can cause regeneration failure of two subalpine conifers. Ecology 99 (4):966-977. 
Harpold AA, Biederman JA, Condon K, Merino M, Korgaonkar Y, Nan T, Sloat LL, Ross M, Brooks PD. 2014. Changes in snow accumulation and ablation following the Las Conchas Forest Fire, New Mexico, USA. Ecohydrology 7: 440-452. DOI:10.1002/eco.1363

Harvey, B. J., D. C. Donato, and M. G. Turner. 2016. High and dry: post-fire tree seedling establishment in subalpine forests decreases with post-fire drought and large standreplacing burn patches: Drought and post-fire tree seedlings. Global Ecology and Biogeography 25 (6):655-669.

Haugo, R. D., S. A. Hall, E. M. Gray, P. Gonzalez, and J. D. Bakker. 2010. Influences of climate, fire, grazing, and logging on woody species composition along an elevation gradient in the eastern Cascades, Washington. Forest Ecology and Management 260 (12):2204-2213.

Hessburg, P. F., and J. K. Agee. 2003. An environmental narrative of Inland Northwest United States forests, 1800-2000. Forest Ecology and Management 178 (1-2):23-59.

Hessburg, P. F., and J. K. Agee. 2005. Dry forests and wildland fires of the inland Northwest USA: Contrasting the landscape ecology of the pre-settlement and modem eras. :23.

Hesseln, H.; Loomis, J.B.; Gonzalez-Caban, A. 2004. Comparing the economic effects of fire on hiking demand in Montana and Colorado. Journal of Forest Economics. 10: 2135.

Higuera, P. E. 2015. Taking time to consider the causes and consequences of large wildfires: Fig. 1. Proceedings of the National Academy of Sciences 112 (43):1313713138.

Hosmer, D.W., T. Hosmer, S. Lemeshow. 1980. A Goodness-of-Fit Tests for the Multiple Logistic Regression Model. Communications in Statistics, 10, 1043-1069.

Hosmer, D.W., S. Lemeshow, R.X. Sturdivant. 2013. Applied Logistic Regression. John Wiley \& Sons, Hoboken, New Jersey.

Jameson, R. G., A. J. Trant, and L. Hermanutz. 2015. Insects can limit seed productivity at the treeline. Canadian Journal of Forest Research 45 (3):286-296.

Kemp, K. B., P. E. Higuera, and P. Morgan. 2016. Fire legacies impact conifer regeneration across environmental gradients in the U.S. northern Rockies. Landscape Ecology 31 (3):619-636. 
Kemp, K. B., P. E. Higuera, P. Morgan, and J. T. Abatzoglou. 2019. Climate will increasingly determine post-fire tree regeneration success in low-elevation forests, Northern Rockies, USA. Ecosphere 10 (1):e02568.

Key, C. H., and N. C. Benson. 2006. Landscape Assessment (LA). :56.

Kline, J.D. 2004. Issues in evaluating the costs and benefits of fuel treatments to reduce wildfire in the nation's forests. Res. Note PNW-RN-542. Portland, OR: U.S. Department of Agriculture, Forest Service, Pacific Northwest Research Station. 46 p.

Kolden, C., T. Bleeker, A. Smith, H. Poulos, and A. Camp. 2017. Fire Effects on Historical Wildfire Refugia in Contemporary Wildfires. Forests 8 (10):400.

Krawchuk, M. A., S. L. Haire, J. Coop, M.-A. Parisien, E. Whitman, G. Chong, and C. Miller. 2016. Topographic and fire weather controls of fire refugia in forested ecosystems of northwestern North America. Ecosphere 7 (12):e01632.

Krawchuk, M. A., and M. A. Moritz. 2011. Constraints on global fire activity vary across a resource gradient. Ecology 92 (1):121-132.

Krugman, Stanley L.; Jenkinson, James L. 1974. Pinaceae--pine family. In: Schopmeyer, C. S., technical coordinator. Seeds of woody plants in the United States. Agric. Handb. 450. Washington, DC: U.S. Department of Agriculture, Forest Service: 598-637.

LANDFIRE, 2010, Environmental Site Potential, LANDFIRE 1.2.0, U.S. Department of the Interior, Geological Survey. Accessed 2018 at http://landfire.cr.usgs.gov/viewer/.

Little, R. L, D.L Peterson, L.L. Conquest. 1994. Regeneration of subalpine fir (Abies lasiocarpa) following fire: effects of climate and other factors. Canadian Journal of Forest Research. 24(5): 934-944

Loomis, J.; Gonzalez-Caban, A.; Englin, J. 2001. Testing for differential effects of forest fires on hiking and mountain biking demand and benefits. Journal of Agricultural and Resource Economics. 26: 508-522.

Lotan, J. (1976). Cone serotiny - fire relationships in lodgepole pine. In: Tall Timbers Fire Ecology Conference Proceedings 14, Tall Timbers Research Center, Tallahassee, FL. pp. 267-278

Lotan, James E.; Perry, David A. 1983. Ecology and regeneration of lodgepole pine. Agric. Handb. 606. Washington, DC: U.S. Department of Agriculture, Forest Service. 51 p. 
McKenzie, D., and J. S. Littell. 2017. Climate change and the eco-hydrology of fire: Will area burned increase in a warming western USA? Ecological applications 27 (1):26-36.

Meigs, G., and M. Krawchuk. 2018. Composition and Structure of Forest Fire Refugia: What Are the Ecosystem Legacies across Burned Landscapes? Forests 9 (5):243.

Meigs, G. W., R. E. Kennedy, A. N. Gray, and M. J. Gregory. 2015. Spatiotemporal dynamics of recent mountain pine beetle and western spruce budworm outbreaks across the Pacific Northwest Region, USA. Forest Ecology and Management 339:71-86.

Meigs, G. W., H. S. Zald, J. L. Campbell, W. S. Keeton, and R. E. Kennedy. 2016. Do insect outbreaks reduce the severity of subsequent forest fires? Environmental Research Letters 11 (4):045008.

Merschel, A. G., T. A. Spies, and E. K. Heyerdahl. 2014. Mixed-conifer forests of central Oregon: effects of logging and fire exclusion vary with environment. Ecological Applications 24 (7):1670-1688.

Millar, C. I., R. D. Westfall, D. L. Delany, J. C. King, and L. J. Graumlich. 2004. Response of Subalpine Conifers in the Sierra Nevada, California, U.S.A., to 20th-Century Warming and Decadal Climate Variability. Arctic, Antarctic, and Alpine Research 36 (2):181-200.

Minchin, P. R. 1987. An evaluation of the relative robustness of techniques for ecological ordination. Plant Ecology 69 (1-3):89-107.

Minore, D.; Laacke, R.J. 1992. Natural regeneration. In: Hobbs, S.D.; Tesch, S.D.; Owston, P.W., eds. Reforestation practices in southwestern Oregon and northern California. Corvallis, OR: Forest Research Laboratory, Oregon State University: 258-283.

Mohanty, B. P., M. H. Cosh, V. Lakshmi, and C. Montzka. 2017. Soil Moisture Remote Sensing: State-of-the-Science. Vadose Zone Journal 16 (1):0.

Morgan, P., R. E. Keane, G. K. Dillon, T. B. Jain, A. T. Hudak, E. C. Karau, P. G. Sikkink, Z. A. Holden, and E. K. Strand. 2014. Challenges of assessing fire and burn severity using field measures, remote sensing and modelling. International Journal of Wildland Fire 23 (8):1045.

Moritz, M. A., M.-A. Parisien, E. Batllori, M. A. Krawchuk, J. Van Dorn, D. J. Ganz, and K. Hayhoe. 2012. Climate change and disruptions to global fire activity. Ecosphere 3

(6):art49. 
Naficy, C., A. Sala, E. G. Keeling, J. Graham, and T. H. DeLuca. 2010. Interactive effects of historical logging and fire exclusion on ponderosa pine forest structure in the northern Rockies. Ecological Applications 20 (7):1851-1864.

Oksanen, J., F. G. Blanchet, M. Friendly, R. Kindt, P. Legendre, D. McGlinn, P. R. Minchin, R. B. O'Hara, G. L. Simpson, P. Solymos, M. H. Stevens, E. Szoecs, H. Wagner. 2018. vegan: Community Ecology Package. R package version 2.5-3. https://CRAN.Rproject.org/package=vegan

Owen, S. M., C. H. Sieg, A. J. Sánchez Meador, P. Z. Fulé, J. M. Iniguez, L. S. Baggett, P. J. Fornwalt, and M. A. Battaglia. 2017. Spatial patterns of ponderosa pine regeneration in high-severity burn patches. Forest Ecology and Management 405:134-149.

Parks, S., G. Dillon, and C. Miller. 2014. A New Metric for Quantifying Burn Severity: The Relativized Burn Ratio. Remote Sensing 6 (3):1827-1844.

Pearson, M., M. Saarinen, J. Heiskanen, T. Sarjala, and J. Laine. 2013. High and dry: Consequences of drought exposure in Scots pine seedlings grown in authentic peat soil. :22.

Peters. G. 2018. userfriendlyscience: Quantitative analysis made accessible. doi: 10.17605/osf.io/txequ, R package version 0.7.2, https://userfriendlyscience.com.

Prichard, S. J., C. S. Stevens-Rumann, and P. F. Hessburg. 2017. Tamm Review: Shifting global fire regimes: Lessons from reburns and research needs. Forest Ecology and Management 396:217-233.

PRISM Climate Group. 2015. 30-Year Normals. Oregon State University, http://prism.oregonstate.edu, created 4 Feb 2015.

R Development Core Team (2017). R: A language and environment for statistical computing. R Foundation for Statistical Computing,Vienna, Austria. ISBN 3-900051-07-0, URL http://www.R-project.org.

Raffa, K. F., B. H. Aukema, B. J. Bentz, A. L. Carroll, J. A. Hicke, M. G. Turner, and W. H. Romme. 2008. Cross-scale Drivers of Natural Disturbances Prone to Anthropogenic Amplification: The Dynamics of Bark Beetle Eruptions. BioScience 58 (6):501-517.

Reazin, C., S. Morris, J. E. Smith, A. D. Cowan, and A. Jumpponen. 2016. Fires of differing intensities rapidly select distinct soil fungal communities in a Northwest US ponderosa pine forest ecosystem. Forest Ecology and Management 377:118-127. 
Reilly, M. J., M. Elia, T. A. Spies, M. J. Gregory, G. Sanesi, and R. Lafortezza. 2018a. Cumulative effects of wildfires on forest dynamics in the eastern Cascade Mountains, USA. Ecological Applications 28 (2):291-308.

Reilly, M. J., T. A. Spies, J. Littell, R. Butz, and J. B. Kim. 2018b. Chapter 2: Climate, Disturbance, and Vulnerability to Vegetation Change in the Northwest Forest Plan Area. In Synthesis of Science to Inform Land Management Within the Northwest Forest Plan Area, 66. US Dept. of Agriculture, Forest Service, Intermountain Research Station.

Reilly, M. J., C. J. Dunn, G. W. Meigs, T. A. Spies, R. E. Kennedy, J. D. Bailey, and K. Briggs. 2017. Contemporary patterns of fire extent and severity in forests of the Pacific Northwest, USA (1985-2010). Ecosphere 8 (3):e01695.

Reilly, M. J., and T. A. Spies. 2016. Disturbance, tree mortality, and implications for contemporary regional forest change in the Pacific Northwest. Forest Ecology and Management 374:102-110.

Ritchie, G. 2006. Chlorophyll Fluorescence: What Is It and What Do the Numbers Mean? National Proceedings: Forest and Conservation Nursery Associations :10.

Rogeau, M.-P., Q. Barber, and M.-A. Parisien. 2018. Effect of Topography on Persistent Fire Refugia of the Canadian Rocky Mountains. Forests 9 (6):285.

Rochefort, R. M., R. L. Little, A. Woodward, and D. L. Peterson. 1994. Changes in subalpine tree distribution in western North America: a review of climatic and other causal factors. The Holocene 4 (1):89-100.

Serra-Diaz, J. M., C. Maxwell, M. S. Lucash, R. M. Scheller, D. M. Laflower, A. D. Miller, A. J. Tepley, H. E. Epstein, K. J. Anderson-Teixeira, and J. R. Thompson. 2018. Disequilibrium of fire-prone forests sets the stage for a rapid decline in conifer dominance during the 21st century. Scientific Reports 8 (1). http://www.nature.com/articles/s41598-01824642-2 (last accessed 14 March 2019).

Schoennagel, T., R. L. Sherriff, and T. T. Veblen. 2011. Fire history and tree recruitment in the Colorado Front Range upper montane zone: implications for forest restoration. Ecological Applications 21 (6):2210-2222.

SNODAS. 2004. Snow Data Assimilation System (SNODAS) Data Products at NSIDC, Version 1. Snow Water Equivalent. Boulder, Colorado USA. NSIDC: National Snow and Ice Data Center. doi: https://doi.org/10.7265/N5TB14TC. [10/15/2018] 
Steelman, T. 2016. U.S. wildfire governance as social-ecological problem. Ecology and Society 21 (4). http://www.ecologyandsociety.org/vol21/iss4/art3/ (last accessed 19 February 2019).

Stevens-Rumann, C., and P. Morgan. 2016. Repeated wildfires alter forest recovery of mixed-conifer ecosystems. Ecological Applications 26 (6):1842-1853.

Stevens-Rumann, C. S., K. B. Kemp, P. E. Higuera, B. J. Harvey, M. T. Rother, D. C. Donato, P. Morgan, and T. T. Veblen. 2017. Evidence for declining forest resilience to wildfires under climate change ed. F. Lloret. Ecology Letters. http://doi.wiley.com/10.1111/ele.12889 (last accessed 12 January 2018).

Stevens-Rumann, C. S., S. J. Prichard, E. K. Strand, and P. Morgan. 2016. Prior wildfires influence burn severity of subsequent large fires. Canadian Journal of Forest Research 46 (11):1375-1385.

Stine, P., P. Hessburg, T. Spies, M. Kramer, C. J. Fettig, A. Hansen, J. Lehmkuhl, K. O'Hara, K. Polivka, P. Singleton, S. Charnley, A. Merschel, and R. White. 2014. The ecology and management of moist mixed-conifer forests in eastern Oregon and Washington: a synthesis of the relevant biophysical science and implications for future land management. Portland, OR: U.S. Department of Agriculture, Forest Service, Pacific Northwest Research Station. https://www.fs.usda.gov/treesearch/pubs/47086 (last accessed 25 February 2019).

Stokes, M.A., Smiley, T.L., 1968. An Introduction to Tree-ring Dating. University of Arizona Press, Tucson, AZ

Tepley, A. J., F. J. Swanson, and T. A. Spies. 2013. Fire-mediated pathways of stand development in Douglas fir/western hemlock forests of the Pacific Northwest, USA. Ecology 94 (8):1729-1743.

Tepley, A. J., F. J. Swanson, and T. A. Spies. 2014. Post-fire tree establishment and early cohort development in conifer forests of the western Cascades of Oregon, USA. Ecosphere 5 (7):art80.

Tepley, A. J., E. Thomann, T. T. Veblen, G. L. W. Perry, A. Holz, J. Paritsis, T. Kitzberger, and K. J. Anderson-Teixeira. 2018. Influences of fire-vegetation feedbacks and post-fire recovery rates on forest landscape vulnerability to altered fire regimes ed. E. Lines. Journal of Ecology. http://doi.wiley.com/10.1111/1365-2745.12950 (last accessed 3 April 2018). 
Turner, M. G., and W. H. Romme. 1994. Landscape dynamics in crown fire ecosystems. Landscape Ecology 9 (1):59-77.

Turner, M. G., W. H. Romme, R. H. Gardner, R. V. O'Neill, and T. K. Kratz. 1993. A revised concept of landscape equilibrium: Disturbance and stability on scaled landscapes. Landscape Ecology 8 (3):213-227.

Urza, A. K., and J. S. Sibold. 2013. Nondestructive Aging of Postfire Seedlings for Four Conifer Species in Northwestern Montana. Western Journal of Applied Forestry 28 (1):22-29.

USDA. 2018. Web Soil Survey. Available online at the following link: https://websoilsurvey.sc.egov.usda.gov/.

USGS. 2018. Mt. Adams. Mt. Jefferson. Volcano Hazards Program. URL. https://volcanoes.usgs.gov/volcanoes/mount jefferson/;

https://volcanoes.usgs.gov/volcanoes/adams/

van Wagtendonk, J. W., K. A. van Wagtendonk, and A. E. Thode. 2012. Factors Associated with the Severity of Intersecting Fires in Yosemite National Park, California, USA. Fire Ecology 7] (1):11-31.

Veblen, T. T. 2017. Disturbance in Biogeography. In International Encyclopedia of Geography: People, the Earth, Environment and Technology, eds. D. Richardson, N. Castree, M. F. Goodchild, A. Kobayashi, W. Liu, and R. A. Marston, 1-13. Oxford, UK: John Wiley \& Sons, Ltd http://doi.wiley.com/10.1002/9781118786352.wbieg0884 (last accessed 25 October 2017).

Venables, W. N., Ripley, B. D. 2002. Modern Applied Statistics with R. Fourth Edition. Springer, New York. ISBN 0-387-95457-0

Vereecken, H., J. A. Huisman, H. J. Hendricks Franssen, N. Brüggemann, H. R. Bogena, S. Kollet, M. Javaux, J. van der Kruk, and J. Vanderborght. 2015. Soil hydrology: Recent methodological advances, challenges, and perspectives: Soil hydrology. Water Resources Research 51 (4):2616-2633.

Ward, A., C. A. Cansler, and A. J. Larson. 2017. Black Carbon on Coarse Woody Debris in Once- and Twice-Burned Mixed-Conifer Forest. Fire Ecology 13 (2):143-147.

Welch, K. R., H. D. Safford, and T. P. Young. 2016. Predicting conifer establishment post wildfire in mixed conifer forests of the North American Mediterranean-climate zone. Ecosphere 7 (12):e01609. 
Westerling, A. L. 2006. Warming and Earlier Spring Increase Western U.S. Forest Wildfire Activity. Science 313 (5789):940-943.

Westerling, A. L. 2016. Increasing western US forest wildfire activity: sensitivity to changes in the timing of spring. Philosophical Transactions of the Royal Society B: Biological Sciences 371 (1696):20150178.

Whitman, E., M.-A. Parisien, D. K. Thompson, R. J. Hall, R. S. Skakun, and M. D. Flannigan. 2018. Variability and drivers of burn severity in the northwestern Canadian boreal forest. Ecosphere 9 (2):e02128.

Whittier, T. R., and A. N. Gray. 2016. Tree mortality based fire severity classification for forest inventories: A Pacific Northwest national forests example. Forest Ecology and Management 359:199-209.

Wickham, H. 2016. ggplot2: Elegant Graphics for Data Analysis. Springer-Verlag New York.

Wieting, C., B. A. Ebel, and K. Singha. 2017. Quantifying the effects of wildfire on changes in soil properties by surface burning of soils from the Boulder Creek Critical Zone Observatory. Journal of Hydrology: Regional Studies 13:43-57.

Zhang, X., T. Zhang, P. Zhou, Y. Shao, and S. Gao. 2017. Validation Analysis of SMAP and AMSR2 Soil Moisture Products over the United States Using Ground-Based Measurements. Remote Sensing 9 (2):104.

Zuur A, E. N. Ieno, N. Walker, A. A. Savaliev, G. M. Smith. 2009. Mixed effects models and extensions in ecology with R. Springer Science \& Business Media, LLC. New York, NY, U.S.A

Zuur, A. F., E. N. leno, and C. S. Elphick. 2010. A protocol for data exploration to avoid common statistical problems: Data exploration. Methods in Ecology and Evolution 1 (1):3-14.

Zuur A.F., A. A. Savaliev, E. N. leno. 2012. Zero inflated models and generalized linear mixed models with R. Highland Statistics Ltd., Newburg, U.K. 